\title{
Plasminogen activator inhibitor 1: Mechanisms of its synergistic regulation by growth factors
}

\author{
By \\ XIAOLING SONG \\ A dissertation submitted to the graduate faculty \\ In partial fulfillment of the requirements for the degree of \\ DOCTOR OF PHILOSOPHY
}

Major: Genetics

Program of Study Committee:

Marit Nilsen-Hamilton, Major professor

W. Allen Miller

Christopher K. Tuggle

Gustavo MacIntosh

Linda Ambrosio

Iowa State University

Ames, Iowa

2010

Copyright $@$ Xiaoling Song, 2010. All rights reserved. 
UMI Number: 3438735

All rights reserved

INFORMATION TO ALL USERS

The quality of this reproduction is dependent upon the quality of the copy submitted.

In the unlikely event that the author did not send a complete manuscript and there are missing pages, these will be noted. Also, if material had to be removed, a note will indicate the deletion.

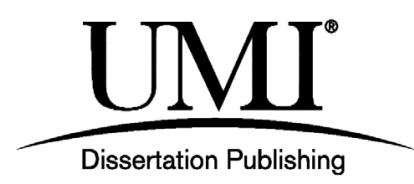

UMI 3438735

Copyright 2011 by ProQuest LLC.

All rights reserved. This edition of the work is protected against unauthorized copying under Title 17, United States Code.

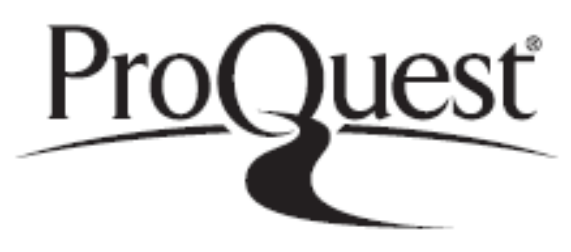

ProQuest LLC

789 East Eisenhower Parkway

P.O. Box 1346

Ann Arbor, MI 48106-1346 


\section{TABLE OF CONTENTS}

CHAPTER 1. INTRODUCTION 1

Dissertation organization 1

Significance of the study on PAI-1 regulation 2

Hypothesis and major results on PAI-1 synergistic regulation by EGF and

TGF- $\beta$

Significance and major results from studies on RNA accessible region $\quad 7$

CHAPTER 2. REVIEW OF LITERATURE 9

1. Plasminogen activator inhibitor, type 1(PAI-1) and its functions 9

$\begin{array}{ll}\text { PAI-1 activity changes via active/latent conversion } & 10\end{array}$

$\begin{array}{ll}\text { Fast acting inhibitor } & 11\end{array}$

$\begin{array}{lr}\text { Negatively regulates fibrinolysis } & 12\end{array}$

$\begin{array}{ll}\text { Modulate extracellular matrix remodeling } & 13\end{array}$

$\begin{array}{ll}\text { Modulates cell attachment and migration } & 13\end{array}$

2. Aberrant expression of PAI-1 associated diseases 16

$\begin{array}{ll}\text { PAI-1 deficiency in disease } & 17\end{array}$

$\begin{array}{lr}\text { PAI-1 over expression in disease } & 18\end{array}$

$\begin{array}{ll}\text { Great therapeutic potential for PAI-1 inhibitors } & 20\end{array}$

3. Regulation of PAI-1 expression 21 
Immediate early expression

Promoter elements corresponding to transcription activation

PAI-1 RNA stability regulation

4. Regulation of PAI-1 expression by TGF- $\beta$

Smad-mediated TGF- $\beta$ signaling

Interaction of Smad with other transcription factor.

The Smads interact with co-activators, co-repressors and chromatin

modeling factors.

Non Smad-mediated TGF- $\beta$ signaling

PAI-1 regulation by TGF- $\beta$

Signaling pathways involved in TGF- $\beta$ regulates PAI-1 expression.

Cis-elements required for TGF- $\beta$-induced PAI-1 expression.

5. Regulation of PAI-1 expression by EGF

EGF and EGF-mediated signaling

PAI-1 regulation by EGF

6. Synergistic regulation of PAI-1 by EGF and TGF- $\beta$

TGF- $\beta$ cooperates with EGF affecting many biological processes 
7. Molecular mechanism of the interaction between the TGF- $\beta$ and EGFmediated signaling

Mechanisms of synergistic regulation of gene expression by EGF and TGF- $\beta \quad 46$

8. Summary

References

Figure legends

CHAPTER 3. SYNERGISTIC AND MULTIDIMENSIONAL REGULATION OF PLASMINOGEN ACTIVATOR INHIBITOR TYPE 1 EXPRESSION BY TRANSFORMING GROWTH FACTOR TYPE $\beta$ AND EPIDERMAL GROWTH

Abstract:

Introduction

Results

Discussion

References

Footnotes 
Tables

Supplementary Table

111

Figures Legends

112

\section{CHAPTER 4. TILED MICROARRAYS IDENTIFY EFFECTIVE ANTISENSE OLIGODEOXYNUCLEOTIDE AND SIRNA TARGET SEQUENCES}

Abstract

Introduction

Results

131

Determination of sites accessible by oligonucleotide arrays

Prediction of accessible regions by computational analyses

133

Efficiency of selected antisense oligonucleotides on Lcn2 protein levels

Efficiency of selected antisense oligonucleotides and siRNA on Lcn2 mRNA 135

Discussion

136

Conclusions

Methods

Authors' contributions

148

Acknowledgements

References

149

Figure Legends

Figures 
Goal of this study

Significance of this study

Major findings and conclusion

Impacts of this study

167

Limitations of this study

168

Questions remain to be answered

169

Conclusions of using tiled microarray to identify RNA accessible region

174

References

177

APPENDIX I. ABBREVIATIONS

181

ACKNOWLEDGEMENTS

186 


\section{CHAPTER 1. INTRODUCTION}

\section{Dissertation organization}

There are five chapters in this thesis. Chapter 1 covers the general introduction of my research on the synergistic regulation of PAI-1 by EGF and TGF- $\beta$, including the significance, questions to be addressed and major results of this study. Chapter 2 is a literature review of PAI-1 function, related diseases and expression regulation, with an emphasis on PAI-1 regulation by EGF and TGF- $\beta$. Chapter 3 addresses the mechanism of synergistic regulation of PAI-1 by EGF and TGF- $\beta$. The manuscript will be submitted to the Journal of Biological Chemistry. The co-authors are Xiaoling Song (performed the majority of studies for the synergistic regulation of PAI-1 at mRNA level and wrote the manuscript), Frederic W. Thalacker (previous lab member, performed the metabolic labeling studies of mink PAI-1 protein), Tsung-Hsien Chuang (previous lab member, performed the Northern blots and initiated the studies on mRNA stability) and Marit Nilsen-Hamilton (corresponding author, mentored Song XL, Chang TH and Thalacker F, initiated the study, oversaw the work including data analysis and revised the manuscript). Chapter 4 is a manuscript that has been submitted to Biomed central Biotechnology. The chapter describes methods for effective identification of RNA accessible sites for antisense oligodexoxynucleotides (ODNs) and siRNA. The coauthors are Xiaoling Song (performed the majority of the cell biology studies with antisense, participated in the statistical analysis and computer analysis and in preparing the figures), Xiangyu Cong (conceived of the idea to use tiled microarrays, carried out most of the microarray studies on Len2 and contributed to the computer analysis), Ahmed M. 
Awad (initiated the cell biology studies, performed the Bcl2 microarray analysis and wrote the $1^{\text {st }}$ draft of the paper), Long $\mathrm{Qu}$ (performed the cluster analyses and the majority of statistics analysis of the experimental results), Lijie Zhai (performed the siRNA cell studies) and Marit Nilsen-Hamilton (corresponding author, mentored Song XL, Cong XY, Awad AM and Zhai LJ, initiated the study, oversaw the work and participated in analysis of the data). Contributions to the writing of the manuscript were made by all co-authors with the major contributions being by Xiaoling Song and Marit Nilsen-Hamilton. The general conclusion of the thesis is summarized in chapter 5 .

\section{Significance of the study on PAI-1 regulation}

Plasminogen activator inhibitor type 1 (PAI-1), a protein that is found in many vertebrates, plays important roles in extracellular matrix remodeling and fibrinolysis. PAI-1 is one of the early inflammatory response genes, and its expression level changes dramatically in response to the stimulation by growth factors, lipopolysaccharide, cytokines or PMA. PAI-1 is very important for the regulation of plasminogen activation in the fibrinolysis system and for cell motility regulation. The PAI-1 expression level changes in many diseases. Over-expression of PAI-1 is found in cancers, fibrosis and metabolic syndromes. Studying the molecules involved in PAI-1 regulation will help us to understand the mechanism of PAI-1 regulation and the role of PAI-1 in many physiological and pathological processes.

Previously, the lab found a synergistic interaction between epidermal growth factor (EGF) and transforming growth factor beta (TGF- $\beta$ ), which elevates the PAI-1 expression up to 80- 
fold at the mRNA level. The purpose of this project was to understand the molecular mechanism of the synergism.

Synergism is the situation when the effect of a combination of factors is greater than the sum of effects of each individual factor. There are many important roles of synergism in the normal function of cells. First, synergism helps to increase the specificity of the response because two or more stimuli are required. Second, synergism increases the range of the response because the responses are more enhanced comparing to the additive effects. Thirdly, it also provides the cell with a means of ignoring environmental noises such as changes of one of two factors, which will not affect the specific responses.

EGF and TGF- $\beta$ have been shown to cooperatively affect many cellular events, including transformation, the epithelial-mesenchymal transition (EMT). These growth factors are also involved in many normal physiological processes, such as wound healing, and disease processes, such as tumor metastasis and fibrosis. Elevated PAI-1 plays a critical role in the EGF and TGF- $\beta$-affected processes such as the EMT most likely by influencing cell motility. Studies of the synergistic regulation of PAI-1 will help to understand the synergistic interaction between EGF and TGF- $\beta$ and to develop therapeutic targets to modulate the processes where PAI-1 is highly elevated.

\section{Hypothesis and major results on PAI-1 synergistic regulation by EGF and}

\section{$T G F-\beta$}

A series of hypotheses have benn proposed and tested to address the question of how EGF and TGF- $\beta$ synergistically regulate PAI-1 expression. First, we tested if synergism 
between EGF and TGF- $\beta$ is gene or cell type specific. The mRNA levels of uPA (urokinase type plasminogen activator), uPAR (receptor of urokinase type plasminogen activator) and Cox2 (cyclooxygenase 2) were determined after stimulation by EGF and TGF- $\beta$. The results showed that the PAI-1 mRNA was uniquely induced in a synergistic manner. Four cell lines were used to determine the cell-type specificity. The results showed that PAI-1 was synergistically increased by EGF and TGF- $\beta$ in epithelial cells types such as mink lung epithelial cells (Mv1Lu) and human hepatoma (HepG2) cells, but not in fibroblast cell types. The mechanism of synergism was investigated in Mv1Lu cells in this study. Mv1Lu cells express a very low basal level of PAI-1 and the expression of PAI-1 is highly sensitive to outside stimuli, especially TGF- $\beta$. Therefore, Mv1Lu cell line is a very good model to study PAI-1 gene regulation.

EGF and TGF- $\beta$ regulate PAI-1 expression mainly at the transcriptional level (Riccio, Lund et al. 1988). TGF- $\beta$ activates PAI-1 expression through Smad2/ Smad3 binding to the promoter of PAI-1, and EGF functions through Src to activate gene transcription in human mensengial cells (Harradine and Akhurst 2006). It was of interest to know whether the synergistic induction of PAI-1 by EGF and TGF- $\beta$ occurs at the transcriptional or posttranscriptional level. Preliminary results from our lab suggested that the combination of EGF and TGF- $\beta$ stabilizes PAI-1 mRNA. Our first hypothesis of the study was: the synergistic effect of EGF and TGF- $\beta$ on PAI-1 induction occurs at both the transcriptional and RNA stability level. However, our data show that the synergism occurs only at the transcriptional level, although EGF stabilizes PAI-1 mRNA. TGF- $\beta$ also increases the sensitivity of PAI-1 induction by EGF. It is known that EGF and TGF- $\beta$ regulate the 
expression of their target genes through different signaling pathways. And our data shows that de novo protein synthesis is not necessary for the synergistic regulation because pretreating cells with cycloheximide did not alter the synergistic effect. Our second hypothesis was that the synergism occurs during the process of the signal transduction. A series of assays were performed to test this hypothesis. To understand which signaling pathway is involved in the synergistic regulation of PAI-1, specific chemical inhibitors of protein kinases, including Mek1/2 (mitogen-activated protein kinase kinase), p38 MAPK (mitogen-activated protein kinase), PI3K (phosphatidylinositol 3'-kinase), Src (v-src sarcoma (Schmidt-Ruppin A-2) viral oncogene homolog (avian)) and Jnk (c-Jun NH2-terminal protein kinase), were used to block different signaling pathways. The synergism was lost only when Erk1/2 phosphorylation was blocked. The Erk1/2 (extracellular signal-regulated kinase) mediated MAPK signaling pathway is activated by many growth factors through their tyrosine kinase receptors (RTKs). We were interested to know if other growth factors that activate the MAPK pathway could also synergistically regulate PAI-1 with TGF- $\beta$. Our results showed that the growth factors IGF-1 (insulin-like growth factor 1), FGF-2 (fibroblast growth factor 2) and the cytokine TNFa (tumor necrosis factor alpha) also synergize with TGF- $\beta$ to increase PAI-1 mRNA expression. However, the synergistic event is not uniquely downstream of tyrosine kinases because PMA, a PKC agonist, also acts synergistically with TGF- $\beta$ on PAI-1 expression as demonstrated in both normal and MSV-transformed Mv1Lu cells. This effect was specific for PAI-1 as demonstrated by the lack of synergistic effect of TGF- $\beta$ and PMA on the production of other secreted proteins including a $73 \mathrm{Kd}$ protein, a TGF- $\beta$ inducible protein. 
The induction of PAI-1 mRNA by EGF and TGF- $\beta$ requires ongoing protein synthesis because the treatment of protein synthesis inhibitor reduces PAI-1 mRNA level by about $40 \%$. However, the synergism was not significantly reduced by the inhibition of protein synthesis when the protein synthesis inhibitor is added one hour before growth factors treatment. When protein synthesis was stopped at a series of time intervals after adding the growth factors the level of PAI-1 induced by EGF and TGF- $\beta$ in combination, was observed to decrease at a constant rate. This decay rate in the form of a decrease in PAI-1 mRNA level probably reflects the stability of a protein required for the growth factor response. The calculated half-lives of the postulated proteins for each treatment were different. The half-life of the EGF and TGF- $\beta$-induced protein is about 1 hour and the half life of the protein induced by either EGF or TGF- $\beta$ appeared to be biphasic, possibly including a limited contribution from the 1 hour half life and the contribution of a second protein with a longer half-life. These data could be interpreted as the proteins required for PAI-1 synthesis in single and double growth factor treatments were differentially regulated. These biphasic decay curves reflect the presence of a small amount of the protein responsible for synergism that is augmented by the combination of EGF and TGF- $\beta$.

It has been shown that c-Fos protein has a very short half-life in vivo. EGF is known to activate the transcriptional activity of activator protein 1 (AP-1: a dimer of c-Fos and c-Jun family proteins). Smad and the AP-1 have been shown to act synergistically on gene transcription. Our next hypothesis is that AP-1 is the rapidly turning over protein and is required for the synergistic regulation of PAI-1 by EGF and TGF- $\beta$. To address this question, we investigated the regulation of several synthetic promoters containing Smad binding 
element and/or AP-1 binding sites. The data showed that AP-1 and Smad binding elements in $\mathrm{p} 3 \mathrm{TP}$ promoter synergistically respond to EGF and TGF- $\beta$. Suppressing the AP-1 transcriptional activity by a dominant negative construct for c-Fos, or chemical inhibitors reduced the synergistic effect on $\mathrm{p} 3 \mathrm{TP}$ reporter. The synergism on PAI-1 mRNA was also blocked by inhibition of AP-1 activity. However, neither Fos nor Jun phosphorylation is synergistically activated by the combination of EGF and TGF- $\beta$. Thus, although AP-1 is necessary for the synergistic effect, it may not be the target for synergism between the two growth factors.

\section{Significance and major results from studies on RNA accessible region}

Antisense oligonucleotide and RNAi technology, especially the latter, has been widely used to knock down gene expression. The efficiency of silencing gene expression has attracted great attention due to the possible use of these technologies in gene therapy for variety of diseases. Because mRNA is usually folded in secondary or tertiary structure in vivo, only a limited portion of the mRNA is available for targeting. Different technologies have been developed to provide information for optimal RNA accessible sites, including software prediction by using computer algorithm and experimental screening. Software utilizes minimum energy calculations to predict RNA secondary structures based on their primary sequences, however these computer programs do not predict RNA tertiary structures that may affect RNA accessible sites. Experimentally screening every possible RNA site is expensive and time consuming. 
Here we showed that tiled microarray is an effective way to identify accessible regions in mRNAs with high accuracy. We investigated the accessible regions of two mRNAs (B-cell CLL/lymphoma 2 [Bcl2] and mouse lipocalin 2 [Lcn2]) by tiled microarray and computational algorithms. The efficacy of microarray and computational algorithm predictions for Lcn2 were tested in cell culture by using antisense oligodeoxynucleotides (ODNs) and siRNA. For Bcl2, the microarray results were compared to the data in literature where antisense oligodeooxynucleotides were reported effective in vivo. Firstly, we found that the tiled microarray analysis provides more selective identification of available sites on the mRNA than do computational algorithms. Secondarily, the regions identified by titled microarray accurately predicted the most accessible area in RNA as tested by antisense ODNs and siRNA in vivo. With the advantage of high throughput and high accuracy information provided for RNA accessible regions, we proposed tiled microarray is an efficient way of identifying effective antisense ODNs or siRNAs. Tiled microarrays also provide a high throughput approach for validating and improving the results from computational programs. 


\section{CHAPTER 2. REVIEW OF LITERATURE}

Plasminogen activator inhibitor type 1 (PAI-1) is one of the early inflammatory response genes, and its expression level changes dramatically in response to many stimuli, including growth factors and endotoxins. The half-life of PAI-1 mRNA is very short (less than three hours in human cells and only 21 minutes in mink cells). Because of the short half-life, the PAI-1 mRNA steady level drops quickly once transcription stops. Our previous results showed that EGF and TGF- $\beta$ synergistically induce PAI-1 expression in mink lung epithelial cells Mv1Lu (ATCC\# CCL64). The purpose of my major project is to understand the synergistic mechanism of PAI-1 regulation by EGF and TGF- $\beta$. Previous research studies regarding PAI-1, EGF and TGF- $\beta$ are reviewed here.

\section{Plasminogen activator inhibitor, type 1(PAI-1) and its functions}

PAI-1, a secreted single-chain glycoprotein, regulates plasmin function during fibrinolysis and extracellular matrix remodeling. Plasmin, a broad spectrum serine protease, degrades fibrin and extracellular matrix proteins by which it plays a central role in clot dissolution and extracellular remodeling. Plasminogen activators (PA, tissue-type or urokinase-type) are required to convert the inactive proenzyme plasminogen to active plasmin by cleavage at a single arginine-valine bond (Kruithof, Tran-Thang et al. 1984). While tissue-type plasminogen activator (t-PA) mainly regulates intravascular plasmin activity though binding to its receptor annexin II on the endothelial cell surface, urokinasetype plasminogen activator (uPA) acts by binding to its cell membrane receptor (uPAR) to promote plasmin induced pericellular proteolysis and to modulate cell migration (Czekay and 
Loskutoff 2004; Myohanen and Vaheri 2004; Kwaan and McMahon 2009). PAI-1, also called as SerpinE 1 (serine peptidase inhibitor, clade E, member 1), is the primary of four serpin inhibitors of plasminogen activators (Kruithof 1988). By controlling the plasminogen activator-plasmin proteolysis cascade, PAI-1 is crucial to maintain haemostasis and many other biological processes that involve the remodeling of the extracellular matrix (ECM, Sprengers and Kluft 1987; Loskutoff, Sawdey et al. 1989; Dellas and Loskutoff 2005). PAI-1 is evolutionarily conserved and found in many animal species, including human, mouse and mink (Ginsburg, Zeheb et al. 1986; Prendergast, Diamond et al. 1990; Chuang, Hamilton et al. 1995).

\section{PAI-1 activity changes via active/latent conversion}

PAI-1 belongs to the serpin super family that contains conserved structures for inhibiting proteinases. Like other serpins, PAI-1 serves as a pseudo substrate of plasminogen activators (Sancho, Declerck et al. 1995). One distinct character of PAI-1 that distinguishes it from other serpin family members is that PAI-1 can automatically convert to a stable latent form (Kruithof 1988). During the spontaneous conversion, the N-terminal reactive center loop is inserted into the major $\beta$-sheet to form the inactive form and the half-life of PAI-1 protein is increased from one hour to three hours (Mottonen, Strand et al. 1992; De Taeye, Gils et al. 2004). The activity of PAI-1 can be partially restored through denaturation-renaturation with sodium dodecyl sulfate, guanidinium chloride and urea (Hekman and Loskutoff 1985).

PAI-1 appears as three different forms in normal human plasma: the inactive form of free PAI-1 with the molecular weight about $50 \mathrm{Kd}$, the active PAI-1/vitronectin complex with the 
molecular weight about $450 \mathrm{Kd}$, and a high molecular weight inactive t-PA/PAI-1 complex (about $700 \mathrm{KD}$,Alessi, Juhan-Vague et al. 1991). The binding of active PAI-1 to vitronectin stabilizes PAI-1 but does not affect the inhibitory effect of PAI-1 on plasminogen activators or the activity of vitronectin on cell adhesion (Lindahl, Sigurdardottir et al. 1989). Additionally, by interacting with vitronectin, PAI-1 restricts pericellular proteolysis at focal contact sites (Salonen, Vaheri et al. 1989). In many cases, levels of active and inactive PAI-1 change in the same direction. For instance, activation of platelets mainly leads to increasing the free PAI-1 level and, to a less extent, the active PAI-1/ vitronectin complex increases. And in most patients with elevated PAI-1 activity, both the free PAI-1 and the active PAI-1/ vitronectin complex are increased (Alessi, Juhan-Vague et al. 1991).

\section{Fast acting inhibitor}

PAI-1 is a fast PA inhibitor. Clearance of PA-inhibitory activity from the circulation is rapid with measured half lives of 3.5 to 7 min (Colucci, Paramo et al. 1985). Like other serpins, PAI-1 inhibits cognate proteases by mimicking their substrates, which results in the formation of an ester bond between the carboxyl group of serpin P1 residue and the hydroxyl group of the protease serine residue to produce a stable covalently linked inhibitor/protease inactive complex (De Taeye, Gils et al. 2004). PAI-1 inhibits the activity of plasminogen activators (uPA and tPA) by binding to them at a 1:1 ratio. The binding process is fast and results in inactivation of plasminogen activators. The binding rate for both plasminogen activators (urokinase-type plasminogen activator, and tissue type plasminogen activator) is

about $10^{7} \mathrm{M}^{-1} \mathrm{sec}^{-1}\left(\mathrm{k}_{\mathrm{cat}}\right.$ ), which reaches the upper theoretical limit of the rate constant of protein-protein interactions (Kruithof, Tran-Thang et al. 1984; Hekman and Loskutoff 1988). 
After binding, a slow cleavage at the PAI-1 reactive site $\operatorname{Arg} 346-M e t 347\left(\mathrm{P}_{1}-\mathrm{P}_{1}{ }^{\prime}\right)$ occurs followed by the release of the C-terminal peptide of PAI-1 from the PAI-1/PA complex (Lindahl, Ohlsson et al. 1990). The PAI-1/PA complex is internalized by forming a complex with integrin and the endocytic receptor low-density lipoprotein receptor-related protein (LRP), then both PAI-1 and PAs are then degraded in the lysosomes (Chazaud, Bonavaud et al. 2000; Cao, Lawrence et al. 2006). The fast inhibition of the plasminogen activators allows the rapid reduction of plasmin-mediated proteolysis.

\section{Negatively regulates fibrinolysis}

PAI-1 negatively regulates fibrinolysis. Tissue-type plasminogen activator (t-PA) is the main plasminogen activator involved in fibrinolysis because the urokinase-type (uPA) does not bind fibrin. Through inhibiting the activity of t-PA, PAI-1 regulates fibrinolysis which is very important for removing the clot after injury (Kawasaki, Dewerchin et al. 2000; Gils and Declerck 2004). Shortly after wounding, coagulation occurs to keep the blood within a damaged blood vessel. Fibrin, together with plasminogen, platelets and other blood proteins, form a fibrin clot at the place of damage. After bleeding stops, fibrinolysis occurs to remove fibrin clot. During fibrinolysis, t-PA produced by endothelial cells immediately surrounds the clot to convert plasminogen into the active enzyme plasmin. Plasmin then degrades fibrin in the fibrin mesh to resolve the clot (Ranby and Brandstrom 1988). The release of t-PA is very slow, and the fibrinolytic process, which depends on the activation of plasmin, takes days to finish (Harvey, Kim et al. 1989). Fibrinolysis is negatively regulated by plasminogen activation inhibitors (mainly by PAI-1) (Zorio, Gilabert-Estelles et al. 2008). 


\section{Modulate extracellular matrix remodeling}

PAI-1 also modulates extracellular matrix remodeling. During tissue remodeling, proteolysis is required to degrade the extracelluar matrix barrier to allow cell movement. Plasmin plays an active role in remodeling the airway and vascular systems (Lijnen 2001; Kucharewicz, Kowal et al. 2003; Rakic, Maillard et al. 2003). Plasmin not only directly degrades most glycoproteins but also can activate the proenzymes of matrix metalloproteinases (MMPs), including MMP1 and MMP3, to degrade gelatin and collagen in extracellular matrix (Lijnen 2001). Plasmin-mediated proteolysis is positively regulated by uPA. uPA activates plasminogen by binding to its receptor urokinase plasminogen activator receptor (uPAR). UPAR is a glycosyl phosphatidyl inositol (GPI) - anchored protein that tethers uPA on the cell surface to regulate pericellular proteolysis (Blasi, Vassalli et al. 1987; Vassalli, Sappino et al. 1991; Ossowski and Aguirre-Ghiso 2000).

PAI-1 helps to maintain the integrity of the extracellular matrix in three ways. First, PAI-1 directly blocks uPA activity to constrain the proteolytic activity of plasmin. Second, it reduces the uPA level on the cell surface by promoting low-density lipoprotein receptorrelated protein (LRP) mediated endocytosis (Degryse, Sier et al. 2001). Third, elevated PAI-1 can cause accumulation of fibrous material, which promotes fibrosis (Loskutoff and Quigley 2000; Kucharewicz, Kowal et al. 2003).

\section{Modulates cell attachment and migration}

Cell migration occurs during normal physiological processes such as embryonic morphogenesis, and during pathological processes such as wound healing, inflammation and 
cancer metastasis. Cell migration requires a series of dynamic motions including protrusion in the front, adhesion to the extracellular matrix or adjacent cells, detachment and retraction in the back (Ridley, Schwartz et al. 2003).

PAI-1 plays a role in regulating cell movements. This is demonstrated by the following observations. PAI-1 is deposited onto the migration trail of keratinocytes during the healing of monolayer wound (Providence, Higgins et al. 2008). Addition of active PAI-1 promotes directional migration of both wild type and PAI-1 deficient (PAI-1, -/-) keratinocytes (Providence, Higgins et al. 2008). Treating cells with PAI-1 neutralizing antibody significantly slowed wound repair (Providence, Higgins et al. 2008). It has also been reported that PAI-1 controls uPA-mediated cell migration by balancing cell adhesion and detachment activities (Deng, Curriden et al. 1996).

PAI-1 modulates cell migration in two opposing ways. On the one hand, PAI-1 inhibits smooth muscle cell movement by inhibiting cell adhesion (Stefansson and Lawrence 1996). On the other hand, PAI-1 stimulates migration of a variety of cells, including rat smooth muscle cells (RSMC), highly invasive human fibrosarcoma HT-1080 cell, and non-invasive human melanoma IF6 cells (Degryse, Sier et al. 2001). PAI-1 recruits interstitial macrophages and myofibroblasts, which are key cellular factors in fibrosis (Oda, Jung et al. 2001).

PAI-1 modulates cell migration through regulating pericellular proteolysis. Plasminmediated proteolysis removes the tissue barrier that prevents cell migration (Allan and Martin 1995). Plasmin also promotes cell migration by activating cell signaling pathways 
such as p38MAPK/Akt2 pathway (Li, Syrovets et al.). A high level of PAI-1 inhibits cell migration by blocking cell surface proteolysis by plasmin (Andreasen, Egelund et al. 2000). Meanwhile, a low concentration of PAI-1 is required for blocking excessive plasminmediated degradation of the extracellular matrix to maintain the matrix scaffold required for cell migration. Because both the plasminogen activation system and PAI-1 are involved in cell migration, the balance between plasminogen activators (t-PA and u-PA) and PAI-1 plays a crucial role in modulating the cell migration (Booth 1999).

PAI-1 inhibits uPAR-integrin mediated cell adhesion and regulates cell detachment. During wound healing, the expression of the vitronectin receptor, integrin and plasminogen activators is greatly increased in migrating cells. UPAR forms a stable complex with integrins on the cell surface, which promotes cell binding to vitronectin through uPAR in the extracellular matrix (Wei, Lukashev et al. 1996). With a relatively high affinity to vitronectin $\left(0.5 \times 10^{-7}-2 \times 10^{-7} \mathrm{M}\right)$, PAI-1 promotes cell migration by competing with uPAR and releasing the cell from the vitronectin attachment. In human fibrosarcoma HT-1080 cells, which use uPAR and integrin as anchors to vitronectin, addition of PAI-1 itself did not detach these cells from the vitronectin coated surface (Czekay and Loskutoff 2004). Sequential addition of UPA and PAI-1 promoted cell detachment, which suggests this PAI-1 function requires uPA. Binding of PAI-1 to the uPA-uPAR-integrin complex initiates internalization of the complex, which is mediated by low-density lipoprotein receptor-related protein (LRP) (Chazaud, Bonavaud et al. 2000). PAI-1 and uPA are then degraded in the lysosomes, but uPAR, integrin and LRP are recycled back to the cell surface. Disengagement of the adhesive receptors uPAR and integrin from the ECM promotes cell 
detachment. Interfering with the formation of the PAI-1-uPA-uPAR complex or the binding of this complex to LRP significantly suppresses cell motility (Chazaud, Bonavaud et al. 2000).

PAI-1 affects the signaling pathway to promote cell migration. By binding to LRP, PAI-1 activates Jak (Janus kinase 2) /Stat (Signal transducer and activator of transcription protein) signaling and promotes rat smooth muscle cell (RSMC) migration in chemotaxis and monolayer wound-healing assays (Degryse, Neels et al. 2004). Addition of PAI-1 rapidly and transiently changes the cell morphology by reorganizing actin skeleton during cell migration (Degryse, Neels et al. 2004). Cell migration is inhibited by blockage of the interaction between PAI-1 and LRP through either mutation of LRP binding site on PAI-1 or LRP antagonist (Degryse, Neels et al. 2004).

Although PAI-1 has important roles in cell migration, it is not sufficient to promote migration by itself. Other factors are required to regulate cell migration. For example, PAI-1 and $\mathrm{uPA}, \mathrm{uPAR}$, are essential for the invasion of lung cancer cells through Matrigel barrier (Liu, Shuman et al. 1995).

In summary, by influencing fibrinolysis, extracellular matrix remodeling and cell migration, PAI-1 is involved in many physiological and pathological processes.

\section{Aberrant expression of PAI-1 associated diseases}

Both PAI-1 deficiency and PAI-1 overexpression are correlated with many human diseases. Therefore, the expression of PAI-1 must be tightly regulated. The antigen level 
and activity of PAI-1 in plasma or serum are parameters for screening PAI-1 deficiency and overexpression. In healthy individuals, the PAI-1 antigen level ranges from undetectable to $28 \mathrm{ng} / \mathrm{ml}$ in plasma (Declerck, Moreau et al. 1993), and the activity of PAI-1 ranges from 0.5 $\mathrm{U} / \mathrm{ml}$ to $47 \mathrm{U} / \mathrm{ml}$ (t-PA neutralizing units, 1 ng of active PAI-1 corresponds to $0.7 \mathrm{U}$ ) (Lijnen 2005).

\section{PAI-1 deficiency in disease}

PAI-1 deficiency was found in a hemostatic defect patient (Fay, Parker et al. 1997). However, no developmental defect has been found in PAI-1-deficient patients. PAI-1 deficiency was documented for a child who carried a homozygous PAI-1 loss of function allele due to a frame shift (Fay, Shapiro et al. 1992). In his family, 7 patients with homozygous PAI-1 mutation were identified by using allele-specific oligonucleotide hybridization (Fay, Parker et al. 1997). PAI-1 deficiency causes abnormal bleeding in homozygous deficient patients. However, the abnormal bleeding only occurs after trauma or surgery. A variety of bleeding patterns were documented for these patients including intracranial and joint bleeding after less serious trauma, delayed surgical bleeding, severe menstrual bleeding and frequent bruising. Oral fibrinolysis inhibitors, such as tranexmic acid or $\varepsilon$-aminocaproic acid can be used to treat this bleeding effectively. Heterozygous individuals have no history of excessive bleeding even after a significant trauma or surgical procedure. Mice with a homozygous PAI-1 null allele also exhibit an accelerated vascular fibrinolysis but do not bleed spontaneously (Carmeliet, Stassen et al. 1993). 
Although there is a defect in hemostasis, genetic PAI-1 deficiency might be beneficial to cancer or fibrosis patients due to its attenuation of the fibrogenic response. Studies in mice show that PAI-1 deficiency prevents the invasion and vascularization of transplanted cancers, and supplying PAI-1 by way of a transgene restores the cancer cell invasion and angiogenesis (Bajou, Noel et al. 1998). PAI-1 deficient mice have less chance of developing fibrosis after lung injury (Hattori, Degen et al. 2000), bile duct ligation (Wang, Zhang et al. 2007) or after renal surgery (Oda, Jung et al. 2001).

\section{PAI-1 over expression in disease}

PAI-1 levels are elevated in variety of diseases including cardiovascular diseases, fibrosis, and malignant tumors (Kruithof, Gudinchet et al. 1988; Urano, Wu et al. 1996). Abnormal induction of PAI-1 activity can result in a fibrinolysis defect. In the nervous system, the fibrinolysis defect caused by PAI-1 overexpression is associated with multiple sclerosis (Gveric, Herrera et al. 2003). In the cardiovascular system, PAI-1 elevation leads to thrombosis by blocking fibrin degradation and vessel wall remodeling. PAI-1 levels can be used as an independent risk factor of cardiovascular diseases (Kruithof, Gudinchet et al. 1988; Landin, Tengborn et al. 1990; Segarra, Chacon et al. 2001). The increase of PAI-1 in plasma is positively correlated with a variety of thrombotic vascular diseases, such as myocardial infarction (Scarabin, Aillaud et al. 1998), deep venous thrombosis (Kruithof, Gudinchet et al. 1988) and Budd-Chiari syndrome (BCS) (Hoekstra, Guimaraes et al.) in the human. Studies

of transgenic mice consistently showed that overexpression of PAI-1 results in venous thrombosis (Erickson, Fici et al. 1990). 
Overexpression of PAI-1 is also positively correlated with tissue fibrosis, and the overexpression is found in many experimental fibrosis models (Yang, Hsieh et al. 2003; Liu 2008). Fibrosis, a dysregulated tissue repair process, is characterized by excessive accumulation of fibrous connective tissue after injury or infection. PAI-1 is involved in the recruitment of myofibroblasts that express excessive amount of fibrous tissue during fibrosis (Oda, Jung et al. 2001). PAI-1 also plays an important role by inhibiting pericellular proteolysis and promoting accumulation of fibrous tissue (Yang, Hsieh et al. 2007). Treatments that decrease PAI-1 level can lower the chance of developing fibrosis. For instance, inhibition of PAI-1 by decoy peptides attenuated tubulointerstitial (Gonzalez, Klein et al. 2009). Suppression of PAI-1 by siRNA protects affected mice from the development and progression of pulmonary fibrosis (Senoo, Hattori et al. 2010). A positive feedback loop between TGF- $\beta$ and PAI-1 is involved in the development of renal fibrosis in diabetes (Seo, Park et al. 2009). TGF- $\beta$ induces fibronectin and collagen I expression through PAI-1, at the same time PAI- 1 activates transcription of TGF- $\beta$ in mouse mesangial cells (Seo, Park et al. 2009).

PAI-1 is also involved in tumorigenesis and metastasis by influencing pericellular proteolysis and cell migration during angiogenesis (Liu, Shuman et al. 1995). PAI-1 levels are elevated in many cancers including breast cancer (Meryet-Figuieres, Resina et al. 2007), endometrial cancer (Steiner, Pollow et al. 2008) and lung cancer (Annecke, Schmitt et al. 2008). PAI-1 promotes tumor growth and invasion in stromal fibroblast and endothelial cells (Andreasen 2007). Overexpression of PAI-1 is associated with poor prognosis for several human cancer types, especially for breast cancer (Andreasen 2007). In breast cancer, PAI-1 
and uPA are the most powerful prognostic markers (Andreasen 2007; Annecke, Schmitt et al. 2008). However, high levels of uPA and PAI-1 in node-negative primary breast cancers patients could predict beneficial responses to adjuvant chemotherapy (Annecke, Schmitt et al. 2008).

PAI-1 over-activation is also found in many other diseases, such as obesity and some metabolic syndromes including insulin-resistance syndrome (Idell 2003; Prabhakaran, Ware et al. 2003; Dellas and Loskutoff 2005). Obese patients, especially those with abdominal fat tissue distribution, have a high level of PAI-1 antigen and activity (Valle, Gascon et al. 2000). In those patients, PAI-1 is expressed in mature adipocytes, vascular smooth muscle cells and occasional endothelial cells in adipose tissue (Samad and Loskutoff 1996). Many factors in these patients can induce PAI-1 expression, including insulin, glucocorticoids, angiotensin II, fatty acid and tumor necrosis factor-alpha and transforming growth factor beta (Skurk and Hauner 2004). PAI-1 levels are positively correlated with the serum triglyceride levels and hypertension (Scarabin, Aillaud et al. 1998). However, some changes in life style, such as weight reduction and increased physical activity, can decrease plasma PAI-1 activity in affected individuals (Hoekstra, Geleijnse et al. 2004).

\section{Great therapeutic potential for PAI-1 inhibitors}

Because overexpression of PAI-1 contributes to thrombosis and the complications of obesity and cancer, strategies blocking PAI-1 activity could reduce cardiovascular risk and tumor metastasis. A variety of PAI-1 antagonists have shown promising results in treating PAI-1 elevation related diseases in experimental models. Tiplaxtinin (PAI-039), an orally 
active PAI-1 inhibitor, specifically inhibits the newly activated but not vitronectin-bound PAI-1 (Elokdah, Abou-Gharbia et al. 2004; Gorlatova, Cale et al. 2007). It significantly reduces thrombus formation in a variety of animal injury or thrombosis models (Elokdah, Abou-Gharbia et al. 2004; Smith, Dixon et al. 2006; Hennan, Morgan et al. 2008). Tiplaxtinin blocks angiogenesis in a Matrigel implant (Leik, Su et al. 2006) and protects mice from developing diet-induced obesity (Crandall, Quinet et al. 2006). Another PAI-1 inhibitor S35225 directly inhibits PAI-1 activity in vitro and in vivo (Rupin, Gaertner et al. 2008). PAI-1 aptamer SM-20 has been shown to be a potential anti-metastatic reagent for breast cancer (Blake, Sullenger et al. 2009). The aptamer blocks PAI-1 promoted cell detachment by inhibiting vitronectin binding but not its anti-proteolysis function.

\section{Regulation of PAI-1 expression}

PAI-1 gene expression is regulated by many factors including cytokines, growth factors, hormones, phorbol esters, endotoxins, glucocorticoids, angiotensin II, and fatty acids (Sandberg, Eriksson et al. 1997; Loskutoff and Samad 1998; Skurk and Hauner 2004). Some of these effects on PAI-1 expression are cell-type specific. For example, a main G-actinsequestering peptide Thymosin $\beta 4$ (TB4) enhances PAI-1 only in human endothelial cell lines HUVEC and EA.hy926 but not in human fibroblasts, prostate cancer cell line PC3 or promonocyte cell line U937 (Al-Nedawi, Czyz et al. 2004). Most regulation of PAI-1 occurs at the transcriptional level. Examples of factors that regulate PAI-1 at the transcriptional level include EGF, TGF- $\beta$, glucocorticoids, PMA (Phorbol 12-Myristate-13-acetate), T $\beta 4$ and P53 (Riccio, Lund et al. 1988). Factors that influence cellular microfilament 
organization, such as cytochalasin D (CD), also activate PAI-1 transcription (Higgins, Ryan et al. 1994).

PAI-1 is expressed in many tissues including liver, lung, heart, kidney (Quax, van den Hoogen et al. 1990), blood platelets (Kruithof, Tran-Thang et al. 1986) and adipose tissue (Samad and Loskutoff 1996). Cell culture studies show that PAI-1 is expressed in many cell types in the vascular system such as platelets (Quax, van den Hoogen et al. 1990), vascular endothelial cells (Hekman and Loskutoff 1985) and vascular smooth muscle cells (Reilly and McFall 1991). PAI-1 is also expressed by many nonvascular cells including hepatocytes (Hopkins, Westerhausen et al. 1991). While PAI-1 serves as an important regulator of fibrinolysis in the vascular system, it is also deposited in the extracellular matrix where it regulates plasmin-mediated extravascular proteolysis in the nonvascular system. PAI-1 expression is also regulated by cellular growth state (Ryan and Higgins 1993). The expression is higher in low density, exponentially growing normal rat kidney (NRK) cells than in confluent and post-confluent cells (Ryan and Higgins 1993).

\section{Immediate early expression}

Under normal physiological conditions, PAI-1 expression levels are very low. Stimuli that induce inflammation such as LPS (lipopolysaccharide) increase PAI-1 expression (Quax, van den Hoogen et al. 1990; Luyendyk, Mattes et al. 2004). PAI-1 activity in plasma is rapidly elevated with the peak level at $4 \mathrm{~h}$ after endotoxin injected into the rat (Quax, van den Hoogen et al. 1990). PAI-1 is markedly increased in lung and liver, and moderately induced in heart and kidney (Quax, van den Hoogen et al. 1990). Some mediators of the acute phase 
response, such as interleukin-1 (IL-1), IL-6 and dexamethasone, also induce PAI-1 expression (Healy and Gelehrter 1994). The induction of PAI-1 in quiescent cells by EGF, TGF- $\beta$ and serum is also in an immediate early pattern (Nilsen-Hamilton and Holley 1983; Thalacker and Nilsen-Hamilton 1987; Kutz, Hordines et al. 2001). After adding serum, transcription of PAI-1 occurs within 10 min (Ryan, Kutz et al. 1996). Insulin injection in lean mice increased the PAI-1 mRNA level in the adipose tissue during the first $6 \mathrm{~h}$ and then it gradually declined to the basal level (Samad and Loskutoff 1996).

PAI-1 is synthesized in the leading motile cohort of keratinocytes shortly after the scraping of monolayer wound (Providence and Higgins 2004). Blockage of Erk activity, either with chemical inhibitors or with dominant-negative Erk, suppressed PAI-1 expression and keratinocyte migration (Providence and Higgins 2004). Suppression of PAI-1 by antisense RNA or PAI-1 neutralizing antibodies blocked wound closure over a $24 \mathrm{~h}$ period (Providence and Higgins 2004). De novo PAI-1 synthesis is not required for early cell movement during wound healing because inhibition of PAI-1 RNA synthesis does not affect the response of cell migration. However PAI-1 synthesis is required to maintain the normal rate of wound closure (Providence and Higgins 2004).

\section{Promoter elements corresponding to transcription activation}

Many cis-elements in the PAI-1 promoter region have been identified as involved in PAI-1 transcriptional regulation including a CAGA box, activator protein 1 (AP-1) like site, E-box, specificity protein 1 (Sp1) bind site, glucocorticoid regulatory element (GRE), hypoxia-response element (HRE) and Nuclear Factor-KappaB (NFkB)-binding sites. Some 
cis-elements are involved in the basal expression of human PAI-1, such as one activator protein 2 consensus binding sequence in the region of -78 to -69 . It is recognized by helicase-like transcription factors (HLTF) that controls PAI-1 basal level (Ding, Benotmane et al. 1999). Most of these cis-elements are involved in positive regulation of PAI-1 upon stimulation. For example, two Sp1 binding sites in the proximal PAI-1 promoter (-85 to -42$)$ are required for PAI-1 expression induced by glucose (Chen, Su et al. 1998; Du, Edelstein et al. 2000) and PMA (Descheemaeker, Wyns et al. 1992). Some motifs could be either positive or negative regulatory elements depending on the interacting transcription factor. For example, an E-box motif (CACGTG) located at -160 to -165 in the PAI-1 promoter mediates the transcriptional response to the helix-loop-helix family transcription factors that include TFE3 (transcription factor binding to IGHM enhancer 3), USF-1 (upstream transcription factor 1), USF-2 \& HIF-1 (hypoxia-inducible factor 1) and Max (MYC associated factor X) (Hua, Liu et al. 1998; Kietzmann, Roth et al. 1999; Providence, White et al. 2002; Grinberg and Kerppola 2003). While TFE3 cooperates with Smad3/4 to activate transcription of TGF- $\beta$-responsive genes, Max inhibits Smad-mediated TGF- $\beta$-induced PAI1 expression (Grinberg and Kerppola 2003). The same cis-elements can be activated in response to different stimuli. For example, AP-1 (PMA-responsive element: TRE; 5'TGAG/CTCA-3') like sites in the PAI-1 promoter are involved in growth factors and PMAinduced transcriptional activity (Descheemaeker, Wyns et al. 1992).

\section{PAI-1 RNA stability regulation}

PAI-1 mRNA has a very short half-life. The half-life of PAI-1 mRNA is 1 to $3 \mathrm{hs}$ in human and only 21 min in mink (Hopkins, Westerhausen et al. 1991; Chuang, Hamilton et al. 
1995). However, the half-life of human PAI-1 might have been overestimated due to using actinomycin D in the experiment. Actinomycin D has been shown to stabilize PAI-1 mRNA in human HepG2 cells (Bosma and Kooistra 1991) and in mink lung epithelial Mv1Lu cells (Chuang, Hamilton et al. 1995). The stability of PAI-1 mRNA can be changed in response to different stimuli. PAI-1 mRNA can be stabilized by oxidized high-density lipoprotein (Ox-HDL) in endothelial cells (Norata, Banfi et al. 2004), insulin and insulin-like growth factor-1 (IGF-1) in HepG2 cells (Fattal, Schneider et al. 1992) and progesterone in endometrial stromal cells (Sandberg, Eriksson et al. 1997). In some tumors, the observed increases in PAI-1 protein level may be due to the stabilization of PAI-1 mRNA. The half-life of PAI-1 is over 20 hs in human glioblastoma A172 cells (Paugh, Paugh et al. 2008). Again this study blocked transcription using actinomycin D which probably stabilized PAI-1 mRNA.

In human, two isoforms of PAI-1 mRNA are reported. One is $2.3 \mathrm{~kb}$ and the other is 3.2 $\mathrm{kb}$, which results from alternative splicing at the 3' UTR region. The AU-rich element in 3' UTR is very important for the PAI-1 mRNA half-life. The longer transcript of PAI-1, which contains an AU-rich region, has a much shorter half-life (73 min) than the short one (215 min) (Hopkins, Westerhausen et al. 1991). Regulatory factors may affect the PAI-1 protein level by specifically increasing one transcript. For example, TGF- $\beta$ preferentially increases the 2.3 kb PAI-1 mRNA in retinal endothelial cells (Wileman, Booth et al. 2000), while cycloheximide (CHX) preferentially stabilizes the $3.2 \mathrm{~kb}$ PAI-1 mRNA in keloid fibroblasts (Zhang, Wu et al. 2003). IL-1 induces 40-fold the $3.2 \mathrm{~kb}$ PAI-1 mRNA and 30-fold of the 2.2 kb PAI-1 mRNA in HepG2 cells (Healy and Gelehrter 1994). Nuclear run-on 
experiments showed a 10-fold increase in transcription after $2 \mathrm{~h}$ addition of IL-1 (Healy and Gelehrter 1994). However no change in PAI-1 mRNA stability was found $4 \mathrm{~h}$ after IL-1 addition (Healy and Gelehrter 1994). PMA preferentially firstly increases 3.2 kb PAI-1 mRNA, and then $2.4 \mathrm{~kb}$ mRNA (Bosma and Kooistra 1991). The differential regulation of these two PAI-1 mRNA isoforms results from their differences in transcriptional termination, RNA processing and mRNA half-lives (Bosma and Kooistra 1991).

The mechanism(s) by which PAI-1 mRNAs are stabilized are not fully understood. Radha found that a nuclear protein stabilized PAI-1 mRNA by binding to its $3^{\prime}$ UTR in an iron-dependent manner in adenocarcinoma cells (Radha, Sugiki et al. 2005). In human lung carcinoma cells, a $60-\mathrm{Kd}$ mRNA binding protein destabilizes PAI-1 mRNA by binding to another region in the 3'UTR (Shetty and Idell 2000). The stability of PAI-1 mRNA regulated by cyclic nucleotide cAMP was extensively studied in HAT rat heptoma cells. Cyclic nucleotide cAMP down-regulates PAI-1 expression in many cell types (Heaton and Gelehrter 1990). The PAI-1 mRNA decay rate is increased by two-fold with 8-bromo-cAMP, a cAMP analog (Heaton, Kathju et al. 1992). An interaction between a distal region cis-element of $3^{\prime}$ UTR ( $3{ }^{\prime}$-most $134 \mathrm{nt}$ ) in PAI-1 mRNA and a PAI-1 mRNA binding protein (Serbp1) (Heaton, Tillmann-Bogush et al. 1998) is involved in this regulation (Heaton, Dlakic et al. 2003). However, due to the weak binding of Serbp1 to PAI-1 mRNA, Serbp1 is not sufficient to stabilize PAI-1 mRNA (Heaton, Dlakic et al. 2003). Other proteins that are involved in this regulation remain to be identified. 


\section{Regulation of PAI-1 expression by TGF- $\beta$}

TGF- $\beta$ is a multifunctional growth factor, which controls cell proliferation, differentiation, apoptosis and cell migration (Harradine and Akhurst 2006). It is expressed broadly by many cell types and is up-regulated in some human cancers. TGF- $\beta$ functions in a cell type specific manner. It inhibits the proliferation of epithelial, endothelial and haematopoietic cells (Like and Massague 1986; Jennings, Mohan et al. 1988; Moses, Yang et al. 1991); but promotes the growth of many mesenchymal cells (Andrades, Han et al. 1999). TGF- $\beta$ also induces the epithelial-mesenchymal transition (EMT) (Levy and Hill 2005; Valcourt, Kowanetz et al. 2005). For example, TGF- $\beta$ inhibits the growth of mouse mammary epithelial cell EPH4, and promotes EpRas, a v-Ha-Ras-transformed EPH4 derived cell line, to undergo EMT (Oft, Peli et al. 1996). TGF- $\beta$ treatment inhibits mammary epithelial NMuMG cell growth and stimulates cell apoptosis (Gal, Sjoblom et al. 2008). However, surviving cells undergo epithelial-mesenchymal transition (EMT) (Gal, Sjoblom et al. 2008). TGF- $\beta$ can also induce anchorage-independent growth, which requires the presence of mitogens including EGF (Uttamsingh, Bao et al. 2008) and hepatocyte growth factor (HGF) (Taipale and Keski-Oja 1996).

\section{Smad-mediated TGF- $\beta$ signaling}

TGF- $\beta$-initiated signaling is mainly mediated by the Smad proteins (Derynck, Zhang et al. 1998; Miyazono 2000). TGF- $\beta$ binds to its specific receptors on the cell surface as a dimer (Massague 1998; Massague and Wotton 2000). There are three types of TGF- $\beta$ receptors: type I and type II serine/ threonine kinase receptors (T $\beta R$-I, T $\beta R$-II) and type III receptor (T $\beta R$-III). T $\beta$ R-III does not transduce TGF- $\beta$ signaling. T $\beta$ R-I is normally repressed by a 
negative regulatory protein FKBP12 (the $12-\mathrm{kDa}$ FK506-binding protein). T $\beta \mathrm{R}-\mathrm{II}$ is constantly present on the cell surface. Upon binding to TGF- $\beta$, T $\beta$ R-II recruits and

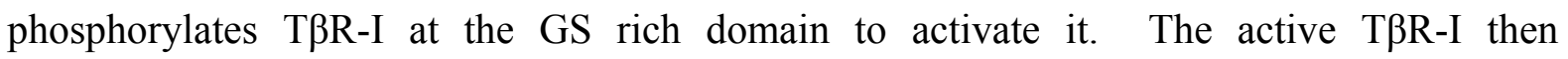
phosphorylates the Smad proteins to initiate intracellular signaling.

Three types of Smads have been reported in mammals, including receptor-regulated Smads (R-Smads, such as Smad2 or Smad 3), common partner Smads (Co-Smads such as Smad4) and inhibitory Smads (I-Smad such as Smad 7). The Smads contain an N-terminal MH1 (MAD homolog 1) DNA binding domain, and a C-terminal transcription activation domain (MH2 domain), which are connected by a linker region. Without TGF- $\beta$, Smad2 and Smad 3 are located on the cell membrane and interact with membrane bound proteins such as Smad Anchor for Receptor Activation (SARA). Upon TGF- $\beta$ stimulation, Smad2 and Smad3 are phosphorylated by T $\beta$ R-I at the C terminal SSXS motif (pSmadC). Homodimers or heterodimers of phosphorylated Smad2 and Smad3 form complexes with Smad4 (Yingling, Datto et al. 1997). The Smad complexes then move into the nucleus and mediate transcriptional activation (Nakao, Imamura et al. 1997). Both the MH1 domain and the linker region of the Smads are required for direct DNA binding. The Smad Binding Element (SBE), the optimal binding sequence for the Smad3/ Smad4 complex, is identified in vitro as an 8 bp palindrome, GTCTAGAC (Zawel, Dai et al. 1998). A CAGA box, which is exactly a half of the typical SBE, is also sometimes called the SBE. This element, which is found in the promoters of many TGF- $\beta$ responsive genes such as PAI-1 (Dennler, Itoh et al. 1998), JunB (Jonk, Itoh et al. 1998), and Smad7 (Stopa, Anhuf et al. 2000), is responsible for the binding of the TGF- $\beta$-induced Smad3/Smad4 complex. Although there is over $90 \%$ amino 
acid sequence identity between Smad2 and Smad3, the complex of Smad2/ Smad4 does not bind to the SBE. Two extra amino acids in the DNA-binding $\beta$-hairpin of N-terminal MH1 domain in Smad2 may be responsible for this difference in the binding capability (Dennler, Huet et al. 1999). Although phosphorylated Smad2 does not bind DNA, it forms a complex with Smad4 and the forkhead activin signal transducers (FAST) and activates transcription via the DNA binding function of FAST and Smad4. In the FAST-1/Smad2/Smad4 complex, Smad4 provides the transactivation domain (TAD) that interacts with the basal transcription machinery (Liu, Pouponnot et al. 1997). This complex has been reported to regulate the Xenopus homeobox gene mix2 during early embryogenesis (Yeo, Chen et al. 1999; Attisano, Silvestri et al. 2001).

Interaction of Smad with other transcription factor. Smad mediates transcriptional regulation by directly binding to the SBE and by interacting with other transcription factors. The affinity of the Smad3 MH1 domain for the SBE is relatively low, with a Kd of about $10^{-7}$ M (Shi, Wang et al. 1998). By contrast, the DNA binding affinities of different AP-1 proteins to TRE are very high, with $\mathrm{Kds}$ of about $12.5-50 \mathrm{nM}$ as tested by EMSA (Tateyama, Horisawa et al. 2006). Although there are usually several copies of SBE sites in TGF- $\beta$ responsive genes, other factors that facilitate Smad binding are required, and are usually present in a cell and tissue specific manner. Smad proteins have been shown to physically interact with DNA-specific binding proteins to modify Smad mediated transcriptional activation. Adjacent binding sites of Smad interacting partners are required. For example, Smad3 physically interacts with a variety of transcription factors such as AP-1, transcription factor microE3 (TFE3) and hepatocyte nuclear factor 4 (HNF-4), each in 
specific situations (Hua, Liu et al. 1998; Zhang, Feng et al. 1998; Wong, Rougier-Chapman et al. 1999). Cooperative binding of Smad3/4 and AP-1 to their recognition sites synergistically activates transcription of TGF- $\beta$ responsive genes such as collagenase I (Qing, Zhang et al. 2000).

\section{The Smads interact with co-activators, co-repressors and chromatin}

\section{modeling factors.}

Smad-mediated transcription is modulated by co-activators and co-repressors. CREB binding protein (CBP) and p300 (also known as E1A binding protein) are co-activators of Smad2 and Smad3. They recruit the Smad nuclear complexes to the basal transcription machinery via direct interaction (Derynck, Zhang et al. 1998; Feng, Zhang et al. 1998). Smad co-repressors include TG-interacting factor (TGIF), c-Ski and SnoN (Pessah, Prunier et al. 2001; Pessah, Marais et al. 2002). The transcription factor c-Jun directly binds to the transcription repressors Ski or TGIF and Smad2 to restrict Smad2-mediated transcription. TGF- $\beta$ activates Smad2-mediated transcription by causing the dissociation of c-Jun from Ski. Thus, by recruiting coactivators or corepressors to the Smad transcriptional complexes in the promoter, the transcriptional activity of Smad is differentially modulated.

\section{Non Smad-mediated TGF-ß signaling}

Besides the Smad-mediated signaling, TGF- $\beta$ activates other signaling pathways including the mitogen-activated protein kinases (MAPK), Rho-like GTPase and phosphatidylinositol-3-kinase (PI3K)/ Akt signaling pathways (Runyan, Schnaper et al. 2004; Moustakas and Heldin 2005; Zhang 2009). These non-Smad signaling pathways act 
independently or cooperatively with the Smad-mediated pathway. Three most extensively studied MAPKs subfamilies: Erk/MAPK, p38 kinases and Jnks, can be activated by TGF- $\beta$. TGF- $\beta$ can rapidly and directly activate Ras and Erk1 in the untransformed Mv1Lu epithelial cells (Mulder and Morris 1992). Erk activated by TGF- $\beta$ has two different roles: first, it phosphorylates of Smad2/3; second, it works in the Smad3-independent manner such as acting through AP-1 (Hayashida, Decaestecker et al. 2003). The p38 MAPK activated by TGF- $\beta$ can promote apoptosis (Yu, Hebert et al. 2002; Undevia, Dorscheid et al. 2004), cell adhesion (Hayes, Huang et al. 2003 ; Walsh, Ampasala et al. 2008), and fibroblastic transdifferentiation (Vayalil, Iles et al. 2007). Meanwhile, TGF- $\beta$ can activate Mek/Erk and PI3K/Akt-mediated signaling to regulate cell proliferation, survival and the EMT (Davies, Robinson et al. 2005).

\section{$P A I-1$ regulation by $T G F-\beta$}

TGF- $\beta$ stimulates PAI-1 expression in almost all cell types. PAI-1 induced by TGF- $\beta$ is close related to the increase of $\mathrm{T} 2$ renal epithelial cell motility (Kutz, Hordines et al. 2001). At low doses (1-2 ng/ml), TGF- $\beta$ promotes cell migration, while at high doses $(\geq 5 \mathrm{ng} / \mathrm{ml})$ it inhibits migration (Kutz, Hordines et al. 2001). PAI-1 is stimulated by both low and high doses of TGF- $\beta$, and the bi-functional role of PAI-1 on cell migration is consistent with the dual function of TGF- $\beta$ in regulating migration (Kutz, Hordines et al. 2001). Cells lacking PAI-1 do not respond to TGF- $\beta$ with suppressed basal locomotion. PAI-1 is also required for maintaining the TGF- $\beta$-induced growth arrest (Kortlever, Nijwening et al. 2008). Knockdown of PAI-1 by RNA interference blocks the antiproliferative activity of TGF- $\beta$ in human keratinocytes (HaCaTs) and primary mouse embryo fibroblasts. Prolonged activation 
of protein kinase B by PAI-1 repression leads to the escape of cells from TGF- $\beta$-induced growth inhibition (Kortlever, Nijwening et al. 2008).

Signaling pathways involved in TGF- $\beta$ regulates PAI-1 expression. TGF- $\beta$ regulates PAI-1 mainly through Smad-mediated signaling (Nakao, Imamura et al. 1997). There are also several CAGA boxes in the PAI-1 promoter to which the TGF- $\beta$-activated nuclear Smad3/Smad4 heterodimer binds (Dennler, Itoh et al. 1998). Meanwhile, other signaling pathways activated by TGF- $\beta$, include Erk in the MAPK pathway (Harradine and Akhurst 2006), Jnk (Matsuzaki, Murata et al. 2007), P38 kinase (Vayalil, Iles et al. 2007) and PI3 kinase/Akt(Das, Ghosh-Choudhury et al. 2008) also contribute to increases PAI-1 level (Figure 2A). Experiments with pharmacologic inhibitors or dominant negative proteins show that maximal PAI-1 induction by TGF- $\beta$ requires the EGFR, P21 Ras, Mek, Erk1/2 and pp60 (c-Src) signaling (Kutz, Hordines et al. 2001; Kutz, Higgins et al. 2006). In renal mesangial cells, TGF- $\beta$-induced PI3 Kinase/Akt signaling enhances Smad-mediated PAI-1 expression by promoting CBP-mediated Smad3 acetylation (Das, Ghosh-Choudhury et al. 2008). Matsuzaki reported that Jnk, activated by TGF- $\beta$, phosphorylates Smad 3 at the linker region (pSmad3L), which increases PAI-1 expression in heptocellular carcinoma (HCC) (Matsuzaki, Murata et al. 2007).

Regulators that affect the MAPK pathway also modulate TGF- $\beta$-induced PAI-1 expression. For example, by inhibiting the Jnk/P38 pathway in 3T3 cells, glutathione (GSH) represses TGF- $\beta$-induced PAI-1 expression (Vayalil, Iles et al. 2007). During this process, the binding of transcription factors, like AP-1, sp1 and Smad, to the cis-elements in PAI-1 promoter is blocked (Vayalil, Iles et al. 2007). In human mesangial cells, actin cytoskeleton 
reorganization affects TGF- $\beta$ induced PAI-1 expression by influencing MAPK and Jnk activity (Yang, Hsieh et al. 2007). In these cells, Erk and Jnk are colocalized with $\alpha$-actinin along with F-actin. Actin disassembly reduces basal and TGF- $\beta$-induced PAI-1 expression by inhibiting the phosphorylation of Erk and Jnk (Yang, Hsieh et al. 2007). T2 renal epithelial cells grown as monolayer cultures produce more PAI-1 in response to TGF- $\beta$ than cells grown in suspension culture due to different Mek activities in adhesive and suspended culture state (Kutz, Hordines et al. 2001).

Cis-elements required for TGF- $\beta$-induced PAI-1 expression. The elements responsible for TGF- $\beta$ induction mainly locate at two regions within the 800 bp region upstream of the PAI-1 transcription initiation site. The distal promoter region (-636 to -740$)$ contains the cooperative SBE-like site (-684/-677) and AP-1 like site (-670/-664, GGAGTCA) which mediate most of the response to TGF- $\beta$ stimulation in Hep3B and HepG2 cells (Keeton, Curriden et al. 1991; Westerhausen, Hopkins et al. 1991). Electrophoresis Mobility Shift Assays (EMSA) assay using overlapping oligonucleotide in this distal region identified these two sites are important for binding of Smad (Stroschein, Wang et al. 1999). Mutation of either site significantly reduced the binding of Smad4 and Smad3, and mutation of both sites completely blocked Smad binding and PAI-1 gene activation in response to TGF- $\beta$ (Stroschein, Wang et al. 1999). A CAGA element (-732 to -721) in the distal region is also important for the TGF- $\beta$ response in Hep3B cells (Song, Siok et al. 1998). The proximal region (-77/-40) containing one AP-1 like site (-61 to -54) and two Sp1 DNA binding sites also elevated PAI-1 promoter activity in response to TGF- $\beta$ (11-fold) (Keeton, Curriden et al. 1991; Datta, Blake et al. 2000). An intact E box motif (5 CACGTG3`) at -566 to -561 of 
PAI-1 promoter was also reported to be required for maximal PAI-1 induction by TGF- $\beta$ in human epidermal keratinocytes (Allen, Qi et al. 2005).

Due to the relatively low affinity of Smad to the SBE, other transcription factors are essential to enhance the binding of Smad to PAI-1 promoter. Overexpression of both Smad3 and c-Jun AP-1 protein synergistically activates transcription of PAI-1 with a 50 fold increase in promoter activity, which is most likely through their binding to the SBE-like motif and AP-1 like motif in the distal promoter region (Verrecchia, Vindevoghel et al. 2001). The cooperative binding of TFE3 to the E-box $(-160 /-165)$ and Smad3 to the nearby SBE in the promoter region is critical to meditate TGF- $\beta$-induced PAI-1 promoter activity from a 56 bp enhancer (Hua, Liu et al. 1998; Hua, Miller et al. 1999). Datta et al. showed that two Sp1 sites in the proximal PAI-1 promoter (-77/-40) were involved in PAI-1 induction by TGF- $\beta$ in Mv1Lu and HepG2 cells where TGF- $\beta$ promoted the physical interaction between the carboxyl terminus of Sp1 and the activated Smad3 at the Sp1 binding sites (Datta, Blake et al. 2000). However, in fibroblasts, Sp1 was dispensable in TGF- $\beta$-induced PAI-1 expression (Ghosh, Mori et al. 2007). Thus it is possible that the function of Sp1 on PAI-1 expression is cell type specific or indirect. In summary, the distal region containing the SBE-like and the AP-1-like sites and the proximal region containing AP1 sites contribute to the most of the induction of PAI-1 by TGF- $\beta$. In the meanwhile activation of other elements, such as E-box and Sp1, may also be required for the maximal PAI-1 induction. 


\section{Regulation of PAI-1 expression by EGF}

\section{EGF and EGF-mediated signaling}

Epidermal growth factor (EGF) is another important growth factor that regulates cell proliferation, differentiation and survival. EGF is up-regulated in many cancers, and it promotes tumor cell motility and invasion (Hofler and Becker 2003). These mitogenic effects are initiated by the binding of EGF to its receptor (EGFR) with high affinity on the cell surface (Goi, Shipitsin et al. 2000). The binding of EGF to EGFR triggers the receptor to form dimmers and phosphorylate each other through its tyrosine kinase activities. The phosphorylated receptors can initiate signal transduction, including the MAPK, Akt and Jnk pathways and regulate gene expression (Wang, McCullough et al. 2000; Jiang, Zhou et al. 2006).

\section{$P A I-1$ regulation by $E G F$}

EGF-induced PAI-1 expression has been reported in a variety of cells types, including liver epithelial cells (Seebacher, Manske et al. 1992), microvascular endothelial cells (Mawatari, Okamura et al. 1991), endometrial (Miyauchi, Momoeda et al. 1995), astrocytes (Tranque, Naftolin et al. 1994), gliomas (Paugh, Paugh et al. 2008), hepatomas (Hopkins, Westerhausen et al. 1991) and trophoblasts (Anteby, Greenfield et al. 2004). EGF-stimulated PAI-1 (earlier reported as EGF/TGF $\alpha$-inducible protein EIP-1) synthesis is closely associated with EGF-induced cell migration in both normal and Ha-Ras-transformed liver epithelial cells (Bade and Feindler 1988; Manske, Feindler et al. 1990; Seebacher, Manske et al. 1992). PAI-1 (reported earlier as inhibitor inducible protein-48 kDa IIP48) protein levels could be 
detected as early as two hours after EGF stimulation (Nilsen-Hamilton and Holley 1983; Thalacker and Nilsen-Hamilton 1987; Bade and Feindler 1988), and these proteins are deposited into the ECM migration tracks (Seebacher, Manske et al. 1992). However, PAI-1 is not sufficient to stimulate cell migration in these cells (Seebacher, Manske et al. 1992).

Although EGF activated Erk1/2, Jnk phosphorylation and DNA binding activity of AP-1, none of these were involved in PAI-1 stimulation in human glioma cells. An ordered activation of EGFR, Src, PKC $\delta$ (protein kinase C delta), SphK1 (sphingosine kinase 1) and S1P (sphingosine 1-phosphate) signaling is required for EGF activating PAI-1 transcription in a c-Jun dependent manner (Paugh, Paugh et al. 2008). Experiments using specific chemical inhibitors showed that inhibitors of PKC (protein kinase C) and c-Src efficiently blocked PAI-1 induction by EGF (Paugh, Paugh et al. 2008). Knock-down of sphingosine kinase 1 by siRNA eliminated the EGF-induced PAI-1 expression in human glioma cells (Paugh, Paugh et al. 2008).

\section{Synergistic regulation of PAI-1 by EGF and TGF- $\beta$}

\section{TGF-ß cooperates with EGF affecting many biological processes}

Integration of the EGF- and the TGF- $\beta$ - mediated signaling dramatically influences cell function in normal processes and during disease progression including cell transformation (Roberts, Frolik et al. 1983), the epithelial-mesenchymal transition (EMT) (Uttamsingh, Bao et al. 2008; Hardy, Booth et al.; Taylor, Parvani et al.), migration (Stolz and Michalopoulos 1997), proliferation (Saltis, Agrotis et al. 1992) and survival (Saha, Datta et al. 1999). 
Cooperation between EGF and TGF- $\beta$ also affects wound healing (Lawrence, Norton et al. 1986).

EGF and TGF- $\beta$ cooperate to promote the transformation of many cells such as normal rat kidney (NRK) cells (Roberts, Frolik et al. 1983), rabbit corneal keratocytes (RCKs) (He and Bazan 2008) and rat intestinal epithelial cell (RIE) (Uttamsingh, Bao et al. 2008). Transformation of eukaryotic cells results in anchorage dependent cells losing contact inhibition of growth, gaining the capability of growing in soft agar and becoming anchorageindependent. These changes are found during tumorigenesis in vivo. The transformation induced by EGF and TGF- $\beta$ changes keratinocytes to myofibroblasts with the loss of dendritic shape and synergistically increased fibronectin synthesis (He and Bazan 2008). By significantly increasing the levels of extracellular matrix protein expression in myofibroblasts, EGF and TGF- $\beta$ play a crucial role in tissue fibrosis (He and Bazan 2008).

As well as acting independently, EGF and TGF- $\beta$ cooperate to promote a variety of epithelial cells to undergo the EMT (Uttamsingh, Bao et al. 2008; Hardy, Booth et al.; Taylor, Parvani et al.). An epithelial cell is characterized by apical-basal polarity and tight cell-cell contact (Xu, Lamouille et al. 2009). During the epithelial-mesenchymal transition, epithelial cells lose their polarity and epithelial cell markers such as E-cadherin, and transform to a spindle like cell shape similar to that of fibroblasts. They also express mesenchymal markers such as vimentin and smooth muscle actin, and their motility is enhanced $(\mathrm{Xu}$, Lamouille et al. 2009). Elevated TGF- $\beta$ synthesis and amplified EGFR signaling cooperatively promote cell migration and the invasive phenotype (Wilkins-Port, Higgins et al. 2007). TGF- $\beta$ alone inhibits epithelial cell migration and stimulates the synthesis of fibronectin, laminin, 
proteoglycans and PAI-1 to increase the matrix deposition (Freytag, Wilkins-Port et al. 2009). The inhibiting effect of TGF- $\beta$ on cell growth and migration is reversed by the positive effect of EGFR signaling and cell migration is synergistically enhanced by the combination of these growth factors (Uttamsingh, Bao et al. 2008). Both metallomatrix proteinases (MMPs) and PAI-1 are synergistically induced by the presence of EGF and TGF- $\beta$ to enhance focal degradation and extracellular matrix remodeling (Freytag, Wilkins-Port et al. 2009). Blocking the activities of these metalloproteinase (MMP1 and MMP9) significantly reduces EGF and TGF- $\beta$-induced cell migration and colony formation (Uttamsingh, Bao et al. 2008). The remodeling of extracellular matrix enables acquisition of motility and plasticity of epithelial cells (Freytag, Wilkins-Port et al. 2009).

EMT plays a critical role in morphogenesis during early embryonic development (Shook and Keller 2003) and in many pathological processes including wound healing, tissue fibrosis and tumor progression (Bates and Mercurio 2005; Radisky, Kenny et al. 2007; Kalluri 2009). EMT in cancers signals the change of cancer cells from the benign to malignant forms with increased potential of invasion and metastasis (Kalluri 2009). In the late stages of tumor progression, the EGFR mediated signaling is often amplified. Sustained activation of MAPK, which is enhanced in the presence of TGF- $\beta$, is required for EGF and TGF- $\beta$-induced EMT. Cooperation between EGFR and TGF- $\beta$ explains the tumor-promoting activity of TGF- $\beta$, which is frequently found elevated in advanced stages of tumors.

TGF- $\beta$ also acts synergistically with EGF to stimulate hepatocyte motility during liver tissue regeneration (Stolz and Michalopoulos 1997). The increased motility is observed in the non-transformed primary rat heptocytes and hepatoblastoma HepG2 cells (Stolz and 
Michalopoulos 1997). It occurs only on a collagen surface and is independent of the effect of these growth factors on DNA synthesis (Stolz and Michalopoulos 1997).

\section{TGF- $\beta$ also synergizes with other ligands of tyrosine kinase receptors}

Besides EGF, TGF- $\beta$ also acts synergistically with TGF $\alpha$ (transforming growth factor alpha). TGF $\alpha$ is a member of EGF family and shares the same receptor (EGFR) as EGF (Roberts, Frolik et al. 1983). In many cases, TGF $\alpha$ can replace EGF to synergize with TGF- $\beta$. For example TGF- $\beta$ enhances the TGF $\alpha$ effect on promoting the motility of primary rat hepatocytes and HepG2 cells (Stolz and Michalopoulos 1997) and inducing the transformation of normal rat kidney (NRK) fibroblast (Roberts, Frolik et al. 1983). Both EGF and TGF $\alpha$ synergize with TGF- $\beta$ to stimulate inorganic pyrophosphate (PPi) production by articular cartilage during the formation of calcium pyrophosphate dehydrate (CPPD) crystals in joints (Rosenthal, Cheung et al. 1991). Thus the mechanism of synergism is likely arising from cross talk between the signaling pathways mediated by EGFR and TGF- $\beta$.

Other growth factors have also been found to synergistically interact with TGF- $\beta$. For example, hepatocyte growth factor (HGF) cooperatively acts with TGF- $\beta$ to induce scattering phenotype of epithelial cells (Stolz and Michalopoulos 1997). Insulin like growth factor I (IGF-I) synergizes with TGF- $\beta$ in inducing the EMT of RIE cells (Uttamsingh, Bao et al. 2008). Basic fibroblast growth factor (bFGF or FGF-2) and platelet-derived growth factor (PDGF), cooperate with TGF- $\beta$ to enhance the proliferation of vascular smooth muscle cells (Saltis, Agrotis et al. 1992). 
There are four canonical signaling pathways induced by RTKs, including the mitogenactivated protein kinase cascades (MAPKs), the lipid kinase phosphatidylinositol 3 kinase (PI3K), a group of Stat transcription factors, and the phospholipase C $\gamma$ (PLC $\gamma$ ) mediated pathway (Katz, Amit et al. 2007). These signaling pathways are shared by all RTKs and are potentially involved in the mechanism(s) of synergism with TGF- $\beta$.

\section{$P A I-1$ is synergistically induced by EGF and TGF- $\beta$}

PAI-1 is synergistically induced by EGF and TGF- $\beta$ in both normal and MSVtransformed mink lung epithelial (Mv1Lu) cells (Thalacker and Nilsen-Hamilton 1987; Thalacker and Nilsen-Hamilton 1992). A synergistic induction of PAI-1 was also found during EGF and TGF- $\beta$ activated EMT (Wilkins-Port, Ye et al. 2009). The PAI-1 cellular protein level is synergistically increased in Ras transformed human HaCaT II-4 keratinocytes in the presence of both growth factors (Wilkins-Port, Ye et al. 2009). Microarray experiments also showed that PAI-1 is the most highly expressed early gene during EGF and TGF- $\beta$ induced EMT of transformed human keratinocytes (Freytag, Wilkins-Port et al. 2009).

MAPK signaling plays an important role in the synergistic induction of PAI-1. Maximal expression of PAI-1 induced by EGF and TGF- $\beta$ requires the activation of Mek/Erk and p38 MAPK signaling (Freytag, Wilkins-Port et al. 2010). Inhibition of the Mek and p38 MAPKmediated pathways blocks both PAI-1 expression and EGF and TGF- $\beta$ induced cell locomotion (Freytag, Wilkins-Port et al. 2010). Transactivation of the EGFR is also involved in the synergistic regulation of PAI-1 in human keratinocytes (Freytag, Wilkins-Port et al. 
2010). Blocking EGFR signaling with an inhibitor AG1478 attenuated PAI-1 synthesis (Wilkins-Port, Ye et al. 2009).

PAI-1 plays a critical role in the EGF and TGF- $\beta$-affected processes such as EMT, which is mostly likely through influencing cell motility. Cotreatment with EGF and TGF- $\beta$ induces the plastic phenotype of several epithelial tumor cells including SCC (Wilkins-Port, Ye et al. 2009; Freytag, Wilkins-Port et al. 2010). PAI-1 is critical in the EGF and TGF- $\beta$-induced invasion in Ras-transformed human (HaCaT II-4) keratinocytes and human cutaneous squamous carcinoma cells (Wilkins-Port, Higgins et al. 2007; Freytag, Wilkins-Port et al. 2010). Suppression of PAI-1 expression efficiently blocks cell locomotion (Freytag, Wilkins-Port et al. 2010) and colony formation induced by EGF and TGF- $\beta$ (Wilkins-Port, Ye et al. 2009). Addition of exogenous PAI-1 or inhibitor of urokinase-type plasminogen activator supressed the dissolution of the collagen matrix (Wilkins-Port, Ye et al. 2009). Knockdown of PAI-1 by siRNA also inhibited TGF- $\beta$-induced EMT in mouse lung epithelial LA-4 cells (Senoo, Hattori et al. 2010). In summary, the role of PAI-1 in EMT is likely related to its ability in modulating remodeling of extracellular matrix and cell migration.

7. Molecular mechanism of the interaction between the TGF- $\beta$ and EGFmediated signaling

\section{Pathways involved in EGF and TGF- $\beta$ affected EMT}

The TGF- $\beta$-induced EMT requires activity of the MAPK, Smad and AP-1 signaling pathways (Davies, Robinson et al. 2005). Blocking the MAPK signaling supresses progress of the EMT (Grande, Franzen et al. 2002). In cells bearing a normal Ras, EGF cooperates 
with TGF- $\beta$ to promote EMT by activating MAPK and AP-1 (Davies, Robinson et al. 2005). PMA substitutes for EGF in promoting EMT with TGF- $\beta$ via AP-1 activation (Davies, Robinson et al. 2005). In rat intestine epithelial (RIE) cells, TGF- $\beta$ enhances the EGFinduced MAPK signaling and prolongs the EGF-activated AKT signaling (Uttamsingh, Bao et al. 2008). Both PI3K and MAPK-mediated pathways are involved in EGF and TGF- $\beta$ mediated cell migration and invasion, but only the MAPK pathway is required for EGF and TGF- $\beta$ induced EMT in RIE cells (Uttamsingh, Bao et al. 2008). The EMT in mouse mammary epithelial cells requires synergistic interaction between TGF- $\beta$ receptor and EGF signaling, especially involving the Ras/MAPK signaling (Janda, Lehmann et al. 2002). During EGF and TGF- $\beta$ induced EMT, the EGFR level or its phosphorylation was not significantly increased by TGF- $\beta$ (Uttamsingh, Bao et al. 2008). The EMT induced by EGF

and TGF- $\beta$ can be reversed by removing the growth factors from medium. However, sustained TGF- $\beta$ receptor activation cooperates with the prolonged Ras/Raf signaling to maintain the EMT in EpRas4 cells (Janda, Lehmann et al. 2002). Autocrine regulation of TGF- $\beta$ production is also involved in the stabilization of the EMT progression (Janda, Lehmann et al. 2002).

\section{MAPK signaling influences Smad-mediated transcriptional activity}

The effect of Mek/Erk on Smad activity may depend on the Erk activity. A certain amount of Erk activity is needed for maximal activation of Smads by TGF- $\beta$. For example, in human mesangial cells, Erk activation by TGF- $\beta$ helps to phosphorylate the carboxylterminal serines $\left(\mathrm{SS}^{\mathrm{P}} \mathrm{XS}^{\mathrm{P}}\right.$ motif) of R-Smad ( $\left.\mathrm{pSmadC}\right)$, which greatly promotes TGF- $\beta$ induced transcriptional activity (Hayashida, Decaestecker et al. 2003). Inhibiting Erk activity 
decreased TGF- $\beta$ induced Smad transcription in an AP-1 independent way (Hayashida, Decaestecker et al. 2003). MAPK activated by other factors can also enhance Smadmediated transcription. For example, HGF and EGF phosphorylate Smad2 in the SSMS motif in a T $\beta R$-I independent manner, which promotes nuclear translocation of Smad2 that depends on Mek1 (de Caestecker, Parks et al. 1998)

However phosphorylation of the linker region of R-Smads (pSmadL) by EGF- or oncogenic Ras-induced Mek/Erk inhibits nuclear translocation of Smad2/3 in mammary and lung epithelial cells (Kretzschmar, Doody et al. 1999). The inhibition of nuclear translocation of Smad2/3 is much stronger by oncogenic Ras than by EGF (Kretzschmar, Doody et al. 1999). The inhibiting effect of EGF on nuclear translocation of $S m a d 2 / 3$ is more effective at a low concentration than at a high concentration of TGF- $\beta$. Thus the relative strength of the EGF signal compared to the TGF- $\beta$ signal affects nuclear accumulation of Smad2/3 and TGF- $\beta$-mediated transcription. These effects were confirmed to be true in Mv1Lu cells (Kretzschmar, Doody et al. 1999).

\section{AP-1 and Smad cooperatively activate transcription}

Transcription factor AP-1 is made of either homodimer of Jun family proteins or heterodimer of Jun and Fos family proteins (Nakabeppu, Ryder et al. 1988; Angel and Karin 1991). There are five known members in Fos family: c-Fos (Curran and Teich 1982), Fos B (Zerial, Toschi et al. 1989), $\Delta$ FosB, Fra-1 (Cohen and Curran 1988) and Fra-2 (Matsui, Tokuhara et al. 1990) and three known members in Jun family: c-Jun (Ball, Bos et al. 1988), JunB (Ryder, Lau et al. 1988) and JunD (Hirai, Ryseck et al. 1989). Although all AP-1 
complexes bind to the common AP-1 site (TRE), the transcription activity of AP-1 is determined by the composition of the dimer and the phosphorylation states of each component (Kaminska, Pyrzynska et al. 2000). c-Jun is the most important Jun family member because it recruits Jnk to phosphorylate its binding partner (Kaminska, Pyrzynska et al. 2000). Upon stimulation by UV-irradiation, growth factors and cytokines, c-Jun is rapidly phoshorylated by Jnk at serine 63 and 73 within the amino terminal transactivation domain (TAD) resulting in increased protein stability and significantly enhanced transcriptional activity (Morton, Davis et al. 2003). Fos is the most important member in Fos family, which is activated by Erk1/2 and Frk (Fos regulating kinase) at the Thr-232, Thr-325 (Erk2), Thr-331, Ser-374 (Erk1/2) and Ser362 within the carboxy-terminal TAD resulting in activation of AP-1 (Chen, Abate et al. 1993; Cavigelli, Dolfi et al. 1995; Murphy, Smith et al. 2002; Monje, Marinissen et al. 2003). Fos is also rapidly phosphorylated in its transactivation domain by p38 kinases upon UV-light exposure (Tanos, Marinissen et al. 2005).

It has been shown that AP-1 transcription factor cooperates with Smads to activate the transcription of some TGF- $\beta$ responsive genes including Collagenase I (Zhang, Feng et al. 1998; Qing, Zhang et al. 2000). The cooperative binding of Smad to the SBE and the AP-1 complex to its recognition sites (TRE) results in the synergistic activation of TGF- $\beta$ inducible genes. During this interaction, Smad3/Smad4 forms a complex with AP-1 via the physical interaction of the Smad3 MH1-linker binding to c-Jun and the Smad3 MH2 domain to c-Fos at AP-1 binding sites (Zhang, Feng et al. 1998; Liberati, Datto et al. 1999). Cooperative interaction between AP-1 and Smad also elevates the transcription of PAI-1 (Verrecchia, 
Vindevoghel et al. 2001). Overexpression of Smad3 elevated the transcriptional activity from a 800-bp PAI-1 proximal promoter (p800-Lux) by 18-fold, and overexpression of c-Jun alone only slightly increased PAI-1 promoter activity (about 2-fold) (Verrecchia, Vindevoghel et al. 2001). However, simultaneous overexpression of both Smad3 and c-Jun increased the promoter activity of PAI-1 by about 50-fold over control (Verrecchia, Vindevoghel et al. 2001). Although JunB alone showed the similar stimulation on PAI-1 transcription as c-Jun, it only had slightly additive effect with Smad3 (Verrecchia, Vindevoghel et al. 2001).

AP-1 induced by other stimuli also acts synergistically with the Smad proteins to activate gene transcription. For example, AP-1 activated by Gonadotropin-releasing hormone (GnRH) and Smad activated by activin synergistically induce transcription of the FSH $\beta$ subunit (Coss, Hand et al. 2007). AP-1 is involved in the modulation of TGF- $\beta$-induced PAI-1 expression by promoting cytoskeleton reorganization in human mesangial cells. Actin stabilization prolongs the phosphorylation of Erk and Jnk and enhances the binding of AP-1 to its DNA binding sites (Yang, Patel et al. 2007). Dominant negative mutants for either MAPK or Jnk decrease TGF- $\beta$ - induced PAI-1 promoter activity and the binding of AP-1 to the PAI-1 promoter (Yang, Patel et al. 2007).

However, not all AP-1 sites promote TGF- $\beta$-induced transcriptional activity. An overlapping Smad binding site is required to produce the cooperative transcriptional activation by Smads and AP-1 (Zhang, Feng et al. 1998). Thus, the impact of AP-1 on Smad-mediated transcription depends on the position of its recognition sites in the promoter and the availability of active AP-1 transcription factors. For example, of two AP-1-like sites 
in PAI-1 distal promoter, only one in the region of -670 to -664 acts cooperatively with the adjacent SBE-like site (-684 to -677$)$ and the other one (-659/-653) does not have such effect (Stroschein, Wang et al. 1999).

\section{Mechanisms of synergistic regulation of gene expression by EGF and TGF- $\beta$}

The synergistic effects of EGF and TGF- $\beta$ on different biological processes involve the expression of different target genes. For example during the EMT, matrix metalloproteinases (MMPs) are synergistically induced by EGF and TGF- $\beta$ to break down the extracellular matrix components to promote the motility of cells (Uttamsingh, Bao et al. 2008; WilkinsPort, Ye et al. 2009). In addition with synergistically induced PAI-1, these proteins facilitate the formation of a proper environment for epithelial cells to acquire the invasive phenotype (Wilkins-Port, Ye et al. 2009).

The synergistic regulation of target gene expression by EGF and TGF- $\beta$ occurs mainly at the transcriptional level. EGF alone shows very weak activation of Smad3-mediated transcription in hepatocytes (Peron, Rahmani et al. 2001). However, the transcriptional activity mediated by either Smad 2 or Smad3 is synergistically increased by EGF and TGF- $\beta$ (Peron, Rahmani et al. 2001). This synergism requires the activity of AP-1 because the synergism between EGF and TGF- $\beta$ is reduced by dominant negative c-Jun, which inhibits the AP-1 activity by preventing the endogenous Jun and Fos protein from forming a functional heterodimer. Dominant negative c-Jun or c-Jun RNAi decreases the transcriptional activity of Smad3 in the EGF and TGF- $\beta$ cotreatment but not that in the treatment of either growth factor alone. Co-immunoprecipitation experiments have shown 
that c-Jun is physically associated with Smad3 (Peron, Rahmani et al. 2001). PI3K and p38 MAPK, but not JNK-mediated pathways activate c-Jun by phosphorylation. EGF and TGF- $\beta$ synergize in the transcriptional activation of the SBE promoter, which can be blocked by dominant negative AP-1 (Peron, Rahmani et al. 2001). In Mv1Lu cells, EGF and TGF- $\beta$ synergistically induce the expression of cyclooxygenase-2 (COX-2) and prostaglandin E2 (PGE2) to inhibit cell apoptosis and promote cell invasion and angiogenesis (Saha, Datta et al. 1999). TGF- $\beta$ receptor type I (T $\beta$ R-I) and the EGF receptor are required in the synergistic induction of COX2 and PGE2 (Saha, Datta et al. 1999). Mek/Erk and p38 MAPK are also involved because blocking either activity by specific inhibitors significantly reduces the induction of COX-2 (Saha, Datta et al. 1999).

Post-transcriptional regulation also plays an important role in the synergistic induction of some target genes by EGF and TGF- $\beta$. For example, EGF and TGF- $\beta$ synergistically increase the mRNA level of leukemia-inhibitory factor (LIF) by increasing the mRNA stability in thymic epithelial cells (Schluns, Cook et al. 1997). However the mechanism of this post transcriptional regulation is unclear.

\section{Summary}

PAI-1 plays important roles in inhibiting fibrinolysis, regulating extracelluar matrix remodeling and modulating cell migration. Elevated PAI-1 levels are correlated with many diseases including thrombosis, cancer, fibrosis and metabolic diseases. PAI-1 antagonists have shown promising results in treating such diseases. Many stimuli, including growth factors, cytokines and LPS, that stimulate the expression of PAI-1 may induce PAI-1 in vivo. EGF and TGF- $\beta$ synergistically induce PAI-1 expression in both normal and transformed 
mink lung epithelial Mv1Lu cells (Thalacker and Nilsen-Hamilton 1987; Thalacker and Nilsen-Hamilton 1992) and transformed human keratinocytes (Freytag, Wilkins-Port et al. 2009). PAI-1 plays important roles in EMT induced by EGF and TGF- $\beta$ in human keratinocytes (Freytag, Wilkins-Port et al. 2009). TGF- $\beta$ activates PAI-1 expression through Smad3/Smad4, while EGF functions through Src activating gene transcription in human mensengial cells (Harradine and Akhurst 2006). However the synergistic regulation of PAI-1 is not fully understood. This thesis will address the mechanism of synergistic regulation of PAI-1 by EGF and TGF- $\beta$. 


\section{References}

Al-Nedawi, K. N., M. Czyz, et al. (2004). "Thymosin beta 4 induces the synthesis of plasminogen activator inhibitor 1 in cultured endothelial cells and increases its extracellular expression." Blood 103(4): 1319-24.

Alessi, M. C., I. Juhan-Vague, et al. (1991). "Molecular forms of plasminogen activator inhibitor-1 (PAI-1) and tissue-type plasminogen activator (t-PA) in human plasma." Thromb Res 62(4): 275-85.

Allan, E. H. and T. J. Martin (1995). "The plasminogen activator inhibitor system in bone cell function." Clin Orthop Relat Res(313): 54-63.

Allen, R. R., L. Qi, et al. (2005). "Upstream stimulatory factor regulates E box-dependent PAI-1 transcription in human epidermal keratinocytes." J Cell Physiol 203(1): 156-65.

Andrades, J. A., B. Han, et al. (1999). "A recombinant human TGF-betal fusion protein with collagen-binding domain promotes migration, growth, and differentiation of bone marrow mesenchymal cells." Exp Cell Res 250(2): 485-98.

Andreasen, P. A. (2007). "PAI-1 - a potential therapeutic target in cancer." Curr Drug Targets 8(9): 1030-41.

Andreasen, P. A., R. Egelund, et al. (2000). "The plasminogen activation system in tumor growth, invasion, and metastasis." Cell Mol Life Sci 57(1): 25-40.

Angel, P. and M. Karin (1991). "The role of Jun, Fos and the AP-1 complex in cellproliferation and transformation." Biochim Biophys Acta 1072(2-3): 129-57.

Annecke, K., M. Schmitt, et al. (2008). "uPA and PAI-1 in breast cancer: review of their clinical utility and current validation in the prospective NNBC-3 trial." Adv Clin Chem 45: 31-45.

Anteby, E. Y., C. Greenfield, et al. (2004). "Vascular endothelial growth factor, epidermal growth factor and fibroblast growth factor-4 and -10 stimulate trophoblast plasminogen activator system and metalloproteinase-9." Mol Hum Reprod 10(4): 229-35.

Attisano, L., C. Silvestri, et al. (2001). "The transcriptional role of Smads and FAST (FoxH1) in TGFbeta and activin signalling." Mol Cell Endocrinol 180(1-2): 3-11.

Bade, E. G. and S. Feindler (1988). "Liver epithelial cell migration induced by epidermal growth factor or transforming growth factor alpha is associated with changes in the gene expression of secreted proteins." In Vitro Cell Dev Biol 24(2): 149-54.

Bajou, K., A. Noel, et al. (1998). "Absence of host plasminogen activator inhibitor 1 prevents cancer invasion and vascularization." Nat Med 4(8): 923-8.

Ball, A. R., Jr., T. J. Bos, et al. (1988). "Jun: oncogene and transcriptional regulator." Cold Spring Harb Symp Quant Biol 53 Pt 2: 687-93.

Bates, R. C. and A. M. Mercurio (2005). "The epithelial-mesenchymal transition (EMT) and colorectal cancer progression." Cancer Biol Ther 4(4): 365-70. 
Blake, C. M., B. A. Sullenger, et al. (2009). "Antimetastatic potential of PAI-1-specific RNA aptamers." Oligonucleotides 19(2): 117-28.

Blasi, F., J. D. Vassalli, et al. (1987). "Urokinase-type plasminogen activator: proenzyme, receptor, and inhibitors." J Cell Biol 104(4): 801-4.

Booth, N. A. (1999). "Fibrinolysis and thrombosis." Baillieres Best Pract Res Clin Haematol 12(3): 423-33.

Bosma, P. J. and T. Kooistra (1991). "Different induction of two plasminogen activator inhibitor 1 mRNA species by phorbol ester in human hepatoma cells." J Biol Chem 266(27): 17845-9.

Cao, C., D. A. Lawrence, et al. (2006). "Endocytic receptor LRP together with tPA and PAI1 coordinates Mac-1-dependent macrophage migration." EMBO J 25(9): 1860-70.

Carmeliet, P., J. M. Stassen, et al. (1993). "Plasminogen activator inhibitor-1 gene-deficient mice. II. Effects on hemostasis, thrombosis, and thrombolysis." J Clin Invest 92(6): 275660.

Cavigelli, M., F. Dolfi, et al. (1995). "Induction of c-fos expression through JNK-mediated TCF/Elk-1 phosphorylation." EMBO J 14(23): 5957-64.

Chazaud, B., S. Bonavaud, et al. (2000). "Involvement of the [uPAR:uPA:PAI-1:LRP] complex in human myogenic cell motility." Exp Cell Res 258(2): 237-44.

Chen, R. H., C. Abate, et al. (1993). "Phosphorylation of the c-Fos transrepression domain by mitogen-activated protein kinase and 90-kDa ribosomal S6 kinase." Proc Natl Acad Sci U S A 90(23): 10952-6.

Chen, Y. Q., M. Su, et al. (1998). "Sp1 sites mediate activation of the plasminogen activator inhibitor-1 promoter by glucose in vascular smooth muscle cells." J Biol Chem 273(14): 8225-31.

Chuang, T. H., R. T. Hamilton, et al. (1995). "Cloning of the mink plasminogen activator inhibitor type-1 messenger RNA: an mRNA with a short half life." Gene 162(2): 303-8.

Cohen, D. R. and T. Curran (1988). "fra-1: a serum-inducible, cellular immediate-early gene that encodes a fos-related antigen." Mol Cell Biol 8(5): 2063-9.

Colucci, M., J. A. Paramo, et al. (1985). "Generation in plasma of a fast-acting inhibitor of plasminogen activator in response to endotoxin stimulation." J Clin Invest 75(3): 818-24.

Coss, D., C. M. Hand, et al. (2007). "p38 mitogen-activated protein kinase is critical for synergistic induction of the $\mathrm{FSH}$ (beta) gene by gonadotropin-releasing hormone and activin through augmentation of c-Fos induction and Smad phosphorylation." Mol Endocrinol 21(12): 3071-86.

Crandall, D. L., E. M. Quinet, et al. (2006). "Modulation of adipose tissue development by pharmacological inhibition of PAI-1." Arterioscler Thromb Vasc Biol 26(10): 2209-15.

Curran, T. and N. M. Teich (1982). "Candidate product of the FBJ murine osteosarcoma virus oncogene: characterization of a 55,000-dalton phosphoprotein." J Virol 42(1): 11422. 
Czekay, R. P. and D. J. Loskutoff (2004). "Unexpected role of plasminogen activator inhibitor 1 in cell adhesion and detachment." Exp Biol Med (Maywood) 229(11): 1090-6.

Das, F., N. Ghosh-Choudhury, et al. (2008). "Akt kinase targets association of CBP with SMAD 3 to regulate TGFbeta-induced expression of plasminogen activator inhibitor-1." Cell Physiol 214(2): 513-27.

Datta, P. K., M. C. Blake, et al. (2000). "Regulation of plasminogen activator inhibitor-1 expression by transforming growth factor-beta -induced physical and functional interactions between smads and Sp1." J Biol Chem 275(51): 40014-9.

Davies, M., M. Robinson, et al. (2005). "Induction of an epithelial to mesenchymal transition in human immortal and malignant keratinocytes by TGF-beta1 involves MAPK, Smad and AP-1 signalling pathways." J Cell Biochem 95(5): 918-31.

de Caestecker, M. P., W. T. Parks, et al. (1998). "Smad2 transduces common signals from receptor serine-threonine and tyrosine kinases." Genes Dev 12(11): 1587-92.

De Taeye, B., A. Gils, et al. (2004). "The story of the serpin plasminogen activator inhibitor 1: is there any need for another mutant?" Thromb Haemost 92(5): 898-924.

Declerck, P. J., H. Moreau, et al. (1993). "Multicenter evaluation of commercially available methods for the immunological determination of plasminogen activator inhibitor-1 (PAI1)." Thromb Haemost 70(5): 858-63.

Degryse, B., J. G. Neels, et al. (2004). "The low density lipoprotein receptor-related protein is a motogenic receptor for plasminogen activator inhibitor-1." J Biol Chem 279(21): 22595-604.

Degryse, B., C. F. Sier, et al. (2001). "PAI-1 inhibits urokinase-induced chemotaxis by internalizing the urokinase receptor." FEBS Lett 505(2): 249-54.

Dellas, C. and D. J. Loskutoff (2005). "Historical analysis of PAI-1 from its discovery to its potential role in cell motility and disease." Thromb Haemost 93(4): 631-40.

Deng, G., S. A. Curriden, et al. (1996). "Is plasminogen activator inhibitor-1 the molecular switch that governs urokinase receptor-mediated cell adhesion and release?" J Cell Biol 134(6): 1563-71.

Dennler, S., S. Huet, et al. (1999). "A short amino-acid sequence in MH1 domain is responsible for functional differences between Smad2 and Smad3." Oncogene 18(8): 1643-8.

Dennler, S., S. Itoh, et al. (1998). "Direct binding of Smad3 and Smad4 to critical TGF betainducible elements in the promoter of human plasminogen activator inhibitor-type 1 gene." EMBO J 17(11): 3091-100.

Derynck, R., Y. Zhang, et al. (1998). "Smads: transcriptional activators of TGF-beta responses." Cell 95(6): 737-40.

Descheemaeker, K. A., S. Wyns, et al. (1992). "Interaction of AP-1-, AP-2-, and Sp1-like proteins with two distinct sites in the upstream regulatory region of the plasminogen 
activator inhibitor-1 gene mediates the phorbol 12-myristate 13-acetate response." J Biol Chem 267(21): 15086-91.

Ding, H., A. M. Benotmane, et al. (1999). "Functional interactions between Sp1 or Sp3 and the helicase-like transcription factor mediate basal expression from the human plasminogen activator inhibitor-1 gene." J Biol Chem 274(28): 19573-80.

Du, X. L., D. Edelstein, et al. (2000). "Hyperglycemia-induced mitochondrial superoxide overproduction activates the hexosamine pathway and induces plasminogen activator inhibitor-1 expression by increasing Spl glycosylation." Proc Natl Acad Sci U S A 97(22): 12222-6.

Elokdah, H., M. Abou-Gharbia, et al. (2004). "Tiplaxtinin, a novel, orally efficacious inhibitor of plasminogen activator inhibitor-1: design, synthesis, and preclinical characterization." J Med Chem 47(14): 3491-4.

Erickson, L. A., G. J. Fici, et al. (1990). "Development of venous occlusions in mice transgenic for the plasminogen activator inhibitor-1 gene." Nature 346(6279): 74-6.

Fattal, P. G., D. J. Schneider, et al. (1992). "Post-transcriptional regulation of expression of plasminogen activator inhibitor type $1 \mathrm{mRNA}$ by insulin and insulin-like growth factor 1." J Biol Chem 267(18): 12412-5.

Fay, W. P., A. C. Parker, et al. (1997). "Human plasminogen activator inhibitor-1 (PAI-1) deficiency: characterization of a large kindred with a null mutation in the PAI-1 gene." Blood 90(1): 204-8.

Fay, W. P., A. D. Shapiro, et al. (1992). "Brief report: complete deficiency of plasminogenactivator inhibitor type 1 due to a frame-shift mutation." N Engl J Med 327(24): 1729-33.

Feng, X. H., Y. Zhang, et al. (1998). "The tumor suppressor Smad4/DPC4 and transcriptional adaptor $\mathrm{CBP} / \mathrm{p} 300$ are coactivators for smad3 in TGF-beta-induced transcriptional activation." Genes Dev 12(14): 2153-63.

Freytag, J., C. E. Wilkins-Port, et al. (2009). "PAI-1 Regulates the Invasive Phenotype in Human Cutaneous Squamous Cell Carcinoma." J Oncol 2009: 963209.

Freytag, J., C. E. Wilkins-Port, et al. (2010). "PAI-1 Mediates the TGF-beta1+EGF-Induced "Scatter" Response in Transformed Human Keratinocytes." J Invest Dermatol.

Gal, A., T. Sjoblom, et al. (2008). "Sustained TGF beta exposure suppresses Smad and nonSmad signalling in mammary epithelial cells, leading to EMT and inhibition of growth arrest and apoptosis." Oncogene 27(9): 1218-30.

Ghosh, A. K., Y. Mori, et al. (2007). "Trichostatin A blocks TGF-beta-induced collagen gene expression in skin fibroblasts: involvement of Sp1." Biochem Biophys Res Commun 354(2): 420-6.

Gils, A. and P. J. Declerck (2004). "Plasminogen activator inhibitor-1." Curr Med Chem 11(17): 2323-34.

Ginsburg, D., R. Zeheb, et al. (1986). "cDNA cloning of human plasminogen activatorinhibitor from endothelial cells." J Clin Invest 78(6): 1673-80. 
Goi, T., M. Shipitsin, et al. (2000). "An EGF receptor/Ral-GTPase signaling cascade regulates c-Src activity and substrate specificity." EMBO J 19(4): 623-30.

Gonzalez, J., J. Klein, et al. (2009). "Delayed treatment with plasminogen activator inhibitor1 decoys reduces tubulointerstitial fibrosis." Exp Biol Med (Maywood) 234(12): 1511-8.

Gorlatova, N. V., J. M. Cale, et al. (2007). "Mechanism of inactivation of plasminogen activator inhibitor-1 by a small molecule inhibitor." J Biol Chem 282(12): 9288-96.

Grande, M., A. Franzen, et al. (2002). "Transforming growth factor-beta and epidermal growth factor synergistically stimulate epithelial to mesenchymal transition (EMT) through a MEK-dependent mechanism in primary cultured pig thyrocytes." J Cell Sci 115(Pt 22): 4227-36.

Grinberg, A. V. and T. Kerppola (2003). "Both Max and TFE3 cooperate with Smad proteins to bind the plasminogen activator inhibitor-1 promoter, but they have opposite effects on transcriptional activity." J Biol Chem 278(13): 11227-36.

Gveric, D., B. Herrera, et al. (2003). "Impaired fibrinolysis in multiple sclerosis: a role for tissue plasminogen activator inhibitors." Brain 126(Pt 7): 1590-8.

Hardy, K. M., B. W. Booth, et al. (2010). "ErbB/EGF Signaling and EMT in Mammary Development and Breast Cancer." J Mammary Gland Biol Neoplasia.

Harradine, K. A. and R. J. Akhurst (2006). "Mutations of TGFbeta signaling molecules in human disease." Ann Med 38(6): 403-14.

Harvey, R. A., H. C. Kim, et al. (1989). "Binding of tissue plasminogen activator to vascular grafts." Thromb Haemost 61(1): 131-6.

Hattori, N., J. L. Degen, et al. (2000). "Bleomycin-induced pulmonary fibrosis in fibrinogennull mice." J Clin Invest 106(11): 1341-50.

Hayashida, T., M. Decaestecker, et al. (2003). "Cross-talk between ERK MAP kinase and Smad signaling pathways enhances TGF-beta-dependent responses in human mesangial cells." FASEB J 17(11): 1576-8.

Hayes, S. A., X. Huang, et al. (2003). "p38 MAP kinase modulates Smad-dependent changes in human prostate cell adhesion." Oncogene 22(31): 4841-50.

He, J. and H. E. Bazan (2008). "Epidermal growth factor synergism with TGF-betal via PI-3 kinase activity in corneal keratocyte differentiation." Invest Ophthalmol Vis Sci 49(7): 2936-45.

Healy, A. M. and T. D. Gelehrter (1994). "Induction of plasminogen activator inhibitor-1 in HepG2 human hepatoma cells by mediators of the acute phase response." J Biol Chem 269(29): 19095-100.

Heaton, J. H., W. M. Dlakic, et al. (2003). "Posttranscriptional regulation of PAI-1 gene expression." Thromb Haemost 89(6): 959-66.

Heaton, J. H. and T. D. Gelehrter (1990). "Cyclic nucleotide regulation of plasminogen activator and plasminogen activator-inhibitor messenger RNAs in rat hepatoma cells." Mol Endocrinol 4(1): 171-8. 
Heaton, J. H., S. Kathju, et al. (1992). "Transcriptional and posttranscriptional regulation of type 1 plasminogen activator inhibitor and tissue-type plasminogen activator gene expression in HTC rat hepatoma cells by glucocorticoids and cyclic nucleotides." Mol Endocrinol 6(1): 53-60.

Heaton, J. H., M. Tillmann-Bogush, et al. (1998). "Cyclic nucleotide regulation of type-1 plasminogen activator-inhibitor mRNA stability in rat hepatoma cells. Identification of cis-acting sequences." J Biol Chem 273(23): 14261-8.

Hekman, C. M. and D. J. Loskutoff (1985). "Endothelial cells produce a latent inhibitor of plasminogen activators that can be activated by denaturants." J Biol Chem 260(21): 11581-7.

Hekman, C. M. and D. J. Loskutoff (1988). "Kinetic analysis of the interactions between plasminogen activator inhibitor 1 and both urokinase and tissue plasminogen activator." Arch Biochem Biophys 262(1): 199-210.

Hennan, J. K., G. A. Morgan, et al. (2008). "Effect of tiplaxtinin (PAI-039), an orally bioavailable PAI-1 antagonist, in a rat model of thrombosis." J Thromb Haemost 6(9): 1558-64.

Higgins, P. J., M. P. Ryan, et al. (1994). "Induced expression of p52(PAI-1) in normal rat kidney cells by the microfilament-disrupting agent cytochalasin D." J Cell Physiol 159(1): 187-95.

Hirai, S. I., R. P. Ryseck, et al. (1989). "Characterization of junD: a new member of the jun proto-oncogene family." EMBO J 8(5): 1433-9.

Hoekstra, J., A. H. Guimaraes, et al. (2010). "Impaired fibrinolysis as a risk factor for BuddChiari syndrome." Blood 115(2): 388-95.

Hoekstra, T., J. M. Geleijnse, et al. (2004). "Plasminogen activator inhibitor-type 1: its plasma determinants and relation with cardiovascular risk." Thromb Haemost 91(5): 86172.

Hofler, H. and K. F. Becker (2003). "Molecular mechanisms of carcinogenesis in gastric cancer." Recent Results Cancer Res 162: 65-72.

Hopkins, W. E., D. R. Westerhausen, Jr., et al. (1991). "Transcriptional regulation of plasminogen activator inhibitor type-1 mRNA in Hep G2 cells by epidermal growth factor." Nucleic Acids Res 19(1): 163-8.

Hua, X., X. Liu, et al. (1998). "Synergistic cooperation of TFE3 and smad proteins in TGFbeta-induced transcription of the plasminogen activator inhibitor-1 gene." Genes Dev 12(19): 3084-95.

Hua, X., Z. A. Miller, et al. (1999). "Specificity in transforming growth factor beta-induced transcription of the plasminogen activator inhibitor-1 gene: interactions of promoter DNA, transcription factor muE3, and Smad proteins." Proc Natl Acad Sci U S A 96(23): 13130-5.

Idell, S. (2003). "Coagulation, fibrinolysis, and fibrin deposition in acute lung injury." $\underline{\text { Crit }}$ Care Med 31(4 Suppl): S213-20. 
Janda, E., K. Lehmann, et al. (2002). "Ras and TGF[beta] cooperatively regulate epithelial cell plasticity and metastasis: dissection of Ras signaling pathways." J Cell Biol 156(2): 299-313.

Jennings, J. C., S. Mohan, et al. (1988). "Comparison of the biological actions of TGF beta-1 and TGF beta-2: differential activity in endothelial cells." J Cell Physiol 137(1): 167-72.

Jiang, Q., C. Zhou, et al. (2006). "EGF-induced cell migration is mediated by ERK and PI3K/AKT pathways in cultured human lens epithelial cells." J Ocul Pharmacol Ther 22(2): 93-102.

Jonk, L. J., S. Itoh, et al. (1998). "Identification and functional characterization of a Smad binding element (SBE) in the JunB promoter that acts as a transforming growth factorbeta, activin, and bone morphogenetic protein-inducible enhancer." J Biol Chem 273(33): 21145-52.

Kalluri, R. (2009). "EMT: when epithelial cells decide to become mesenchymal-like cells." J Clin Invest 119(6): 1417-9.

Kaminska, B., B. Pyrzynska, et al. (2000). "Modulation of the composition of AP-1 complex and its impact on transcriptional activity." Acta Neurobiol Exp (Wars) 60(3): 395-402.

Katz, M., I. Amit, et al. (2007). "Regulation of MAPKs by growth factors and receptor tyrosine kinases." Biochim Biophys Acta 1773(8): 1161-76.

Kawasaki, T., M. Dewerchin, et al. (2000). "Vascular release of plasminogen activator inhibitor-1 impairs fibrinolysis during acute arterial thrombosis in mice." Blood 96(1): 153-60.

Keeton, M. R., S. A. Curriden, et al. (1991). "Identification of regulatory sequences in the type 1 plasminogen activator inhibitor gene responsive to transforming growth factor beta." J Biol Chem 266(34): 23048-52.

Kietzmann, T., U. Roth, et al. (1999). "Induction of the plasminogen activator inhibitor-1 gene expression by mild hypoxia via a hypoxia response element binding the hypoxiainducible factor-1 in rat hepatocytes." Blood 94(12): 4177-85.

Kortlever, R. M., J. H. Nijwening, et al. (2008). "Transforming growth factor-beta requires its target plasminogen activator inhibitor-1 for cytostatic activity." J Biol Chem 283(36): 24308-13.

Kretzschmar, M., J. Doody, et al. (1999). "A mechanism of repression of TGFbeta/ Smad signaling by oncogenic Ras." Genes Dev 13(7): 804-16.

Kruithof, E. K. (1988). "Plasminogen activator inhibitors--a review." Enzyme 40(2-3): 11321.

Kruithof, E. K., A. Gudinchet, et al. (1988). "Plasminogen activator inhibitor 1 and plasminogen activator inhibitor 2 in various disease states." Thromb Haemost 59(1): 712.

Kruithof, E. K., C. Tran-Thang, et al. (1986). "Studies on the release of a plasminogen activator inhibitor by human platelets." Thromb Haemost 55(2): 201-5. 
Kruithof, E. K., C. Tran-Thang, et al. (1984). "Demonstration of a fast-acting inhibitor of plasminogen activators in human plasma." Blood 64(4): 907-13.

Kucharewicz, I., K. Kowal, et al. (2003). "The plasmin system in airway remodeling." Thromb Res 112(1-2): 1-7.

Kutz, S. M., C. E. Higgins, et al. (2006). "TGF-beta 1-induced PAI-1 expression is E box/USF-dependent and requires EGFR signaling." Exp Cell Res 312(7): 1093-105.

Kutz, S. M., J. Hordines, et al. (2001). "TGF-beta1-induced PAI-1 gene expression requires MEK activity and cell-to-substrate adhesion." J Cell Sci 114(Pt 21): 3905-14.

Kwaan, H. C. and B. McMahon (2009). "The role of plasminogen-plasmin system in cancer." Cancer Treat Res 148: 43-66.

Landin, K., L. Tengborn, et al. (1990). "Elevated fibrinogen and plasminogen activator inhibitor (PAI-1) in hypertension are related to metabolic risk factors for cardiovascular disease." J Intern Med 227(4): 273-8.

Lawrence, W. T., J. A. Norton, et al. (1986). "The reversal of an Adriamycin induced healing impairment with chemoattractants and growth factors." Ann Surg 203(2): 142-7.

Leik, C. E., E. J. Su, et al. (2006). "Effect of pharmacologic plasminogen activator inhibitor1 inhibition on cell motility and tumor angiogenesis." J Thromb Haemost 4(12): 2710-5.

Levy, L. and C. S. Hill (2005). "Smad4 dependency defines two classes of transforming growth factor $\{$ beta $\}$ (TGF-\{beta $\}$ ) target genes and distinguishes TGF- $\{$ beta $\}$-induced epithelial-mesenchymal transition from its antiproliferative and migratory responses." Mol Cell Biol 25(18): 8108-25.

Li, X., T. Syrovets, et al. (2010). "Plasmin triggers chemotaxis of monocyte-derived dendritic cells through an Akt2-dependent pathway and promotes a T-helper type-1 response." Arterioscler Thromb Vasc Biol 30(3): 582-90.

Liberati, N. T., M. B. Datto, et al. (1999). "Smads bind directly to the Jun family of AP-1 transcription factors." Proc Natl Acad Sci U S A 96(9): 4844-9.

Lijnen, H. R. (2001). "Plasmin and matrix metalloproteinases in vascular remodeling." Thromb Haemost 86(1): 324-33.

Lijnen, H. R. (2005). "Pleiotropic functions of plasminogen activator inhibitor-1." J Thromb Haemost 3(1): 35-45.

Like, B. and J. Massague (1986). "The antiproliferative effect of type beta transforming growth factor occurs at a level distal from receptors for growth-activating factors." J Biol Chem 261(29): 13426-9.

Lindahl, T. L., P. I. Ohlsson, et al. (1990). "The mechanism of the reaction between human plasminogen-activator inhibitor 1 and tissue plasminogen activator." Biochem J 265(1): $109-13$.

Lindahl, T. L., O. Sigurdardottir, et al. (1989). "Stability of plasminogen activator inhibitor 1 (PAI-1)." Thromb Haemost 62(2): 748-51. 
Liu, F., C. Pouponnot, et al. (1997). "Dual role of the Smad4/DPC4 tumor suppressor in TGFbeta-inducible transcriptional complexes." Genes Dev 11(23): 3157-67.

Liu, G., M. A. Shuman, et al. (1995). "Co-expression of urokinase, urokinase receptor and PAI-1 is necessary for optimum invasiveness of cultured lung cancer cells." Int J Cancer 60(4): 501-6.

Liu, R. M. (2008). "Oxidative stress, plasminogen activator inhibitor 1, and lung fibrosis." Antioxid Redox Signal 10(2): 303-19.

Loskutoff, D. J. and J. P. Quigley (2000). "PAI-1, fibrosis, and the elusive provisional fibrin matrix." J Clin Invest 106(12): 1441-3.

Loskutoff, D. J. and F. Samad (1998). "The adipocyte and hemostatic balance in obesity: studies of PAI-1." Arterioscler Thromb Vasc Biol 18(1): 1-6.

Loskutoff, D. J., M. Sawdey, et al. (1989). "Type 1 plasminogen activator inhibitor." Prog Hemost Thromb 9: 87-115.

Luyendyk, J. P., W. B. Mattes, et al. (2004). "Gene expression analysis points to hemostasis in livers of rats cotreated with lipopolysaccharide and ranitidine." Toxicol Sci 80(1): 20313.

Manske, M., S. Feindler, et al. (1990). "The epidermal growth factor-induced cell migration and expression of the 47,000 Mr secreted glycoprotein EIP-1 of rat liver epithelial cells are down-modulated by cyclic AMP." Eur J Cell Biol 52(2): 201-6.

Massague, J. (1998). "TGF-beta signal transduction." Annu Rev Biochem 67: 753-91.

Massague, J. and D. Wotton (2000). "Transcriptional control by the TGF-beta/Smad signaling system." EMBO J 19(8): 1745-54.

Matsui, M., M. Tokuhara, et al. (1990). "Isolation of human fos-related genes and their expression during monocyte-macrophage differentiation." Oncogene 5(3): 249-55.

Matsuzaki, K., M. Murata, et al. (2007). "Chronic inflammation associated with hepatitis C virus infection perturbs hepatic transforming growth factor beta signaling, promoting cirrhosis and hepatocellular carcinoma." Hepatology 46(1): 48-57.

Mawatari, M., K. Okamura, et al. (1991). "Tumor necrosis factor and epidermal growth factor modulate migration of human microvascular endothelial cells and production of tissue-type plasminogen activator and its inhibitor." Exp Cell Res 192(2): 574-80.

Meryet-Figuieres, M., S. Resina, et al. (2007). "Inhibition of PAI-1 expression in breast cancer carcinoma cells by siRNA at nanomolar range." Biochimie 89(10): 1228-33.

Miyauchi, A., M. Momoeda, et al. (1995). "Regulation of the plasminogen activator/plasmin system by epidermal growth factor in cultured human endometrial cells." Hum Reprod 10(12): 3284-8.

Miyazono, K. (2000). "TGF-beta signaling by Smad proteins." Cytokine Growth Factor Rev 11(1-2): 15-22. 
Monje, P., M. J. Marinissen, et al. (2003). "Phosphorylation of the carboxyl-terminal transactivation domain of c-Fos by extracellular signal-regulated kinase mediates the transcriptional activation of AP-1 and cellular transformation induced by platelet-derived growth factor." Mol Cell Biol 23(19): 7030-43.

Morton, S., R. J. Davis, et al. (2003). "A reinvestigation of the multisite phosphorylation of the transcription factor c-Jun." EMBO J 22(15): 3876-86.

Moses, H. L., E. Y. Yang, et al. (1991). "Regulation of epithelial proliferation by TGF-beta." Ciba Found Symp 157: 66-74; discussion 75-80.

Mottonen, J., A. Strand, et al. (1992). "Structural basis of latency in plasminogen activator inhibitor-1." Nature 355(6357): 270-3.

Moustakas, A. and C. H. Heldin (2005). "Non-Smad TGF-beta signals." J Cell Sci 118(Pt 16): 3573-84.

Mulder, K. M. and S. L. Morris (1992). "Activation of p21ras by transforming growth factor beta in epithelial cells." J Biol Chem 267(8): 5029-31.

Murphy, L. O., S. Smith, et al. (2002). "Molecular interpretation of ERK signal duration by immediate early gene products." Nat Cell Biol 4(8): 556-64.

Myohanen, H. and A. Vaheri (2004). "Regulation and interactions in the activation of cellassociated plasminogen." Cell Mol Life Sci 61(22): 2840-58.

Nakabeppu, Y., K. Ryder, et al. (1988). "DNA binding activities of three murine Jun proteins: stimulation by Fos." Cell 55(5): 907-15.

Nakao, A., T. Imamura, et al. (1997). "TGF-beta receptor-mediated signalling through Smad2, Smad3 and Smad4." EMBO J 16(17): 5353-62.

Nilsen-Hamilton, M. and R. W. Holley (1983). "Rapid selective effects by a growth inhibitor and epidermal growth factor on the incorporation of [35S]methionine into proteins secreted by African green monkey (BSC-1) cells." Proc Natl Acad Sci U S A 80(18): 5636-40.

Norata, G. D., C. Banfi, et al. (2004). "Oxidised-HDL3 induces the expression of PAI-1 in human endothelial cells. Role of p38MAPK activation and mRNA stabilization." $\mathrm{Br} \mathrm{J}$ Haematol 127(1): 97-104.

Oda, T., Y. O. Jung, et al. (2001). "PAI-1 deficiency attenuates the fibrogenic response to ureteral obstruction." Kidney Int 60(2): 587-96.

Oft, M., J. Peli, et al. (1996). "TGF-betal and Ha-Ras collaborate in modulating the phenotypic plasticity and invasiveness of epithelial tumor cells." Genes Dev 10(19): 2462-77.

Ossowski, L. and J. A. Aguirre-Ghiso (2000). "Urokinase receptor and integrin partnership: coordination of signaling for cell adhesion, migration and growth." Curr Opin Cell Biol 12(5): 613-20. 
Paugh, B. S., S. W. Paugh, et al. (2008). "EGF regulates plasminogen activator inhibitor-1 (PAI-1) by a pathway involving c-Src, PKCdelta, and sphingosine kinase 1 in glioblastoma cells." FASEB J 22(2): 455-65.

Peron, P., M. Rahmani, et al. (2001). "Potentiation of Smad transactivation by Jun proteins during a combined treatment with epidermal growth factor and transforming growth factor-beta in rat hepatocytes. role of phosphatidylinositol 3-kinase-induced AP-1 activation." J Biol Chem 276(13): 10524-31.

Pessah, M., J. Marais, et al. (2002). "c-Jun associates with the oncoprotein Ski and suppresses Smad2 transcriptional activity." J Biol Chem 277(32): 29094-100.

Pessah, M., C. Prunier, et al. (2001). "c-Jun interacts with the corepressor TG-interacting factor (TGIF) to suppress Smad2 transcriptional activity." Proc Natl Acad Sci U S A 98(11): 6198-203.

Prabhakaran, P., L. B. Ware, et al. (2003). "Elevated levels of plasminogen activator inhibitor-1 in pulmonary edema fluid are associated with mortality in acute lung injury." Am J Physiol Lung Cell Mol Physiol 285(1): L20-8.

Prendergast, G. C., L. E. Diamond, et al. (1990). "The c-myc-regulated gene mrl encodes plasminogen activator inhibitor 1." Mol Cell Biol 10(3): 1265-9.

Providence, K. M. and P. J. Higgins (2004). "PAI-1 expression is required for epithelial cell migration in two distinct phases of in vitro wound repair." J Cell Physiol 200(2): 297308.

Providence, K. M., S. P. Higgins, et al. (2008). "SERPINE1 (PAI-1) is deposited into keratinocyte migration "trails" and required for optimal monolayer wound repair." Arch Dermatol Res 300(6): 303-10.

Providence, K. M., L. A. White, et al. (2002). "Epithelial monolayer wounding stimulates binding of USF-1 to an E-box motif in the plasminogen activator inhibitor type 1 gene." $\underline{J}$ Cell Sci 115(Pt 19): 3767-77.

Qing, J., Y. Zhang, et al. (2000). "Structural and functional characterization of the transforming growth factor-beta -induced Smad3/c-Jun transcriptional cooperativity." 즈. Biol Chem 275(49): 38802-12.

Quax, P. H., C. M. van den Hoogen, et al. (1990). "Endotoxin induction of plasminogen activator and plasminogen activator inhibitor type $1 \mathrm{mRNA}$ in rat tissues in vivo." $\mathrm{J}$ Biol Chem 265(26): 15560-3.

Radha, K. S., M. Sugiki, et al. (2005). "Iron-mediated stability of PAI-1 mRNA in adenocarcinoma cells-involvement of a mRNA-binding nuclear protein." Thromb Res 116(3): 255-63.

Radisky, D. C., P. A. Kenny, et al. (2007). "Fibrosis and cancer: do myofibroblasts come also from epithelial cells via EMT?" J Cell Biochem 101(4): 830-9.

Rakic, J. M., C. Maillard, et al. (2003). "Role of plasminogen activator-plasmin system in tumor angiogenesis." Cell Mol Life Sci 60(3): 463-73. 
Ranby, M. and A. Brandstrom (1988). "Biological control of tissue plasminogen activatormediated fibrinolysis." Enzyme 40(2-3): 130-43.

Reilly, C. F. and R. C. McFall (1991). "Platelet-derived growth factor and transforming growth factor-beta regulate plasminogen activator inhibitor-1 synthesis in vascular smooth muscle cells." J Biol Chem 266(15): 9419-27.

Riccio, A., L. R. Lund, et al. (1988). "The regulatory region of the human plasminogen activator inhibitor type-1 (PAI-1) gene." Nucleic Acids Res 16(7): 2805-24.

Ridley, A. J., M. A. Schwartz, et al. (2003). "Cell migration: integrating signals from front to back." Science 302(5651): 1704-9.

Roberts, A. B., C. A. Frolik, et al. (1983). "Transforming growth factors from neoplastic and nonneoplastic tissues." Fed Proc 42(9): 2621-6.

Rosenthal, A. K., H. S. Cheung, et al. (1991). "Transforming growth factor beta 1 stimulates inorganic pyrophosphate elaboration by porcine cartilage." Arthritis Rheum 34(7): 90411.

Runyan, C. E., H. W. Schnaper, et al. (2004). "The phosphatidylinositol 3-kinase/Akt pathway enhances Smad3-stimulated mesangial cell collagen I expression in response to transforming growth factor-beta1." J Biol Chem 279(4): 2632-9.

Rupin, A., R. Gaertner, et al. (2008). "S35225 is a direct inhibitor of Plasminogen Activator Inhibitor type-1 activity in the blood." Thromb Res 122(2): 265-70.

Ryan, M. P. and P. J. Higgins (1993). "Growth state-regulated expression of p52(PAI-1) in normal rat kidney cells." J Cell Physiol 155(2): 376-84.

Ryan, M. P., S. M. Kutz, et al. (1996). "Complex regulation of plasminogen activator inhibitor type-1 (PAI-1) gene expression by serum and substrate adhesion." Biochem J 314 ( Pt 3): 1041-6.

Ryder, K., L. F. Lau, et al. (1988). "A gene activated by growth factors is related to the oncogene v-jun." Proc Natl Acad Sci U S A 85(5): 1487-91.

Saha, D., P. K. Datta, et al. (1999). "Synergistic induction of cyclooxygenase-2 by transforming growth factor-betal and epidermal growth factor inhibits apoptosis in epithelial cells." Neoplasia 1(6): 508-17.

Salonen, E. M., A. Vaheri, et al. (1989). "Interaction of plasminogen activator inhibitor (PAI1) with vitronectin." J Biol Chem 264(11): 6339-43.

Saltis, J., A. Agrotis, et al. (1992). "TGF-beta 1 potentiates growth factor-stimulated proliferation of vascular smooth muscle cells in genetic hypertension." Am J Physiol 263(2 Pt 1): C420-8.

Samad, F. and D. J. Loskutoff (1996). "Tissue distribution and regulation of plasminogen activator inhibitor-1 in obese mice." Mol Med 2(5): 568-82.

Sancho, E., P. J. Declerck, et al. (1995). "Conformational studies on plasminogen activator inhibitor (PAI-1) in active, latent, substrate, and cleaved forms." Biochemistry 34(3): 1064-9. 
Sandberg, T., P. Eriksson, et al. (1997). "Differential regulation of the plasminogen activator inhibitor-1 (PAI-1) gene expression by growth factors and progesterone in human endometrial stromal cells." Mol Hum Reprod 3(9): 781-7.

Scarabin, P. Y., M. F. Aillaud, et al. (1998). "Associations of fibrinogen, factor VII and PAI1 with baseline findings among 10,500 male participants in a prospective study of myocardial infarction--the PRIME Study. Prospective Epidemiological Study of Myocardial Infarction." Thromb Haemost 80(5): 749-56.

Schluns, K. S., J. E. Cook, et al. (1997). "TGF-beta differentially modulates epidermal growth factor-mediated increases in leukemia-inhibitory factor, IL-6, IL-1 alpha, and IL1 beta in human thymic epithelial cells." J Immunol 158(6): 2704-12.

Seebacher, T., M. Manske, et al. (1992). "The EGF-inducible protein EIP-1 of migrating normal and malignant rat liver epithelial cells is identical to plasminogen activator inhibitor 1 and is a component of the ECM migration tracks." Exp Cell Res 203(2): 5047.

Segarra, A., P. Chacon, et al. (2001). "Circulating levels of plasminogen activator inhibitor type-1, tissue plasminogen activator, and thrombomodulin in hemodialysis patients: biochemical correlations and role as independent predictors of coronary artery stenosis." J Am Soc Nephrol 12(6): 1255-63.

Senoo, T., N. Hattori, et al. (2010). "Suppression of plasminogen activator inhibitor-1 by RNA interference attenuates pulmonary fibrosis." Thorax 65(4): 334-40.

Seo, J. Y., J. Park, et al. (2009). "Positive feedback loop between plasminogen activator inhibitor-1 and transforming growth factor-betal during renal fibrosis in diabetes." Am J Nephrol 30(6): 481-90.

Shetty, S. and S. Idell (2000). "Posttranscriptional regulation of plasminogen activator inhibitor-1 in human lung carcinoma cells in vitro." Am J Physiol Lung Cell Mol Physiol 278(1): L148-56.

Shi, Y., Y. F. Wang, et al. (1998). "Crystal structure of a Smad MH1 domain bound to DNA: insights on DNA binding in TGF-beta signaling." Cell 94(5): 585-94.

Shook, D. and R. Keller (2003). "Mechanisms, mechanics and function of epithelialmesenchymal transitions in early development." Mech Dev 120(11): 1351-83.

Skurk, T. and H. Hauner (2004). "Obesity and impaired fibrinolysis: role of adipose production of plasminogen activator inhibitor-1." Int J Obes Relat Metab Disord 28(11): 1357-64.

Smith, L. H., J. D. Dixon, et al. (2006). "Pivotal role of PAI-1 in a murine model of hepatic vein thrombosis." Blood 107(1): 132-4.

Song, C. Z., T. E. Siok, et al. (1998). "Smad4/DPC4 and Smad3 mediate transforming growth factor-beta (TGF-beta) signaling through direct binding to a novel TGF-betaresponsive element in the human plasminogen activator inhibitor-1 promoter." $\mathrm{J}$ Biol Chem 273(45): 29287-90. 
Sprengers, E. D. and C. Kluft (1987). "Plasminogen activator inhibitors." Blood 69(2): 3817.

Stefansson, S. and D. A. Lawrence (1996). "The serpin PAI-1 inhibits cell migration by blocking integrin alpha V beta 3 binding to vitronectin." Nature 383(6599): 441-3.

Steiner, E., K. Pollow, et al. (2008). "Role of urokinase-type plasminogen activator (uPA) and plasminogen activator inhibitor type 1 (PAI-1) for prognosis in endometrial cancer." Gynecol Oncol 108(3): 569-76.

Stolz, D. B. and G. K. Michalopoulos (1997). "Synergistic enhancement of EGF, but not HGF, stimulated hepatocyte motility by TGF-beta 1 in vitro." J Cell Physiol 170(1): 5768.

Stopa, M., D. Anhuf, et al. (2000). "Participation of Smad2, Smad3, and Smad4 in transforming growth factor beta (TGF-beta)-induced activation of Smad7. THE TGF-beta response element of the promoter requires functional Smad binding element and E-box sequences for transcriptional regulation." J Biol Chem 275(38): 29308-17.

Stroschein, S. L., W. Wang, et al. (1999). "Cooperative binding of Smad proteins to two adjacent DNA elements in the plasminogen activator inhibitor-1 promoter mediates transforming growth factor beta-induced smad-dependent transcriptional activation." Biol Chem 274(14): 9431-41.

Taipale, J. and J. Keski-Oja (1996). "Hepatocyte growth factor releases epithelial and endothelial cells from growth arrest induced by transforming growth factor-beta1." J Biol Chem 271(8): 4342-8.

Tanos, T., M. J. Marinissen, et al. (2005). "Phosphorylation of c-Fos by members of the p38 MAPK family. Role in the AP-1 response to UV light." J Biol Chem 280(19): 18842-52.

Tateyama, S., K. Horisawa, et al. (2006). "Affinity selection of DNA-binding protein complexes using mRNA display." Nucleic Acids Res 34(3): e27.

Taylor, M. A., J. G. Parvani, et al. (2010). "The Pathophysiology of Epithelial-Mesenchymal Transition Induced by Transforming Growth Factor-beta in Normal and Malignant Mammary Epithelial Cells." J Mammary Gland Biol Neoplasia.

Thalacker, F. W. and M. Nilsen-Hamilton (1987). "Specific induction of secreted proteins by transforming growth factor-beta and 12-O-tetradecanoylphorbol-13-acetate. Relationship with an inhibitor of plasminogen activator." J Biol Chem 262(5): 2283-90.

Thalacker, F. W. and M. Nilsen-Hamilton (1992). "Opposite and independent actions of cyclic AMP and transforming growth factor beta in the regulation of type 1 plasminogen activator inhibitor expression." Biochem J 287 ( Pt 3): 855-62.

Tranque, P., F. Naftolin, et al. (1994). "Differential regulation of astrocyte plasminogen activators by insulin-like growth factor-I and epidermal growth factor." Endocrinology 134(6): 2606-13.

Undevia, N. S., D. R. Dorscheid, et al. (2004). "Smad and p38-MAPK signaling mediates apoptotic effects of transforming growth factor-betal in human airway epithelial cells." Am J Physiol Lung Cell Mol Physiol 287(3): L515-24. 
Urano, T., K. Wu, et al. (1996). "Novel mechanism to enhance tPA-induced fibrinolysis: effect of limited proteolysis of PAI-1 by neutrophil elastase." Pol J Pharmacol 48(2): 209-13.

Uttamsingh, S., X. Bao, et al. (2008). "Synergistic effect between EGF and TGF-beta1 in inducing oncogenic properties of intestinal epithelial cells." Oncogene 27(18): 2626-34.

Valcourt, U., M. Kowanetz, et al. (2005). "TGF-beta and the Smad signaling pathway support transcriptomic reprogramming during epithelial-mesenchymal cell transition." Mol Biol Cell 16(4): 1987-2002.

Valle, M., F. Gascon, et al. (2000). "Infantile obesity: a situation of atherothrombotic risk?" Metabolism 49(5): 672-5.

Vassalli, J. D., A. P. Sappino, et al. (1991). "The plasminogen activator/plasmin system." J Clin Invest 88(4): 1067-72.

Vayalil, P. K., K. E. Iles, et al. (2007). "Glutathione suppresses TGF-beta-induced PAI-1 expression by inhibiting p38 and JNK MAPK and the binding of AP-1, SP-1, and Smad to the PAI-1 promoter." Am J Physiol Lung Cell Mol Physiol 293(5): L1281-92.

Verrecchia, F., L. Vindevoghel, et al. (2001). "Smad3/AP-1 interactions control transcriptional responses to TGF-beta in a promoter-specific manner." Oncogene 20(26): 3332-40.

Walsh, M. F., D. R. Ampasala, et al. (2008). "Transforming growth factor-beta stimulates intestinal epithelial focal adhesion kinase synthesis via Smad- and p38-dependent mechanisms." Am J Pathol 173(2): 385-99.

Wang, H., Y. Zhang, et al. (2007). "PAI-1 deficiency reduces liver fibrosis after bile duct ligation in mice through activation of tPA." FEBS Lett 581(16): 3098-104.

Wang, X., K. D. McCullough, et al. (2000). "Epidermal growth factor receptor-dependent Akt activation by oxidative stress enhances cell survival." J Biol Chem 275(19): 1462431.

Wei, Y., M. Lukashev, et al. (1996). "Regulation of integrin function by the urokinase receptor." Science 273(5281): 1551-5.

Westerhausen, D. R., Jr., W. E. Hopkins, et al. (1991). "Multiple transforming growth factorbeta-inducible elements regulate expression of the plasminogen activator inhibitor type-1 gene in Hep G2 cells." J Biol Chem 266(2): 1092-100.

Wileman, S. M., N. A. Booth, et al. (2000). "Regulation of plasminogen activation by TGFbeta in cultured human retinal endothelial cells." Br J Ophthalmol 84(4): 417-22.

Wilkins-Port, C. E., C. E. Higgins, et al. (2007). "PAI-1 is a Critical Upstream Regulator of the TGF-beta1/EGF-Induced Invasive Phenotype in Mutant p53 Human Cutaneous Squamous Cell Carcinoma." J Biomed Biotechnol 2007(2): 85208.

Wilkins-Port, C. E., Q. Ye, et al. (2009). "TGF-beta1 + EGF-initiated invasive potential in transformed human keratinocytes is coupled to a plasmin/MMP-10/MMP-1-dependent collagen remodeling axis: role for PAI-1." Cancer Res 69(9): 4081-91. 
Wong, C., E. M. Rougier-Chapman, et al. (1999). "Smad3-Smad4 and AP-1 complexes synergize in transcriptional activation of the c-Jun promoter by transforming growth factor beta." Mol Cell Biol 19(3): 1821-30.

$\mathrm{Xu}$, J., S. Lamouille, et al. (2009). "TGF-beta-induced epithelial to mesenchymal transition." Cell Res 19(2): 156-72.

Yang, C., K. Patel, et al. (2007). "Regulation of TGF-beta1/MAPK-mediated PAI-1 gene expression by the actin cytoskeleton in human mesangial cells." Exp Cell Res 313(6): 1240-50.

Yang, S. F., Y. S. Hsieh, et al. (2007). "Increased plasminogen activator inhibitor-1/tissue type plasminogen activator ratio in oral submucous fibrosis." Oral Dis 13(2): 234-8.

Yang, S. F., Y. S. Hsieh, et al. (2003). "The upregulation of type I plasminogen activator inhibitor in oral submucous fibrosis." Oral Oncol 39(4): 367-72.

Yeo, C. Y., X. Chen, et al. (1999). "The role of FAST-1 and Smads in transcriptional regulation by activin during early Xenopus embryogenesis." J Biol Chem 274(37): 26584-90.

Yingling, J. M., M. B. Datto, et al. (1997). "Tumor suppressor Smad4 is a transforming growth factor beta-inducible DNA binding protein." Mol Cell Biol 17(12): 7019-28.

Yu, L., M. C. Hebert, et al. (2002). "TGF-beta receptor-activated p38 MAP kinase mediates Smad-independent TGF-beta responses." EMBO J 21(14): 3749-59.

Zawel, L., J. L. Dai, et al. (1998). "Human Smad3 and Smad4 are sequence-specific transcription activators." Mol Cell 1(4): 611-7.

Zerial, M., L. Toschi, et al. (1989). "The product of a novel growth factor activated gene, fos $\mathrm{B}$, interacts with JUN proteins enhancing their DNA binding activity." EMBO J 8(3): 805-13.

Zhang, Q., Y. Wu, et al. (2003). "Mechanisms of hypoxic regulation of plasminogen activator inhibitor-1 gene expression in keloid fibroblasts." J Invest Dermatol 121(5): 1005-12.

Zhang, Y., X. H. Feng, et al. (1998). "Smad3 and Smad4 cooperate with c-Jun/c-Fos to mediate TGF-beta-induced transcription." Nature 394(6696): 909-13.

Zhang, Y. E. (2009). "Non-Smad pathways in TGF-beta signaling." Cell Res 19(1): 128-39.

Zorio, E., J. Gilabert-Estelles, et al. (2008). "Fibrinolysis: the key to new pathogenetic mechanisms." Curr Med Chem 15(9): 923-9. 


\section{Figure legends}

\section{Figure 1. The function of PAI-1.}

Plasmin, a broad spectrum serine protease, degrades fibrin and extracellular matrix proteins by which it plays a central role in fibrinolysis and extracellular remodeling. PAI-1 inhibits the conversion of inactive plasminogen to active plasmin mediated by urokinase type or tissue type plasminogen activator ( $\mathrm{uPA}$, tPA), by which PAI-1 negatively regulates fibrinolysis and modulates remodeling of extracellular matrix. PAI-1 modulates cell migration in different ways: 1) by influencing plasmin-mediated pericellular proteolysis. Plasmin-mediated proteolysis removes the tissue barrier to aid cell migration. A certain amount of PAI-1 is required for blocking excessive plasmin-mediated degradation to maintain the necessary matrix scaffold required for cell migration. 2) PAI-1 inhibits uPARintegrin mediated cell adhesion and promotes cell detachment, both of which promoter cell migration. With a high affinity of PAI-1 to matrix protein vitronectin, PAI-1 inhibits the adhesion of uPAR-integrin-baring cells to vitronectin. PAI-1 promotes cell detachment by forming a complex with uPA-uPAR-integrin. Binding of PAI-1 to the complex of uPAuPAR-integrin on the cell surface initiates LRP (low indensity lipoprotein receptor-related protein) mediated complex internalization. Disengagement of the adhesive receptors uPAR and integrin from the extracellular matrix promotes cell detachment and migration.

Figure 2. Signaling pathways that involved in PAI-1 regulation by TGF- $\beta$ and EGF. Induction of PAI-1 by TGF- $\beta$ mainly acts through Smad mediated pathway. Binding of TGF $-\beta$ to its receptors triggers the activation of Smad2/3 by T $\beta R I$ through phosphorylating the C terminal SSXS motif of Smad. Homodimmers or heterodimmers of activated Smad2 
and Smad3 form complexes with Smad4 and then move into nucleus to activate transcription. The Smad3 transcription complex binds to the Smad Binding Elements (SBEs) at PAI-1 promoter. Meanwhile, TGF- $\beta$-activated non-Smad signaling pathways also contribute to PAI-1 induction in various cases including Mek/Erk, p38, Jnk, PI3K and Src, which all can be activated by EGF. The mechanism of PAI-1 induction by EGF was reported only in human glioma cells where an ordered activation of EGFR, Src, PKC $\delta$ (protein kinase C delta), SphK1 (sphingosine kinase 1) and S1P (sphingosine 1-phosphate) signaling is required. Black line: reported required for PAI-1 induction; grey lines: involved in PAI-1 regulation, but function varies in cases; dashed lines, not yet reported in PAI-1 regulation.

\section{Figrue 3. Cis elements involved in PAI-1 regulation by TGF- $\beta$.}

The SBE-like motif is the most important cis elements to mediate the transcription of Smad. Other elements also play important role, including AP-1, Sp-1 and E box. The ciselements involved in TGF- $\beta$-induced PAI-1 are distributed two regions in PAI-1 promoter: The distal region (-636/-740) contributes the most transcriptional activation of PAI-1 by TGF- $\beta$. Cooperative binding of Smad3/4 to the SBE-like motif and AP-1 to AP-1 like motif in the distal promoter region synergistically activates transcription of PAI-1 with a 50 fold. The proximal region (-77/-40) with one AP-1 like site and two Sp1 sites elevates PAI-1 promoter activity by 10 -fold. The cooperative binding of TFE3 to the E-box $(-160 /-165)$ and

Smad3 to the nearby SBE in the promoter region is critical to meditated TGF- $\beta$-induced PAI-1 promoter activity from a $56 \mathrm{bp}$ enhancer. 
Figures

Figure1. The function of PAI-1

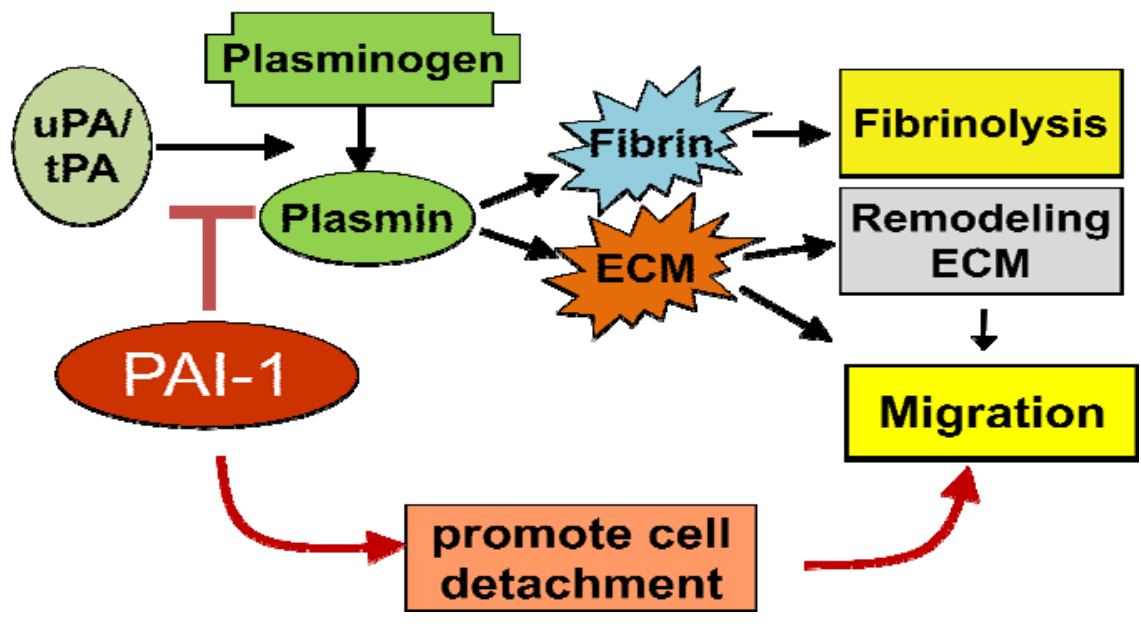


Figure 2. Signaling pathways that involved in $P A I-1$ regulation by EGF \&TGF- $\beta$

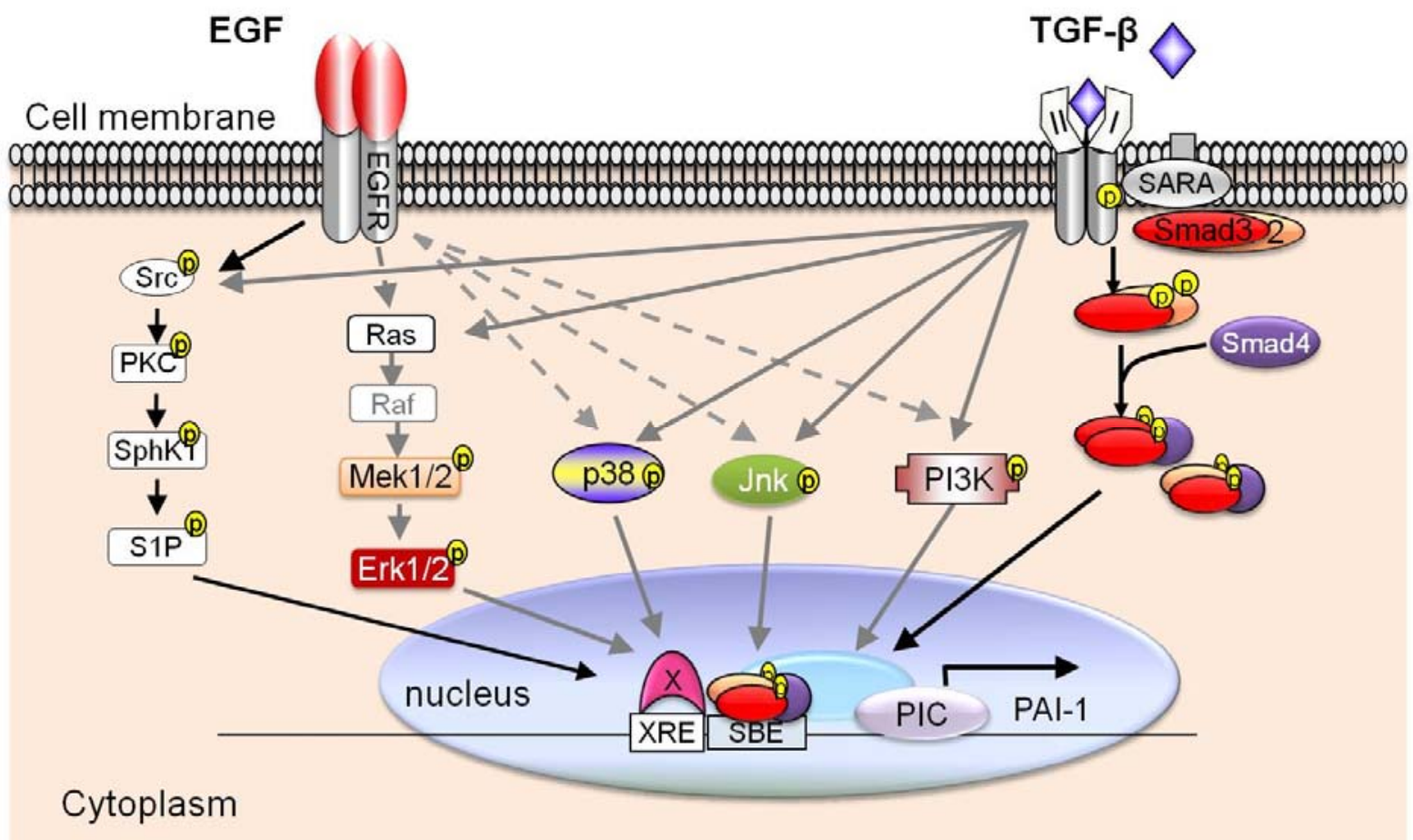


Figure 3. Cis-elements involved in PAI-1 regulation by TGF-ß

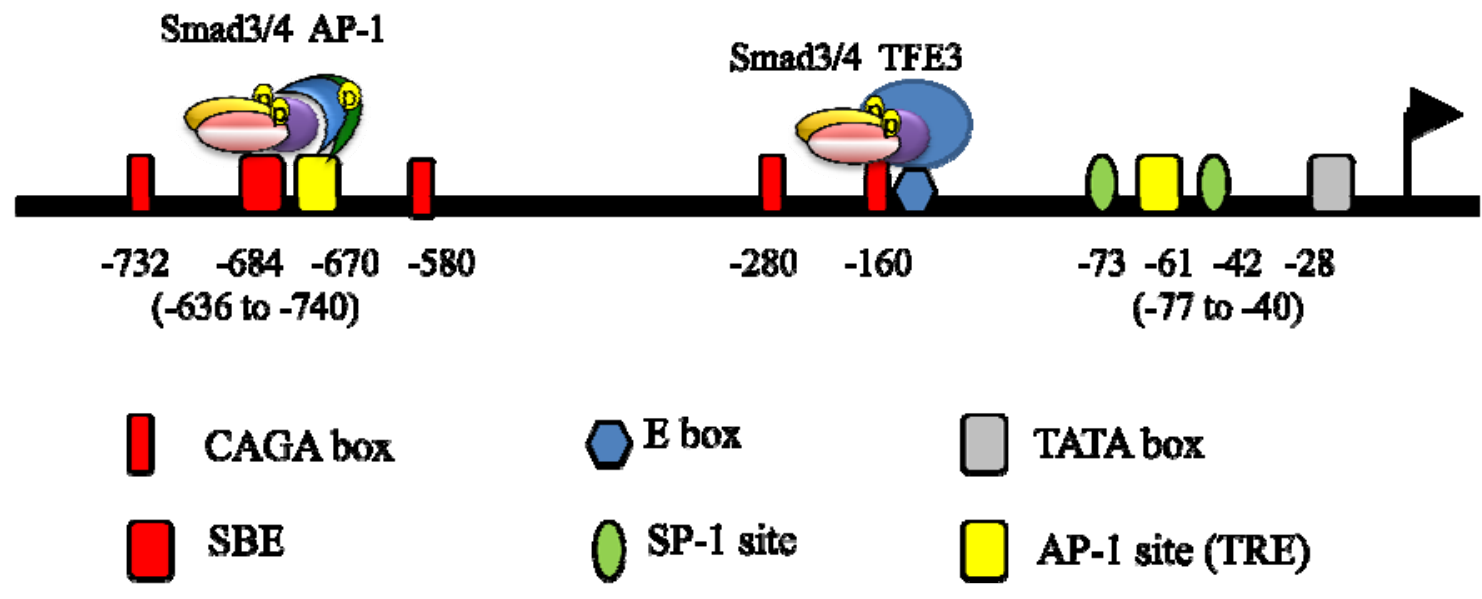




\section{CHAPTER 3. SYNERGISTIC AND MULTIDIMENSIONAL REGULATION OF PLASMINOGEN ACTIVATOR INHIBITOR TYPE 1 EXPRESSION BY TRANSFORMING GROWTH FACTOR TYPE $\beta$ AND EPIDERMAL GROWTH FACTOR}

Xiaoling Song ${ }^{1}$, Frederic W. Thalacker ${ }^{1,2}$, Tsung-Hsien Chuang ${ }^{1,3}$ and Marit NilsenHamilton ${ }^{1}$

From ${ }^{1}$ Department of Biochemistry, Biophysics and Molecular Biology, Iowa State University, Ames, IA 50011., ${ }^{2}$ Covance Laboratories Inc., Madison, WI 53704, ${ }^{3}$ Burnham Institute for Medical Research, La Jolla, CA 92037

Address correspondence to Marit Nilsen-Hamilton, 3206 Molecular Biology Building, Department of Biochemistry, Biophysics and Molecular Biology, TEL: 515-294-9996; FAX: 515-294-0453, E-mail: marit@iastate.edu

\section{Abstract:}

As the major physiological inhibitor of plasminogen activator (PA), the type I plasminogen activator inhibitor (PAI-1) is important for controlling blood clotting and tissue remodeling events such as those that involve cell migration. The changing needs for protease activity under various physiological conditions necessitates a tight cellular control of gene expression to enable rapid changes in the levels of PAI-1 and PA activity. Transforming growth factor- $\beta$ (TGF- $\beta$ ) and epidermal growth factor (EGF) interact synergistically to 
increase PAI-1 mRNA and protein levels in human HepG2 and mink Mv1Lu cells. Other growth factors that activate tyrosine kinase receptors can substitute for EGF. The mechanism by which EGF and TGF $\beta$ synergistically regulate PAI-1 was explored in Mv1Lu cells and found to involve synergistic transcriptional activation that is further amplified by a decrease in the rate of mRNA degradation, the latter being regulated only by EGF. The combined effect of transcriptional activation and mRNA stabilization results in a rapid two-order of magnitude increase in the level of PAI-1 within two $\mathrm{h}$ of growth factor addition and a similar rapid decline after transcription declines. TGF- $\beta$ also increases the sensitivity of the cells to EGF, thereby recruiting EGF at suboptimal concentrations to contribute to the synergistic activation of PAI-1. The contribution of EGF to the regulation of PAI-1 involves the MAPK pathway and the synergistic interface with the TGF $\beta$ pathway is downstream of MEK and involves phosphorylation of neither Erk1/2 nor Smad2/3. Although de novo protein synthesis is not required, a rapidly turning over protein is involved in the synergistic regulation. This protein may be the AP-1 protein, which is required for this regulation and synergism at transcription requires the presence of both Smad and AP-1 recognition sites. This work demonstrates the existence of a multidimensional cellular mechanism by which EGF and TGF $\beta$ are able to promote large and rapid changes in PAI-1 expression.

\section{Introduction}

Plasminogen activator inhibitor type 1 (PAI-1), a secreted glycoprotein, is produced by many cell types and is present in plasma and platelets (Haggroth, Mattsson et al. 1986). It is one of three serpin inhibitors of plasminogen activators, which are serine proteases that convert the zymogen plasminogen into plasmin. A broad spectrum serine protease, plasmin degrades fibrin and extracellular matrix proteins and plays a central role in clot dissolution. 
Interaction between PAI-1 and each of the two plasminogen activators (urokinase-type plasminogen activator, and tissue type plasminogen activator) is rapid with a second order rate constant between $10^{7}-10^{8} \mathrm{M}^{-1} \mathrm{~s}^{-1}$ (Hekman and Loskutoff 1988). By controlling the plasminogen activator-plasmin proteolytic cascade, PAI-1 is a crucial to the regulation of haemostasis and many biological processes that involve remodeling of the extracellular matrix (ECM, Sprengers and Kluft 1987; Loskutoff, Sawdey et al. 1989; Dellas and Loskutoff 2005).

As well as controlling degradation of the ECM, PAI-1 binds with some ECM components, particularly vitronectin (Salonen, Vaheri et al. 1989). The interaction with vitronectin both localizes PAI-1 to the ECM and alters its specificity to cell-associated proteases. Consequently, vitronectin-associated PAI-1 inhibits the proteolysis that promotes cell migration and thereby inhibits angiogenesis and tumor cell migration in vitro (Swiercz, Keck et al. 2001). However, by binding vitronectin, PAI-1 also interferes with the interactions of urokinase plasminogen activator receptor and $\alpha_{\mathrm{V}}$-integrins with vitronectin, thereby preventing cell-substratum association (Stefansson and Lawrence 1996). This action could promote tumor metastasis and angiogenesis (Loskutoff, Curriden et al. 1999). Consistent with this proposed function, high PAI-1 levels are associated with a negative prognosis for tumor metastasis (Pedersen, Brunner et al. 1994; Pedersen, Grondahl-Hansen et al. 1994). However, a careful examination of the relative contributions of the PAI-1 effects on plasmin activity and cell attachment to tumor angiogenesis in vivo revealed that the ability of PAI-1 to promote tumorigenesis is primarily due to its inhibiting plasmin activation (Bajou, Masson et al. 2001). By promoting the formation of ECM, PAI-1 is proposed to provide endothelial 
cells a substratum through which to move, thus promoting angiogenesis and tumor growth (Bajou, Masson et al. 2001).

In addition to its involvement in cancer, altered PAI-1 levels contribute to asthma, cirrhosis of the liver and other fibrotic events. For example, chronically elevated PAI-1 in the brain is believed to promote senility by preventing degradation by PA of aggregated $\alpha$ amyloid peptides that make up senile plaques (Seki, Imai et al. 1996; Buckova, Izakovicova Holla et al. 2002; Higgins 2006).

Consistent with its role in regulating the activity of potent proteases that participate in tissue remodeling and clot resorption, the in vivo levels of PAI-1 can change rapidly. For example, PAI-1 levels in the blood are increased within $1 \mathrm{~h}$ of major surgery, severe trauma, and myocardial infarction (D'Angelo, Kluft et al. 1985; Kluft, Verheijen et al. 1985; Burzotta, Iacoviello et al. 2003; Kruithof, Gudinchet et al. 1988). A major source of PAI-1 is liver because it is an acute phase protein (Kruithof, Gudinchet et al. 1988). Clearance of PAinhibitory activity from circulation is also rapid with measured half lives of 3.5 to 7 min (Colucci, Paramo et al. 1985). Even the PAI-1 that is not cleared from the circulation has a limited half life of about $1-2 \mathrm{~h}$ due to its spontaneous conversion to an inactive latent conformer in which some of the primary recognition residues are incorporated into its largest $\beta$ sheet (Mottonen, Strand et al. 1992).

PAI-1 expression is regulated by many hormones, cytokines and growth factors including insulin, transforming growth factor type beta (TGF- $\beta$ ), epidermal growth factor (EGF), basic fibroblast growth factor (FGF-2), insulin-like growth factor I (IGF-I) and tumor necrosis factor alpha (TNFa) (Thalacker and Nilsen-Hamilton 1987; Landin, Tengborn et al. 1991; 
Schneider and Sobel 1991; Thalacker and Nilsen-Hamilton 1992; Peiretti, Alessi et al. 1997; Watanabe, Kurabayashi et al. 2001). TGF- $\beta$ and EGF cooperatively regulate PAI-1 expression (Thalacker and Nilsen-Hamilton 1987; Hopkins, Westerhausen et al. 1991). Synergism between two or more regulators allows cells to achieve a significantly higher level of response than is possible by stimulation with one regulator alone and is likely the means by which many critical genes are regulated. Cooperation in signaling (synergism) is an important means of ensuring tight biological control and effecting large increases in gene expression, both of which are important for PAI-1. The requirement of two or more regulators for increased gene expression also minimizes the probability of adventitious gene activation that could be deleterious to the organism.

Although transcriptional activity is frequently a point of regulation of gene expression, the level of each mRNA available for translation depends on both it transcription and degradation. Here we examine the contributions of transcription and degradation to the mechanism by which EGF and TGF- $\beta$ on PAI-1 act synergistically on gene expression. We demonstrate that the two growth factors interact synergistically at the level of PAI-1 mRNA transcription and that EGF alone stabilizes PAI-1 mRNA with the result that the mRNA level increases rapidly to two orders of magnitude higher than the basal level. In addition, TGF- $\beta$ recruits the EGF component of the synergistic mechanism by increasing the cells' sensitivity to EGF. The mechanism by which synergism is achieved is unique to the combination of the two growth factors and the same level of expression cannot be achieved by either growth factor alone. These studies demonstrate a powerful interaction on PAI-1 gene expression between two growth factors that are frequently present at elevated levels in diseased tissues such as cancer and during an inflammatory response. 


\section{Experimental procedures}

Materials. Human TGF- $\beta 1$ and recombinant epidermal growth factor were from R\&D systems (Minneapolis, MN). Cordycepin and 4-thiouridine (4SU) were from Sigma (St.

Louis, MO). $\alpha^{32}$ P-dCTP was from New England Nuclear (Boston, MA). $\alpha-{ }^{32}$ P-UTP was from ICN (Irvine, Calif., USA). The ${ }^{35} \mathrm{~S}$-methionine, ${ }^{35} \mathrm{~S}$-Trans-label (mixture of ${ }^{35} \mathrm{~S}$ methionine and ${ }^{35}$ S-cysteine) and Random Primer Labeling Kit were from Amersham (Piscataway, NJ) and the Zeta-probe nylon membrane was from Bio-Rad (Hercules, CA). Trizol, DNase I and reverse transcriptase were from Invitrogen (Carlsbad, CA). EZ-Link Biotin-HPDP was from Thermo Scientific (Rockford, IL). Biotin-16-UTP was from Epicentre Biotechnologies (Madison, WI). All reagents were analytical grade or better. Rabbit monoclonal antibody against phospho-p44/42 MAP Kinase (Thr202|Tyr204) was purchased from Cell Signaling Technology, Inc. (Danvers, MA, cat\# 4370); Rabbit antiSmad2 (Phospho-Ser467) polyclonal antibody was purchased from GenSript USA Inc. (Piscataway, NJ, Cat\#A01037) and $\beta$-actin (C4) mouse monoclonal antibody (HRP conjugated) was purchased from Santa Cruz Biotechnology, Inc. (Santa Cruz, CA, Cat\# sc47778). Antibodies against phosphorelated Fos at ser32, ser362 \& Thr232 (Assay Bio Tech, cat\# A8212, A0429, A8226) and phosphorylated c-Jun at ser63 and ser73 (Assay Bio Tech, cat\# A7045, A7046) were bought from Assay Biotechnology Company Inc (Sunnyvale, CA). Chemicals including MEK1/2 specific inhibitor U0126 and its negative control U0124, Src selective inhibitor PP2 and its negative control PP3, p38 MAPK specific inhibitor SB202190 and its negative control SB202474, PI3K specific inhibitor LY294002 and its negative control LY303511, SP600125, specific inhibitor of JNK and its negative control were purchased from Calbiochem (EMD Chemicals Inc., San Diego, CA, USA). Plasmids p3TP- 
lux (Wrana, Attisano et al. 1992) (plasmid \# 11767), CMV-Fast-1 wild-type (Zhou, Zawel et al. 1998) ( plasmid \# 16521) and SBE4-Luc (Zawel, Dai et al. 1998) (plasmid \# 16495) were purchased from Addgene, Inc. (Cambridge, MA). Vector pRL-SV40 was purchased from Promega (Madison, WI). PAI-1 antiserum ( $\alpha$-Sp46) was a kind gift from JG Rheinwald (Rheinwald, Jorgensen et al. 1987). Curcumin was got from Enzo ${ }^{\circledR}$ Life Science (Plymouth Meeting, PA, Cat\# ALX-350-028). The plasmid encoding $\triangle \mathrm{FosB}$ and the equivalent empty vector control were a kind gift of Y Nakabeppu (Nakabeppu and Nathans 1991).

Cell Culture. The mink lung epithelial cell line, Mv1Lu (ATCC, CCL64, Manassas, VA), was obtained from Dr. Robert W Holley. The cells were maintained as monolayer cultures in Dulbecco-Vogt's medium (DMEM) containing $0.45 \%$ glucose, $10 \%$ calf serum, 10 units $/ \mathrm{ml}$ penicillin and $10 \mu \mathrm{g} / \mathrm{ml}$ streptomycin at $37^{\circ} \mathrm{C}$, in a water saturated atmosphere with $10 \% \mathrm{CO}_{2}$ in air. MLEC cells clone $32(\mathrm{Mv} 1 \mathrm{Lu}$ cells stably transfected with a plasmid containing the human PAI-1 luciferase reporter (van Zonneveld, Curriden et al. 1988)) were a gift from Daniel B Rifkin (New York University, NY). Human hepatocellular carcinoma HepG2 cells (ATCC, HB-8065) were maintained in Eagle's minimal essential medium (MEME, Sigma) supplemented with $10 \%$ fetal calf serum, $1 \%$ non-essential amino acids (Irvine Scientific, Santa Ana, CA), $10 \mu \mathrm{M}$ sodium pyruvate (Gibco, Carlsbad, CA), 10 units $/ \mathrm{ml}$ penicillin and $10 \mu \mathrm{g} / \mathrm{ml}$ streptomycin at $37^{\circ} \mathrm{C}$ in a water-saturated atmosphere with $5 \% \mathrm{CO}_{2}$ in air. All cell lines were confirmed to be mycoplasma negative by regular testing by PCR analysis.

For experiments, cells were seeded and cultured as above until confluent. The medium was then changed to Dulbecco-Vogt's modified Eagle's medium (DMEM) or minimal 
essential medium (MEME) with or without $0.2 \%$ calf serum for $24 \mathrm{~h}$ prior to addition of growth factors and other treatments. The concentrations of growth factors were $1 \mathrm{ng} / \mathrm{ml} \mathrm{EGF}$ and $5 \mathrm{ng} / \mathrm{ml}$ TGF- $\beta$ unless otherwise stated. For testing inhibitors, cells were pretreated with specific kinase inhibitors or their structural inactive analogs at indicated concentration for $1 \mathrm{~h}$ and then incubated with EGF and TGF- $\beta$, alone or in combination for $2 \mathrm{~h}$

Measurement of protein production by metabolic labeling. The rate of PAI-1 protein production was measured using metabolic labeling as previously described (Thalacker and Nilsen-Hamilton 1987). Confluent Mv1Lu cells was first treated with EGF and TGF- $\beta$ for 2 $\mathrm{h}$ respectively, ${ }^{35} \mathrm{~S}$-methionine was added to the conditioned medium to label newly synthesized protein. After $4 \mathrm{~h}$, the medium from mink cells was collected and the amount of radiolabeled PAI-1 protein was determined by SDS-PAGE followed with autoradiography. After $8 \mathrm{~h}$ exposure to growth factors, ${ }^{35} \mathrm{~S}$-Trans-label was added to HepG2 cells to label newly synthesized protein. The amount of human PAI-1 protein was detected after immunoprecipitation by using PAI-1 antiserum ( $\alpha$-Sp46), followed by SDS-PAGE and autoradiography.

Northern blots. A $1.5 \mathrm{~kb}$ mink PAI-1 cDNA fragment corresponding to bases 150-1691 was generated by digesting mink PAI-1 cDNA with Sma I (Chuang, Hamilton et al. 1995). The fragment was resolved by agarose gel electrophoresis and isolated by glass bead affinity adsorption (Geneclean, Qbiogene Inc., Carlsbad, CA). The isolated cDNA fragment was radiolabeled with $\alpha^{32} \mathrm{P}$-dCTP to a specific radioactivity of about $1 \times 10^{9} \mathrm{cpm} / \mu \mathrm{g}$ using random primer extension. For Northern blots, the cells were washed twice with Trisbuffered salts $\left(0.14 \mathrm{M} \mathrm{NaCl}, 5 \mathrm{mM} \mathrm{KCl}, 0.68 \mathrm{mM} \mathrm{CaCl}_{2}, 0.49 \mathrm{mM} \mathrm{MgCl}_{2}, 0.70 \mathrm{mM}\right.$ 
$\mathrm{Na}_{2} \mathrm{HPO}_{4}, 25 \mathrm{mM}$ Tris $\cdot \mathrm{HCl}, \mathrm{pH}$ 7.1) and lysed with $4 \mathrm{M}$ guanidinium isothiocyanate, $25 \mathrm{mM}$ sodium acetate, $\mathrm{pH} 6$. The total RNA was separated from the cell lysate by isopycnic centrifugation in $5.7 \mathrm{M}$ cesium chloride, $25 \mathrm{mM}$ sodium acetate (Chirgwin, Przybyla et al. 1979). After several rinses with $70 \%$ ethanol to remove the cesium chloride, the RNA was resuspended in $0.3 \mathrm{M}$ sodium acetate, $\mathrm{pH} 6$, and preserved at $-75^{\circ} \mathrm{C}$. The RNA was resolved by electrophoresis through $1 \%$ agarose-formaldehyde gels using $1 \mathrm{mM}$ EDTA, $5 \mathrm{mM}$ sodium acetate, $20 \mathrm{mM}$ MOPS (3-[N-morpholino] propanesulfonic acid), $\mathrm{pH} 6$ as running buffer. The RNA was transferred to nylon membranes in $50 \mathrm{mM}$ sodium hydroxide. The RNA on the blots was hybridized with radiolabeled mink PAI-1 probe for $18 \mathrm{~h}$ at $47^{\circ} \mathrm{C}$ in hybridization buffer ( $40 \%$ formamide, $7 \%$ SDS, $1 \%$ polyethylene glycol MW=20000, $0.25 \%$ non-fat milk, $0.6 \mathrm{M} \mathrm{NaCl}, 4 \mathrm{mM}$ EDTA, $50 \mu \mathrm{g} / \mathrm{ml}$ salmon sperm DNA, $40 \mathrm{mM} \mathrm{NaH} \mathrm{NO}_{4}$, $\mathrm{pH}$ 7.5). The blots were washed in a solution of $30 \mathrm{mM} \mathrm{NaCl}, 0.2 \%$ SDS, $3 \mathrm{mM}$ sodium citrate, $\mathrm{pH} 7$ twice for $15 \mathrm{~min}$ at $47{ }^{\circ} \mathrm{C}$ then exposed to Kodak XAR film at $-75^{\circ} \mathrm{C}$ with two intensifying screens. To control for loading of the RNA, the blots were stripped in $0.1 \%$ SDS, $10 \mathrm{mM} \mathrm{NaCl}, 1.5 \mathrm{mM}$ sodium citrate, at $80{ }^{\circ} \mathrm{C}$ for 30 min twice and rehybridized with radiolabeled $18 \mathrm{~S}$ ribosomal RNA probe (Fuke, Dennis et al. 1981).

Reverse Transcription-Quantitative PCR. Total RNA was extracted with Trizol. RNA was first treated with $0.1 \mathrm{U} / \mu 1$ DNase I for $15 \mathrm{~min}$ at $24{ }^{\circ} \mathrm{C}$ and transcribed by Superscript II reverse transcriptase. The samples for qPCR were prepared in a $20 \mu 1$ volume containing $10 \mathrm{mM}$ KCI, $20 \mathrm{mM}$ Tris-HCI, $10 \mathrm{mM}\left(\mathrm{NH}_{4}\right)_{2} \mathrm{SO}_{4}, 2 \mathrm{mM} \mathrm{MgSO}$, $0.1 \%$ Triton X-100 (pH 8.8 at $25^{\circ} \mathrm{C}$ ), $0.2 \mathrm{mM} \mathrm{dNTP}, 50 \mathrm{U} / \mathrm{ml}$ Taq DNA polymerase (New England Biolabs Inc., Ipswich, MA), 0.7 x SYBR ${ }^{\circledR}$ Green I (Molecular Probes Inc., Eugene,OR), the appropriate primers at $0.1 \mu \mathrm{M}$ each and cDNA templates as defined by the experiment and the RNA 
sequence to be quantified. The qPCR was performed in an Opticon real-time PCR detector (MJ Research, Inc., Waltham, MA, model CFD-0200) with a $95{ }^{\circ} \mathrm{C}$ premelt for 5 min followed by 40 cycles of $95{ }^{\circ} \mathrm{C} 15 \mathrm{sec}, 60{ }^{\circ} \mathrm{C} 15 \mathrm{sec}, 72{ }^{\circ} \mathrm{C} 15 \mathrm{sec}$ and including a final determination of melting curves from $65^{\circ} \mathrm{C}$ to $90{ }^{\circ} \mathrm{C}$. The amount of each mRNA was quantified by using a standard curve created in the same qPCR run using a series of known dilutions of the amplified fragments. Values that were outside the range of the standards were not included and the affected samples were reanalyzed at dilutions to ensure that the values were within the range of the standard curve. A mixture of samples was also evaluated at a series of dilutions and the standard cure thus obtained was found to be parallel with the standard curve created by amplified fragments, thus confirming the lack of PCR inhibitors in the range of concentrations of the sample preparations used in this study. The relative PAI-1 mRNA levels were calculated by normalizing the value for PAI-1 mRNA to the result for the amount of reference mRNA, which was either GAPDH or cyclophilin A that had been quantified in the same sample. The primers for mink cDNAs were: PAI-1: TCGCCACCGTCAGCAGCA and TGTGGCCAGTTCCGCTGC; GAPDH: CCCACCCCCAATGTGTCTGT and AATGCCAGCCCCAGCATCGAAG; uPAR: AAGACCAACAGGWCCMTGAG and TSCCRGCCCCTCTCACAGC; COX2: ATTAGCTCCCTT GTTCTC and AGgtCTTCGTAGTCTGTG. Primers for human cDNAs were: PAI-1: GACAACAGGAGGAGAAACCC and AGATCCCGCTGGACGAAG; uPA: TGTGAGATCACTGGCTTTG and TTGGAGGGAACAGACGAG; uPAR: GACCCTGAGCTATCGGACT and GATGAGCCACAGGAAATG; Cyclophin A: GGCAAAGTGAAAGAAGGC and GATACTGCGAGCAAATGG; Primers for mouse cDNAs were: PAI-1: ACAGTGGCGTCTTCCTCC and ATAACATCTCCAGTTTCGTCC; uPA: TAGACCAACAAGGCTTCC and TTGGGAGTTGAATGAAGC; uPAR: CACAGCAGGTTTCCATA- 
GC and GGTTTCCCAGCACATCTAA; GAPDH: TCGTCCCGTAGACAAAAT and GCTCCTGGAAGATGGTGAT.

Nuclear run-on assay Nuclear run-on was performed using a biotin-labeled uridyl precursor followed by RT-qPCR detection (Patrone, Puppo et al. 2000). Briefly, after growth factor treatment, confluent mink lung Mv1Lu cells were collected by scraping into cold PBS (137 mM NaCl, $2.7 \mathrm{mM} \mathrm{KCl}, 10 \mathrm{mM} \mathrm{Na}_{2} \mathrm{PO}_{4}, 2 \mathrm{mM} \mathrm{K}_{2} \mathrm{PO}_{4}, \mathrm{pH}$ 7.4) and the nuclei were isolated by resuspending the cells in NP-40 lysis buffer (10 mM HEPES, pH 7.3, $10 \mathrm{mM}$ $\mathrm{NaCl}, 3 \mathrm{mM} \mathrm{MgCl} 2,150 \mathrm{mM}$ sucrose $0.5 \%$ Nonidet P40) and disrupting the cells with a Dounce homogenizer. The nuclei were pelleted by centrifugation $\left(4{ }^{\circ} \mathrm{C}, 170 \mathrm{x} g\right.$ for $\left.10 \mathrm{~min}\right)$ and washed with lysis buffer lacking NP40. The supernatant was removed and the nuclear pellet was resuspended in $50 \mu \mathrm{l}$ storage buffer ( $5 \mathrm{mM} \mathrm{MgCl} 2,0.1 \mathrm{mM}$ EDTA, $40 \%$ glycerol, $50 \mathrm{mM}$ Tris $\mathrm{HCl}, \mathrm{pH} 8.3$ ) and stored frozen at $-80{ }^{\circ} \mathrm{C}$ until use. Nuclear transcription was performed by incubating the nuclei in reaction buffer (10 mM Tris- $\mathrm{HCl}(\mathrm{pH} 8.0), 100 \mathrm{mM}$ $\mathrm{KCl}, 2.5 \mathrm{mM} \mathrm{MgCl} 2,2 \mathrm{mM}$ DTT, $2 \mathrm{mM}$ ATP, 2 mM CTP, 2 mM GTP, 0.67 UTP, $0.33 \mathrm{mM}$ Biotin-16-UTP, $100 \mathrm{mM}$ sucrose, $10 \%$ glycerol) at $30{ }^{\circ} \mathrm{C}$ for $30 \mathrm{~min}$. Total RNA was extracted with Trizol and newly transcribed RNA, labeled with biotin-16-UTP, was isolated by incubating the RNA with Dynabeads M-270 in binding buffer ( $5 \mathrm{mM}$ Tris- $\mathrm{HCl}$ (pH 7.5), $0.5 \mathrm{mM}$ EDTA, $1 \mathrm{M} \mathrm{NaCl}$ ) at $42{ }^{\circ} \mathrm{C}$ for $20 \mathrm{~min}$ and then room temperature for $30 \mathrm{~min}$. The biotinylated RNA coated streptavidin beads were concentrated by a 3 min exposure to a magnet then washed twice with buffer containing $15 \%$ formamide and 2 x SSC (300 mM $\mathrm{NaCl}, 30 \mathrm{mM}$ sodium citrate, $\mathrm{pH}$ 7.0) for $15 \mathrm{~min}$ and once for $5 \mathrm{~min}$ in $1 \mathrm{ml}$ of $2 \mathrm{x}$ SSC. Beads containing newly synthesized RNA were suspended in $30 \mu \mathrm{l}$ DEPC-treated water. Reverse transcription and qPCR were performed as previously described. 
$m R N A$ half-life. Mv1Lu cells were treated with $5 \mathrm{ng} / \mathrm{ml}$ EGF and $1 \mathrm{ng} / \mathrm{ml} \mathrm{TGF-} \beta$, either alone or in combination for $2 \mathrm{~h}$ then $15 \mu \mathrm{g} / \mathrm{ml}$ cordecypin was added and the cells incubated for the identified time periods before collection and extraction of total RNA for analysis by qRT-PCR. At least five independent experiments were performed for each treatment.

Transcription rate. Metabolic labeling of newly transcribed RNA was performed as previously described (Dolken, Ruzsics et al. 2008) with modifications. Fifteen minutes before the end of the treatment period, $500 \mu \mathrm{M}$ 4-thiouridine was added to the culture medium. The reaction was stopped 15 min later and total cellular RNA was isolated using Trizol reagent. Newly transcribed RNA was biotinylated by incubation with $0.2 \mathrm{mg} / \mathrm{mL}$ biotin-HPDP in $10 \mathrm{mM}$ Tris ( $\mathrm{pH}$ 7.4), $1 \mathrm{mM}$ EDTA for $1.5 \mathrm{~h}$ at room temperature. The RNA was extracted with chloroform/isoamylalcohol (24:1), precipitated with isopropanol, washed with $75 \%$ ethanol and the biotinylated RNA was isolated using streptavidin coated beads, M270. Specific mRNAs were quantified by RT-qPCR.

Western blot. Confluent and quiescent Mv1Lu cells were treated with $1 \mathrm{ng} / \mathrm{ml} \mathrm{EGF,} 5$ $\mathrm{ng} / \mathrm{ml} \mathrm{TGF}-\beta$ or the combination of both growth factors at the same concentration. Cells were treated with growth factors for 10 minutes to check Erk1/2 phosphorylation and 45 minutes to check Smad2 phosphorylation. After wash cells twice in ice-cold PBS, cells were lysed in $100 \mu \mathrm{l}$ RIPA buffer (50 mM Tris- $\mathrm{HCl}$ (pH 8.0), $150 \mathrm{mM} \mathrm{NaCl}, 1 \% \mathrm{NP}-40,0.5 \%$ sodium deoxycholate, $0.1 \%$ SDS, $2 \mathrm{mM}$ EDTA, $1 \mathrm{mM}$ PMSF, $10 \mu \mathrm{M}$ leupeptin) and centrifuged at $10,000 \mathrm{x} g$ at $4{ }^{\circ} \mathrm{C}$ for $10 \mathrm{~min}$. Ten $\mu$ l of protein sample in $62.5 \mathrm{mM}$ Tris- $\mathrm{HCl}$ (pH 6.8), $10 \%$ mercaptoethanol, $2 \%$ SDS, $10 \%$ Glycerol, $0.005 \%$ bromphenol blue was heated at $95{ }^{\circ} \mathrm{C}$ for $5 \mathrm{~min}$. Electrophoresis was performed under 100 volts for $1.5 \mathrm{~h}$ through 
a $4 \%$ stacking gel and $10 \%$ resolving polyacrylamide gel in a Tris-glycine buffer system (Thalacker and Nilsen-Hamilton 1987). Protein was transferred to a nitrocellulose membrane using a TE 22 mighty small transphor electrophoresis unit (Phamacia) in the presence of 25 $\mathrm{mM}$ Tris base, $0.2 \mathrm{M}$ glycine, $20 \%$ methanol ( $\mathrm{pH} \mathrm{8.5)}$. The membrane was blocked for $1 \mathrm{~h}$ in buffer containing TBS (Tris buffered saline, $2.42 \mathrm{~g} / \mathrm{L}$ Tris base, $8 \mathrm{~g} / \mathrm{L} \mathrm{NaCl}, \mathrm{Ph} 7.6$ ), 0.1\% Tween-20 with 5\% w/v nonfat dry milk) and then incubated overnight in TBS, $0.1 \%$ Tween20 with 5\% w/v nonfat dry milk with primary antibody at the indicated dilutions (1:2000 for rabbit phospho-p44/42 monoclonal antibody, 1:1000 for phophore Smad2 polyclonal antibody, 1:1000 for monoclonal antibody against acetylated lysine and 1:1000 for $\beta$-actin monoclonal antibody). After washing the membrane twice with buffer containing TBS and $0.1 \%$ Tween-20 for 10 min each time, the membrane was incubated with secondary antibody diluted by 2000 fold in TBS and $0.1 \%$ Tween- 20 at $24{ }^{\circ} \mathrm{C}$ for $2 \mathrm{~h}$. Following two washes in TBS, $0.1 \%$ Tween-20 for $10 \mathrm{~min}$ each, the membrane was incubated with $2 \mathrm{~mL}$ of $1: 1$ Enhanced Luminol Reagent:Oxidizing Reagent (Western lightning chemiluminescence reagent plus, PerkinElmer Life Sciences, Waltham, MA) for $1 \mathrm{~min}$ and then exposed to autoradiography film.

Transfection. Mv1Lu cells were seeded one day before transfection. Cells were transfected with $1.6 \mathrm{ng} / \mathrm{ml}$ plasmids in DMEG medium in the presence of $0.4 \%$ lipofectamine 2000 (Invitrogen). After $20 \mathrm{~h}$ of transfection, the cells were treated with 1 $\mathrm{ng} / \mathrm{ml} \mathrm{EGF}, 5 \mathrm{ng} / \mathrm{ml}$ TGF- $\beta$ or their combination and incubated for the indicated time period. Samples were collected and analyzed by the luciferase assay or RT-qPCR. 
Luciferase assay. After $6 \mathrm{~h}$ stimulation with growth factor, Mv1Lu cells were washed twice in cold PBS then lysed in passive lysis buffer (PLB). The cell lysates were stored at $20{ }^{\circ} \mathrm{C}$. Both firefly and renilla luciferase activities were measured in a Glomax 20/20 Luminometer (Promega) using the Promega Dual-Glo protocol. The relative reporter activity for each treatment was calculated as the ratio of firefly to renilla luciferase activities.

Statistical analysis. Data from multiple experiments are summarized and represented as the mean \pm standard error of the mean. The data was analyzed by the linear model of ANOVA and multiple comparisons were performed according to the least square means Student's $t$ test. The effects of treatments on the PAI-1 mRNA half-life were assessed by linear regression analysis and analysis of covariance (ANCOVA). All statistical test were performed using the software JMP7.0 (SAS Institute Inc, Cary, NC) unless otherwise stated. Significant differences between samples are indicated as: $* \mathrm{p}<0.05, * *: \mathrm{p}<0.01$ and $* * *$ : $\mathrm{p}<0.001$.

\section{Results}

Synergism between EGF and TGF- $\beta$ in regulating PAI-1 $m R N A$ and protein level. EGF and TGF $\beta$ cooperate to stimulate PAI-1 protein production in mink lung Mv1Lu cells and human liver HepG2 cells. Analysis by metabolic labeling, alone for Mv1Lu cells (Thalacker, 1987 ) or followed by immuno-precipitation in HepG2 cells, showed the increase in PAI-1 protein level is synergistic (Fig. 1A). Analysis by northern blot and RT-qPCR showed that the synergistic increase in PAI-1 gene expression occurs at the mRNA level (Fig. 1B). Synergism is defined as when the increase due to the combination of treatments is more than expected from the sum of the increases due to either treatment alone. 
Synergism in PAI-1 expression was observed in both human and mink cell lines (Fig. 1). Unlike the large changes in gene expression observed for PAI-1, much smaller changes in mRNA levels were observed for urokinase (uPA) and urokinase plasminogen activator receptor (uPAR) in response to EGF and there was no effect of TGF- $\beta$ (Fig. 1B). A small, but not significant, synergistic increase was observed in urokinase plasminogen activator receptor (uPAR) expression (Fig. 1B). Cyclooxygenase (COX2) mRNA was not altered by EGF, TGF- $\beta$, or their combination. Thus, the synergism between EGF and TGF- $\beta$ is gene specific but not species specific.

Synergism occurs with both growth factors at saturating concentrations. If EGF and TGF- $\beta$ utilize the same mechanism to increase PAI-1 gene expression they should only behave synergistically at concentrations below saturation. To test this hypothesis, we titrated the concentration of each growth factor to reach saturation in the presence of a constant saturating concentration of the other (Fig. 2). The results clearly show that neither growth factor can substitute for the other in raising the level of PAI-1 mRNA to the level observed with both together, which is about an order of magnitude beyond that achieved with either growth factor alone. Thus, the mechanism by which PAI-1 gene expression is regulated in cells treated with a combination of EGF and TGF $\beta$ likely involves cooperation occurring at some level of signaling downstream from each growth factor.

$T G F \beta$ increases the sensitivity of cells to EGF but not vice versa. Analysis of the $\mathrm{EC}_{50} \mathrm{~S}$ of the concentration dependencies of the responses of PAI-1 mRNA levels to EGF and TGF $\beta$ also revealed that TGF $\beta$ increases the sensitivity of the cells to EGF by an order of magnitude but the presence of $\mathrm{EGF}$ did not change the $\mathrm{EC}_{50}$ for $\mathrm{TGF} \beta$ responsiveness (Table 
I). Thus, TGF $\beta$ helps to recruit low concentrations of EGF that would not alone be high enough to have an effect to cooperate in increasing PAI-1 expression. This result could explain synergism at concentrations below saturating levels of the two growth factors, but does not explain synergism between saturating levels of EGF and TGF- $\beta$.

The synergism with TGF- $\beta$ is downstream from tyrosine kinases and PKC. To test the hypothesis that a pathway common to tyrosine kinase receptors is responsible for the EGF contribution to the synergism with TGF- $\beta$, we examined the effect on PAI-1 expression of other ligands of tyrosine kinase receptor (fibroblast growth factor 2, FGF-2, and Insulin-like growth factor 1, IGF-1) and that activate soluble tyrosine kinases (tumor necrosis factor alpha, TNF- $\alpha$ ) in combination with TGF- $\beta$. While the PAI-1 mRNA level was not significantly induced after treatment by IGF-1, FGF-2 or TNF- $\alpha$ alone, it was dramatically increased when the cells were treated with one of these stimuli and TGF- $\beta$ (Fig. 3A). In all cases, the combined treatment produced a significantly higher PAI-1 mRNA level than TGF$\beta$ treatment alone. EGF and TGF- $\beta$ exhibited the highest synergism, which elevated PAI-1 mRNA level about 4-fold over the simple additive effects expected from each growth factor acting independently. Although the extent of synergism varied with the growth factor or cytokine, TGF- $\beta$ acted synergistically with all tyrosine kinase activators to induce PAI-1 mRNA.

However, the synergistic event is not uniquely downstream of tyrosine kinases because PMA, a PKC agonist, also acts synergistically with TGF- $\beta$ on PAI-1 protein as demonstrated in Mv1Lu cells (Fig. 3B) and MSV-transformed Mv1Lu cells (data not shown). This effect 
was specific for PAI-1 as demonstrated by the lack of effect of PMA on the production of other secreted proteins including a TGF- $\beta$-induced $73 \mathrm{kDa}$ protein (Fig 3B, C).

The MAPK pathway is required for synergism. The involvement of RTK receptors and PKC identified a subset of signal transduction pathways that might be involved in the synergistic mechanism. To identify the likely pathway(s), a series of kinase inhibitors and their inactive control analogs were tested (Fig. 4, table II). Although several inhibitors decreased the overall responses to EGF and TGF- $\beta$, only inhibition of the p38 MAPK and the MEK1/2 reduced synergism, with the largest effect being produced by the MEK1/2 inhibitor, U0126 (Fig. 4A). The phosphorylation of ERK1/2, a major target of MEK, increased within 10 min after adding EGF but was not altered by the addition of TGF- $\beta$ (Fig. 4F). These results showed that the synergism is a downstream event of MAPK pathway and further downstream than MEK.

EGF stabilizes PAI-1 mRNA. We evaluated if enhanced mRNA stability might be the post-transcriptional step responsible for the period of persistently elevated PAI-1 mRNA level in response to the combination of EGF and TGF- $\beta$. Although the basal level of PAI-1 mRNA was too low to obtain sufficient quantitative values for a decay curve, we were able to determine the mRNA decay rates in cells treated with each growth factor alone and in combination (Fig. 5). The PAI-1 mRNA half-life was determined as $37 \mathrm{~min}$ in TGF- $\beta$ treated cells, $52 \mathrm{~min}$ in EGF-treated cells and $56 \mathrm{~min}$ in cells treated with EGF and TGF- $\beta$. A statistical analysis of the data verified that the PAI-1 mRNA half-life in cells treated with the combination of EGF and TGF- $\beta$ was significantly different from that in cells treated with TGF $-\beta$ alone $(p<0.05)$ but not from that in cells treated with EGF. Thus, by stabilizing PAI- 
1 mRNA, EGF contributes to the magnitude of the increase in expression of PAI-1 mRNA in combined treatment with TGF- $\beta$ and it increases the amount of time during which the increased PAI-1 mRNA levels exist. Transcription of the PAI-1 gene is synergistically induced by TGF- $\beta$ and EGF. To determine if EGF and TGF- $\beta$ cooperate to increase the rate of initiation of PAI-1 transcription, we performed nuclear run-on experiments and found a synergistic effect of about 2-fold for newly transcribed PAI-1 mRNA (Fig. 6A, B).

A trivial explanation for the observation of synergism is that, rather than increasing the maximum level of gene expression, the combination of the two growth factors changes the time course of expression to move the peak expression level closer to the monitored time point. To test this question we performed a time course study where it was seen that the PAI1 transcription and mRNA level was increased within $1 \mathrm{~h}$ of the addition of EGF and TGF- $\beta$ and peaked at 1.5 and $2 \mathrm{~h}$, respectively (Figs. 6C, D). Synergism was observed throughout the induction period. These results demonstrate that the response of PAI-1 gene expression is rapid and that synergism between EGF and TGF $\beta$ does not result from a change in the relative time courses of the responses but the response to EGF and TGF $\beta$ was characterized by persistently elevated PAI-1 expression compared with cells treated with either growth factor alone (Fig. 6D).

The mechanism of synergism between EGF and TGF- $\beta$ does not intersect with the Smad pathway. Crosstalk has been reported between the MAPK and Smad pathways (Verrecchia, 2001; Zhang, 1998 ). To determine if this type of interaction is the basis for the cooperation between EGF and TGF- $\beta$, we examined the phosphorylation of Smad 2/3 using an antibody that recognizes the phosphorylated c-terminal SS (V/M)S motif and found no synergism in 
Smad phosphorylation (Fig. 7A). The Smads were phosphorylated only in response to TGF- $\beta$.

To determine if Smad activity in the nucleus is synergistically increased by mechanisms other than phosphorylation, such as increased rate of nuclear entry or decreased rate of degradation of activated Smads, we utilized the plasmid pSBE4, which contains four Smad binding elements (SBE) that are specifically recognized by activated Smad3/4 (Zawel, Dai et al. 1998). We also tested the possibility that synergism occurs by promoting the interaction of Smad2/4 with forkhead activin signal transducer -1 (FAST-1) transcription factor using the plasmid p3ARE that contains the activin responsive element, (Labbe, Silvestri et al. 1998). TGF- $\beta$ treatment activated Smad3/4 activity (pSBE4) but had little or no effect on Smad2/4 activity (p3ARE), whereas EGF inhibited basal Smad3/4 activity by $50 \%$, TGF- $\beta$ stimulated Smad3/4 activity by $20 \%$ and basal and TGF- $\beta$-stimulated Smad2/3 activity by $65 \%$ (Fig 7B,C). These results support the conclusion that synergism between EGF and TGF- $\beta$ does not involve increasing the nuclear activities of the Smads.

Synergism between EGF and TGF- $\beta$ involves an interaction between AP-1 and Smads. Because the Smads have been reported to interact cooperatively with AP-1, we tested the hypothesis that the point of synergism between TGF- $\beta$ and EGF is at the interaction between AP-1 and Smad. In these experiments EGF and TGF- $\beta$ were found to synergistically increase expression from the plasmid $\mathrm{p} 3 \mathrm{TP}$, which contains three AP-1 recognition sites from the enhancer of collagenase and the Smad binding elements from the distal region of the PAI-1 promoter (Fig. 8A). There was a 3-fold synergism on the transcriptional activity 
observed with p3TP plasmid, which is similar to that observed in endogenous PAI-1 transcription.

To confirm the involvement of AP-1 in the synergism between EGF and TGF- $\beta$, we tested two AP-1 antagonists, curcumin and dominant negative Fos ( $\Delta$ FosB). Both antagonists significantly reduced PAI-1 synthesis in response to the combination of EGF and TGF- $\beta$ but had little effect on the induction of PAI-1 in response to EGF or TGF- $\beta$ alone (Fig. $8 B, C)$. Consequently the synergism between EGF and TGF- $\beta$ was significantly reduced in the presence of either inhibitor. By contrast, curcumin had no effect on transcriptional activation of the pSBE4 promoter that contains only Smad binding elements (Fig. 8D). The same effect of AP-1 suppression was found for the synergistic induction of PAI-1 mRNA demonstrating that the same mechanism as is seen in the reporter constructs is likely to be occurring on the endogenous PAI-1 promoter (Fig. 8F). AP-1 is a heterodimer of Fos and Jun family proteins and phosphorylation of these proteins great increased their transcriptional activities. The phosphorylation of Fos and Jun was checked by western blot against phosphorylated Fos and Jun protein. Results showed that both proteins were phosphorylated in all cases and there was no synergism at the phosphorylation of these protein (Fig. 8E).

AP-1 is specifically required for PAI-1 induced by EGF and TGF- $\beta$. So far we know MAPK and AP-1 were required for the synergism. By studies with inhibitors and trans negative regulators, we found that EGF-induced PAI-1 expression required the activities of MEK, P38 MAPK and JNK (Fig. 4A, C, E). Suppression of MEK produced significant reduction of PAI-1, with a decrease of $75 \%$ of induction by EGF. The antagonists of JNK and PI3K also reduced EGF-induced PAI-1 to variable extents. Blocking the activity of JNK 
by inhibitor or the dominant negative construct inhibited about $30-80 \%$ of PAI-1 mRNA production. Inhibition of PI3K activity reduced $23 \%$ of PAI-1 induction by EGF. The weakest modulators are p38 MAPK and Fos which only moderately attenuated about 14\% PAI-1 induction by EGF as compared to the control. Src is not involved in PAI-1 regulation by EGF because inhibition of Src activity did not altered PAI-1 induction. These results indicated that MEK, JNK and PI3K play important roles in EGF-induced PAI-1 expression. In the meanwhile we found out that TGF- $\beta$-induced PAI-1 expression requires MEK, p38 MAPK and src mediated signaling (Fig. 4A, C \& D). TGF- $\beta$-induced PAI-1 level was significantly decreased when the signaling mediated by MEK, p38 MAPK or src were blocked. Suppression of MEK reduced about $70 \%$ of PAI- 1 induction by TGF- $\beta$. The level of PAI-1 induced by TGF- $\beta$ was decreased $50 \%$ after inhibition of p38 MAPK activity and $37 \%$ after blocking the activity of src. Blocking JNK activity, either by inhibitor or by the trans-negative regulator increased TGF- $\beta$-induced PAI-1 level. Results suggest TGF- $\beta$ induces the expression of PAI-1 through MEK, p38 MAPK and src mediated signaling, and JNK activity negatively affects this regulation. The regulation of PAI-1 by the combination of EGF and TGF- $\beta$ requires the activity of MEK, p38 MAPK and AP-1 (Fig. 4A, 4C, 8F). The PAI- 1 mRNA level induced by the combination of EGF and TGF- $\beta$ was significantly reduced when the activity of MEK was blocked. p38 MAPK is also involved in the regulation of PAI-1 by the combination because suppression the activity of p38 MAPK by small chemical inhibitor significantly reduced PAI-1 mRNA level by $64 \%$. However, only the activity of AP-1 was required for the synergistic induction of PAI-1 by the combination of EGF and TGF- $\beta$. Significant reduction in PAI-1 synthesis by the cotreatment and in the synergism was observed when AP-1 activity was blocked $(\mathrm{p}<0.05)$. These results indicate 
that AP-1 might be the rapidly turning-over protein involved in the synergistic regulation of PAI-1.

Synergism is not at the translational level but a rapidly turning over protein is implicated. To test if new translation were required for synergism, cells were treated with cycloheximide prior to growth factor treatment. Blocking protein synthesis decreased PAI-1 induction by EGF, TGF- $\beta$ or the combination by about the same extent $(40 \%)$ and theresynergism was significantly decreased (83\% of the control, Fig. 9A, B).

Protein synthesis was blocked for various time periods with cyclocheximide according to the scheme in Fig. 9C, which showed that synergism is completely inhibited after longer incubations with cycloheximide. The apparent delay in the loss of the synergistic response compared with the responses to the individual growth factors was further investigated by calculating the rate of decay of the PAI-1 response as a function of growth factor treatment. The decay curves showed a rapid exponential decay of the response in cells treated with EGF and TGF- $\beta$ that can be described by a single half-life. However, the decay curves in cells treated only with EGF or TGF- $\beta$ were not well fit to a single exponential decay (Fig. 9D). These latter data sets were fit with the assumption that they could be described by two exponential decay constants, the first being the decay constant determined from the cells treated with the combination of EGF and TGF- $\beta$ and the second derived by calculation. These results suggested that a rapidly turning over protein is involved in PAI-1 regulation that is weakly activated by each growth factor separately, but in the presence of both growth factors the action of this rapidly turning over protein dominates. 


\section{Discussion}

Under normal physiological conditions, PAI-1 expression levels are very low. However upon stimulation, PAI-1 levels are rapidly increased as an early expressed gene. For example, the induction of PAI-1 in quiescent cells by EGF and TGF- $\beta$ is in an immediate early pattern (Nilsen-Hamilton and Holley 1983; Thalacker and Nilsen-Hamilton 1987; Ryan, Kutz et al. 1996; Kutz, Hordines et al. 2001).

EGF and TGF- $\beta$ act synergistically to activate several important cellular processes including colony formation in soft agar (Roberts, Anzano et al. 1985), the epithelial-to mesenchymal transition (EMT) (Okada, Danoff et al. 1997) and cell movement during tissue remodeling (Stolz and Michalopoulos 1997). Specific gene targets have been identified that are regulated synergistically including genes encoding the EGF receptor, several matrix metalloproteinases, including MMP-10, fibronectin, $\beta$ and $\gamma$ actin (Fernandez-Pol, Hamilton et al. 1989; Ranganathan and Getz 1990; Freytag, Wilkins-Port et al. 2009). As well as at the level of transcription, synergism between EGF and TGF- $\beta$ was reported at the level of RNA turnover for Leukemia-inhibitory factor (LIF), a conclusion based on an observed increase in LIF mRNA with no regulation of transcription (Schluns, Cook et al. 1997). The COX2 protein was found synergistically induced by EGF and TGF- $\beta$ in Mv1Lu cells (Saha, Datta et al. 1999). But, because we observed no synergism in the regulation of cox2 mRNA, COX2 expression may be regulated at a post-transcriptional event such as translation.

Our results, reported here and previously, show that EGF and TGF- $\beta$ synergistically increase PAI-1 protein (Thalacker and Nilsen-Hamilton 1987) and mRNA expression by an order of magnitude over the effect of either growth factor alone and by almost two orders of 
magnitude over that of untreated cells. Here we show that this cooperation in signaling is due to a combination of changes in the cell that include 1) a synergistic increase in transcription that involves AP-1 and Smad, 2) stabilization of PAI-1 mRNA level by EGF, 3) sensitization of EGF signaling by TGF- $\beta$, and 4) a rapidly turning over protein that is uniquely involved in the synergistic response.

Compared with the expected increase due to the sum of responses due to treatment with EGF or TGF- $\beta$ alone, the combination of the two growth factors resulted in about four times the expected level of PAI-1 mRNA. Nuclear run on assays showed that this increase results in part from a synergistic increase in transcriptional activity of the PAI-1 gene giving a twofold increase above the expected sum of effects of the two growth factors. The large increase in PAI-1 expression due to transcription is further amplified by stabilization of PAI-1 mRNA by EGF. The PAI-1 mRNA half-life has been estimated in a variety of cells to be $25 \mathrm{~min}$ in Mv1Lu cells (Chuang, Hamilton et al. 1995), 1-2 h in normal human lung cells (Shetty and Idell 2000), 8-12 $\mathrm{h}$ in a variety of lung cancer cell lines (Shetty and Idell 2000), and $4 \mathrm{~h}$ in rat hepatoma cells (Heaton, Tillmann-Bogush et al. 1998). This variation in reported half-life might be a consequence of the fact that PAI-1 mRNA stability is regulated by a number of conditions, including growth factors that might regulate PAI-1 mRNA turnover in an autocrine fashion (Fattal, Schneider et al. 1992; Sandberg, Eriksson et al. 1997; Heaton, Tillmann-Bogush et al. 1998; Nordt, Lutzi et al. 2001; Devaraj, Xu et al. 2003; Norata, Banfi et al. 2004). However, it may also be the result of the means of measuring PAI-1 mRNA stability because it is stabilized by the presence of actinomycin D, which was used in many of these studies to inhibit transcription (Bosma and Kooistra 1991; Chuang, Hamilton et al. 1995). Contrary to the observation with transcription, EGF and TGF $\beta$ do not cooperate to 
regulate PAI-1 mRNA stability. This effect is entirely due to EGF, which has been reported to stabilize many mRNAs, including those encoding $\beta$-tubulin, the EGF receptor, p21/CIP1, cyclin D1, TGF $\alpha$, amphiregulin (AR), IL-1 $\alpha$, IL-1 $\beta$ and IL-6 LIF, TGF- $\beta$ RII and gastrin (Jinno, Merlino et al. 1988; Le, Lazorick et al. 1991; Schluns, Cook et al. 1997; Johannessen, Knardal et al. 1999; Stoll and Elder 1999; Dufourny, van Teeffelen et al. 2000; Watanabe, Kurabayashi et al. 2001; Song, Song et al. 2006; Lee, Liao et al. 2007).

Because PAI-1 mRNA is rapidly degraded, the regulation of its half-life can have a large impact on PAI-1 expression (Shapiro, Blume et al. 1987). The combination of a small increase in PAI-1 expression in response to EGF alone and the sole effect of EGF on PAI-1 mRNA turnover results in a significant impact of RNA turnover to the synergistic response to the combination of TGF- $\beta$ and EGF. The observed 2-fold synergism in transcriptional activity of the PAI-1 gene combined with the 2-fold increase in stability of PAI-1 mRNA due to EGF calculates to about a 4-fold synergism between EGF and TGF- $\beta$. Therefore, we conclude that the cooperative regulation by TGF- $\beta$ and EGF of PAI-1 expression is accomplished by a combination of synergism between TGF- $\beta$ and EGF in activating transcription and stabilization of PAI-1 mRNA by EGF.

Both Mv1Lu and HepG2 cells are epithelial cell types. By contrast, we have not observed synergism between EGF and TGF- $\beta$ in PAI-1 expression in NRK and AKR-2B cells, both fibroblast cell types (data not shown). This observation may be relevant because PAI-1 plays an important role in the epithelial to mesenchymal transition (EMT) by modulating cell motility and facilitating conversion to an invasive phenotype, perhaps by modifying the cells' environment (Wilkins-Port, Higgins et al. 2007; Freytag, Wilkins-Port et 
al.). PAI-1 and MMPs are synergistically induced by EGF and TGF- $\beta$ during EMT and, as for the studies described here, MAPK signaling is required for the response and could be the point of interaction of EGF and TGF- $\beta$ (Grande, Franzen et al. 2002; Uttamsingh, Bao et al. 2008; Wilkins-Port, Ye et al. 2009).

By activating Mek1 EGF initiates the phosphorylation of Smad2 at its C-terminus to activate Smad-mediated transcription (de Caestecker, Parks et al. 1998). We showed that inhibition of Mek1/2 results in loss of the synergistic effect on PAI-1 regulation of EGF and TGF- $\beta$, which suggests the MAPK pathway contributes to the synergistic regulation. Consistent with this conclusion is our observation that other agents that stimulate the MAPK pathway, including IGF-I (Schmidmaier, Wildemann et al. 2003), FGF-2 (Stern, Lin-Jones et al.1997), TNFa (Schulz and Bauer 2000) and PMA (Hewson, Edbrooke et al. 2004), also stimulated PAI-1 expression synergistically with TGF- $\beta$. However, Erk1/2, the major target of Mek phosphorylation was not synergistically phosphorylated. This suggests that Mek is required for the synergism to occur, but is not downstream from the synergistic event.

TGF- $\beta$ increases the sensitivity to EGF of the PAI-1 response such that a 10 -fold lower EGF concentration produces half maximal PAI-1 induction in the presence of TGF- $\beta$ compared with in its absence. By contrast, EGF did not affect the sensitivity of the cells to TGF- $\beta$. The increase in sensitivity to EGF may allow cells to utilize the synergistic mechanism that produce small quantities of EGF or that are in an environment containing low concentrations of EGF. This effect of TGF- $\beta$ is most likely not mediated by a change in the affinity of the EGF receptor for its ligand, which has been reported not to be influenced by TGF- $\beta$ in Mv1Lu cells (Ranganathan and Getz 1990). Although the increased sensitivity 
to EGF does not contribute to the synergism between EGF and TGF- $\beta$ on PAI-1 expression, its outcome is to make it more likely for cells to respond to EGF in their environment. Thus, when TGF- $\beta$ activates PAI-1 expression in the absence of concurrently added EGF, it might still act synergistically with low levels of EGF in the environment, which it recruits to promote PAI-1 expression by increasing the cell's sensitivity to EGF. This may explain why PAI-1 does not appear to be regulated synergistically by EGF and TGF- $\beta$ in some cells that might synthesize enough EGF or other growth factor to prime the synergistic mechanism in an autocrine fashion such that only TGF- $\beta$ is required to complete the synergistic signal. Modulating the efficiency of signaling of a growth factor with which it acts synergistically is a very effective way for a single growth factor to achieve a large change in gene expression. By this means, the newly arrived single growth factor sensitizes the cells to pick up a signal from a growth factor that is already present in the environment (but at concentrations normally too low to signal) that then provides a synergistic boost to the newly arrived growth factor's signal. Our observation of the effect of TGF- $\beta$ on EGF receptor sensitivity suggests that many cases of synergistic interaction between TGF- $\beta$ and EGF may be missed due to the presence in the serum or the secretion by cultured cells of low concentrations of growth factors that can act in an autocrine manner with a receptor sensitized by the action of TGF- $\beta$.

The target of the cooperation between EGF and TGF- $\beta$ seems to be the interaction of AP1 and Smad. Cooperative interactions between AP-1 and Smads have been shown with several constructed promoters and for endogenous PAI-1 expression (Zhang, Feng et al. 1998; Verrecchia, Vindevoghel et al. 2001). In these studies we found that the $3 \mathrm{TP}$ promoter construct that contains both AP-1 and Smad binding elements is synergistically regulated to the same extent as PAI-1 transcription. Curcumin, an inhibitor or AP-1 activity and a 
dominant negative Fos both independently decrease synergism on the synthetic promoter with both AP-1 and also inhibit expression of the endogenous gene. Neither transcription factor is more highly phosphorylated in cells treated with EGF and TGF- $\beta$ compared with cells treated with a single growth factor. In combination with the results of MEK and p38 inhibition, this suggests that phosphorylation is required for transcription factor activation, but synergism involves another mechanism. These results suggest that the EGF and TGF- $\beta$ pathways meet and act synergistically to increase transcriptional activity that involves the interaction of Smads and AP-1. The mechanism does not involve an increased activation of either transcription factor by phosphorylation but more likely involves enhanced interaction between the transcription factors or increased efficiency of their combined action.

If the pathways by which EGF and TGF- $\beta$ stimulate PAI-1 transcription ultimately converge on the same event, such as to activate a protein kinase or a transcription factor, synergism might occur at concentrations of each that are below saturating for the targeted response. But, once one growth factor is present at saturating concentrations and has thus fully activated the target event, the other growth factor might be expected to have no further stimulatory effect because all target enzymes/proteins would be activated to their maximum. If such were true, the synergism between EGF and TGF- $\beta$ should be observed only when the two growth factors are present at below saturating concentrations and not once either growth factor is present at a saturating concentration. Such is the case for the synergism between EGF and insulin in stimulating S6 phosphorylation (Nilsen-Hamilton, Hamilton et al. 1982). We examined the possibility that the cooperation between EGF and TGF- $\beta$ might be similarly lost at saturating concentrations of both growth factors. However, this was not true and synergism is observed when either or both growth factors are present at saturating 
concentrations. This observation suggests that the combination of the two growth factors results in a signal that is different from those initiated by either growth factor alone.

The involvement of an additional signal that depends on both growth factors is consistent with the published observation that, although recombinant the combined expression of recombinant Smad and AP-1 results in increased promoter activity, this activity is further increased in cells activated by TGF- $\beta$ (Zhang, Feng et al. 1998). Our study, which shows a rapidly turning over protein implicated in synergism, also shows that the decay of PAI-1 expression in the presence of either growth factor is biphasic with a rapid and a slower phase. The results suggest that the cell contains a limiting amount of the rapidly turning over protein that promotes PAI-1 expression in the presence of either growth factor, but that the combination of both growth factors activates this protein or promotes its movement into the nucleus where it can interact with Smad and AP-1 to enhance their combined activity.

Proteins that might be involved in mediating the synergism are CBP which is a coactivator of the Smads and AP-1 (Kamei, Xu et al. 1996; Feng, Zhang et al. 1998; Janknecht, Wells et al. 1998) and its associated protein PCAF, an acetyltransferase with a $2 \mathrm{~h}$ half-life that is regulated by ubiquitination (Jin, Zeng et al. 2004). CBP or its paralog p300 and PCAF have been identified as involved in TGF- $\beta$ signaling and the regulation of several genes. For synergism to occur at saturating concentrations of each growth factor, TGF- $\beta$ and EGF must regulate different functions that together give more activity than can be achieved by a maximum signal from either growth factor. For example, in vitro analysis of the mechanism by which MyoD is activated by a combination of p300 and PCAF showed that p300 acetylates histones $\mathrm{H} 3$ and $\mathrm{H} 4$ and then recruits PCAF to myoD whereupon PCAF 
acetylates myoD and activates transcription (Dilworth, Seaver et al. 2004). We propose a related mechanism to explain the synergism between EGF-TGF- $\beta$ in which EGF-initiated Erk or p38 phosphorylate CBP, which promotes its recruitment of AP-1 (Janknecht and Nordheim 1996; Zanger, Radovick et al. 2001). The CBP then recruits PCAF, which acetylates Smad thus promoting its association with the promoter (Tu and Luo 2007). In this model, the synergism arises from the cooperative interaction on the promoter of two transcription factors that are recruited by different mechanisms; AP-1 recruited by CBP (activated by Erk1/2) and Smad (activated by TGF-beta RII) recruited by PCAF which in turn is recruited by CBP. All the features in this model have been demonstrated to occur on other promoters, but have yet to be demonstrated as the mechanistic basis for synergism between EGF and TGF- $\beta$ in regulating PAI-1.

In summary, we have shown that TGF $\beta$ and EGF synergistically increase PAI-1 expression at the level of transcription. EGF adds to the effect by stabilizing the PAI-1 mRNA and TGF- $\beta$ increases the sensitivity of the cells to EGF by an order of magnitude. The results demonstrate a multidimensional cooperation between growth factors that involves a combination of regulations by one or both growth factors at transcription and mRNA degradation that enables a rapid response in gene expression of two orders of magnitude over the control levels. Expression is also rapidly cut off due to the short half-life of the mRNA, which is regulated by mechanisms different from those that promote transcriptional activation of the gene. In the presence of signals from both growth factors a different mechanism for gene regulation is in place than in the presence of either growth factor alone. In addition, TGF- $\beta$ alone can recruit suboptimal concentrations of EGF into the synergistic mechanism by increasing the sensitivity of the cells to the EGF signal. One or more of these 
regulatory mechanisms are also likely to control the expression of other genes whose products act in concert with the plasminogen activator cascade. Such combined mechanisms of regulation may be how the local and systemic concentrations of PAI-1 are so closely controlled in vivo so as to appropriately regulate the level of plasminogen activator activity and plasmin production. Increased PAI-1 expression has been identified as one of the events responsible for increasing epithelial cell motility during the epithelial mesenchymal transition, a process that is linked to cancer progression. 


\section{References}

Bajou, K., V. Masson, et al. (2001). "The plasminogen activator inhibitor PAl-1 controls in vivo tumor vascularization by interaction with proteases, not vitronectin. Implications for antiangiogenic strategies." J Cell Biol 152(4): 777-84.

Bosma, P. J. and T. Kooistra (1991). "Different induction of two plasminogen activator inhibitor 1 mRNA species by phorbol ester in human hepatoma cells." J Biol Chem 266(27): 17845-9.

Buckova, D., L. Izakovicova Holla, et al. (2002). "Polymorphism 4G/5G in the plasminogen activator inhibitor-1 (PAl-1) gene is associated with IgE-mediated allergic diseases and asthma in the Czech population." Allergy 57(5): 446-8.

Burzotta, F., L. lacoviello, et al. (2003). "4G/5G PAl-1 promoter polymorphism and acutephase levels of PAl-1 following coronary bypass surgery: a prospective study." $\underline{\mathrm{J}}$ Thromb Thrombolysis 16(3): 149-54.

Chirgwin, J. M., A. E. Przybyla, et al. (1979). "Isolation of biologically active ribonucleic acid from sources enriched in ribonuclease." Biochemistry 18(24): 5294-9.

Chuang, T. H., R. T. Hamilton, et al. (1995). "Cloning of the mink plasminogen activator inhibitor type-1 messenger RNA: an mRNA with a short half life." Gene 162(2): 303-8.

Colucci, M., J. A. Paramo, et al. (1985). "Generation in plasma of a fast-acting inhibitor of plasminogen activator in response to endotoxin stimulation." J Clin Invest 75(3): 81824.

D'Angelo, A., C. Kluft, et al. (1985). "Fibrinolytic shut-down after surgery: impairment of the balance between tissue-type plasminogen activator and its specific inhibitor." Eur $\mathrm{J}$ Clin Invest 15(6): 308-12.

de Caestecker, M. P., W. T. Parks, et al. (1998). "Smad2 transduces common signals from receptor serine-threonine and tyrosine kinases." Genes Dev 12(11): 1587-92.

Dellas, C. and D. J. Loskutoff (2005). "Historical analysis of PAl-1 from its discovery to its potential role in cell motility and disease." Thromb Haemost 93(4): 631-40.

Devaraj, S., D. Y. Xu, et al. (2003). "C-reactive protein increases plasminogen activator inhibitor-1 expression and activity in human aortic endothelial cells: implications for the metabolic syndrome and atherothrombosis." Circulation 107(3): 398-404.

Dilworth, F. J., K. J. Seaver, et al. (2004). "In vitro transcription system delineates the distinct roles of the coactivators pCAF and p300 during MyoD/E47-dependent transactivation." Proc Natl Acad Sci U S A 101(32): 11593-8. 
Dolken, L., Z. Ruzsics, et al. (2008). "High-resolution gene expression profiling for simultaneous kinetic parameter analysis of RNA synthesis and decay." RNA 14(9): 1959-72.

Dufourny, B., H. A. van Teeffelen, et al. (2000). "Stabilization of cyclin D1 mRNA via the phosphatidylinositol 3-kinase pathway in MCF-7 human breast cancer cells." $\underline{J}$ Endocrinol 166(2): 329-38.

Fattal, P. G., D. J. Schneider, et al. (1992). "Post-transcriptional regulation of expression of plasminogen activator inhibitor type 1 mRNA by insulin and insulin-like growth factor 1." J Biol Chem 267(18): 12412-5.

Feng, X. H., Y. Zhang, et al. (1998). "The tumor suppressor Smad4/DPC4 and transcriptional adaptor CBP/p300 are coactivators for smad3 in TGF-beta-induced transcriptional activation." Genes Dev 12(14): 2153-63.

Fernandez-Pol, J. A., P. D. Hamilton, et al. (1989). "Transcriptional regulation of protooncogene expression by epidermal growth factor, transforming growth factor beta 1 , and triiodothyronine in MDA-468 cells." J Biol Chem 264(7): 4151-6.

Freytag, J., C. E. Wilkins-Port, et al. (2009). "PAl-1 Regulates the Invasive Phenotype in Human Cutaneous Squamous Cell Carcinoma." J Oncol 2009: 963209.

Fuke, M., K. J. Dennis, et al. (1981). "Characterization of cloned rat ribosomal DNA fragments." Mol Gen Genet 182(1): 25-30.

Grande, M., A. Franzen, et al. (2002). "Transforming growth factor-beta and epidermal growth factor synergistically stimulate epithelial to mesenchymal transition (EMT) through a MEK-dependent mechanism in primary cultured pig thyrocytes." $\underline{\mathrm{J} \text { Cell Sci }}$ 115(Pt 22): 4227-36.

Haggroth, L., C. Mattsson, et al. (1986). "Plasminogen activator inhibitors in plasma and platelets from patients with recurrent venous thrombosis and pregnant women." Thromb Res 42(5): 585-94.

Heaton, J. H., M. Tillmann-Bogush, et al. (1998). "Cyclic nucleotide regulation of type-1 plasminogen activator-inhibitor mRNA stability in rat hepatoma cells. Identification of cis-acting sequences." J Biol Chem 273(23): 14261-8.

Hekman, C. M. and D. J. Loskutoff (1988). "Kinetic analysis of the interactions between plasminogen activator inhibitor 1 and both urokinase and tissue plasminogen activator." Arch Biochem Biophys 262(1): 199-210.

Hewson, C. A., M. R. Edbrooke, et al. (2004). "PMA induces the MUC5AC respiratory mucin in human bronchial epithelial cells, via PKC, EGF/TGF-alpha, Ras/Raf, MEK, ERK and Sp1-dependent mechanisms." J Mol Biol 344(3): 683-95. 
Higgins, P. J. (2006). "The TGF-beta1/Upstream Stimulatory Factor-Regulated PAI-1 Gene: Potential Involvement and a Therapeutic Target in Alzheimer's Disease." $\underline{\mathrm{J} \text { Biomed }}$ Biotechnol 2006(3): 15792.

Hopkins, W. E., D. R. Westerhausen, et al. (1991). "Mediators of induction of augmented expression of plasminogen activator inhibitor type-1 in Hep G2 cells by platelets." Thromb Haemost 66(2): 239-45.

Janknecht, R. and A. Nordheim (1996). "MAP kinase-dependent transcriptional coactivation by Elk-1 and its cofactor CBP." Biochem Biophys Res Commun 228(3): 831-7.

Janknecht, R., N. J. Wells, et al. (1998). "TGF-beta-stimulated cooperation of smad proteins with the coactivators CBP/p300." Genes Dev 12(14): 2114-9.

Jin, Y., S. X. Zeng, et al. (2004). "MDM2 mediates p300/CREB-binding protein-associated factor ubiquitination and degradation." J Biol Chem 279(19): 20035-43.

Jinno, Y., G. T. Merlino, et al. (1988). "A novel effect of EGF on mRNA stability." Nucleic Acids Res 16(11): 4957-66.

Johannessen, L. E., S. L. Knardal, et al. (1999). "Epidermal growth factor increases the level of the cyclin-dependent kinase (CDK) inhibitor p21/CIP1 (CDK-interacting protein 1) in A431 cells by increasing the half-lives of the p21/CIP1 transcript and the p21/CIP1 protein." Biochem J 337 ( Pt 3): 599-606.

Kamei, Y., L. Xu, et al. (1996). "A CBP integrator complex mediates transcriptional activation and AP-1 inhibition by nuclear receptors." Cell 85(3): 403-14.

Kluft, C., J. H. Verheijen, et al. (1985). "The postoperative fibrinolytic shutdown: a rapidly reverting acute phase pattern for the fast-acting inhibitor of tissue-type plasminogen activator after trauma." Scand J Clin Lab Invest 45(7): 605-10.

Kruithof, E. K., A. Gudinchet, et al. (1988). "Plasminogen activator inhibitor 1 and plasminogen activator inhibitor 2 in various disease states." Thromb Haemost 59(1): 7-12.

Kutz, S. M., J. Hordines, et al. (2001). "TGF-beta1-induced PAI-1 gene expression requires MEK activity and cell-to-substrate adhesion." J Cell Sci 114(Pt 21): 3905-14.

Labbe, E., C. Silvestri, et al. (1998). "Smad2 and Smad3 positively and negatively regulate TGF beta-dependent transcription through the forkhead DNA-binding protein FAST2." Mol Cell 2(1): 109-20.

Landin, K., L. Tengborn, et al. (1991). "The acute effect of insulin on tissue plasminogen activator and plasminogen activator inhibitor in man." Thromb Haemost 65(2): 130-3.

Le, P. T., S. Lazorick, et al. (1991). "Regulation of cytokine production in the human thymus: epidermal growth factor and transforming growth factor alpha regulate mRNA levels 
of interleukin 1 alpha (IL-1 alpha), IL-1 beta, and IL- 6 in human thymic epithelial cells

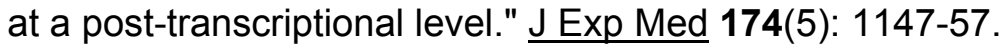

Lee, P. T., P. C. Liao, et al. (2007). "Epidermal growth factor increases the interaction between nucleolin and heterogeneous nuclear ribonucleoprotein $\mathrm{K} / \mathrm{poly}(\mathrm{C})$ binding protein 1 complex to regulate the gastrin mRNA turnover." Mol Biol Cell 18(12): 5004-13.

Loskutoff, D. J., S. A. Curriden, et al. (1999). "Regulation of cell adhesion by PAI-1." APMIS 107(1): 54-61.

Loskutoff, D. J., M. Sawdey, et al. (1989). "Type 1 plasminogen activator inhibitor." Prog Hemost Thromb 9: 87-115.

Mottonen, J., A. Strand, et al. (1992). "Structural basis of latency in plasminogen activator inhibitor-1." Nature 355(6357): 270-3.

Nakabeppu, Y. and D. Nathans (1991). "A naturally occurring truncated form of FosB that inhibits Fos/Jun transcriptional activity." Cell 64(4): 751-9.

Nilsen-Hamilton, M., R. T. Hamilton, et al. (1982). "Synergistic stimulation of S6 ribosomal protein phosphorylation and DNA synthesis by epidermal growth factor and insulin in quiescent 3T3 cells." Cell 31(1): 237-42.

Nilsen-Hamilton, M. and R. W. Holley (1983). "Rapid selective effects by a growth inhibitor and epidermal growth factor on the incorporation of [35S]methionine into proteins secreted by African green monkey (BSC-1) cells." Proc Natl Acad Sci U S A 80(18): 5636-40.

Norata, G. D., C. Banfi, et al. (2004). "Oxidised-HDL3 induces the expression of PAl-1 in human endothelial cells. Role of p38MAPK activation and mRNA stabilization." $\mathrm{Br} \mathrm{J}$ Haematol 127(1): 97-104.

Nordt, T. K., S. Lutzi, et al. (2001). "Attenuation by fibrates of plasminogen activator inhibitor type-1 expression in human arterial smooth muscle cells." Thromb Haemost 86(5): 1305-13.

Okada, H., T. M. Danoff, et al. (1997). "Early role of Fsp1 in epithelial-mesenchymal transformation." Am J Physiol 273(4 Pt 2): F563-74.

Patrone, G., F. Puppo, et al. (2000). "Nuclear run-on assay using biotin labeling, magnetic bead capture and analysis by fluorescence-based RT-PCR." Biotechniques 29(5): 1012-4, 1016-7.

Pedersen, H., N. Brunner, et al. (1994). "Prognostic impact of urokinase, urokinase receptor, and type 1 plasminogen activator inhibitor in squamous and large cell lung cancer tissue." Cancer Res 54(17): 4671-5. 
Pedersen, H., J. Grondahl-Hansen, et al. (1994). "Urokinase and plasminogen activator inhibitor type 1 in pulmonary adenocarcinoma." Cancer Res 54(1): 120-3.

Peiretti, F., M. C. Alessi, et al. (1997). "Intracellular calcium mobilization suppresses the TNF-alpha-stimulated synthesis of PAI-1 in human endothelial cells. Indications that calcium acts at a translational level." Arterioscler Thromb Vasc Biol 17(8): 1550-60.

Ranganathan, G. and M. J. Getz (1990). "Cooperative stimulation of specific gene transcription by epidermal growth factor and transforming growth factor type beta 1." J Biol Chem 265(6): 3001-4.

Rheinwald, J. G., J. L. Jorgensen, et al. (1987). "Mesosecrin: a secreted glycoprotein produced in abundance by human mesothelial, endothelial, and kidney epithelial cells in culture." J Cell Biol 104(2): 263-75.

Roberts, A. B., M. A. Anzano, et al. (1985). "Type beta transforming growth factor: a bifunctional regulator of cellular growth." Proc Natl Acad Sci U S A 82(1): 119-23.

Ryan, M. P., S. M. Kutz, et al. (1996). "Complex regulation of plasminogen activator inhibitor type-1 (PAl-1) gene expression by serum and substrate adhesion." Biochem J 314 (Pt 3): 1041-6.

Saha, D., P. K. Datta, et al. (1999). "Synergistic induction of cyclooxygenase-2 by transforming growth factor-beta1 and epidermal growth factor inhibits apoptosis in epithelial cells." Neoplasia 1(6): 508-17.

Salonen, E. M., A. Vaheri, et al. (1989). "Interaction of plasminogen activator inhibitor (PAI-1) with vitronectin." J Biol Chem 264(11): 6339-43.

Sandberg, T., P. Eriksson, et al. (1997). "Differential regulation of the plasminogen activator inhibitor-1 (PAl-1) gene expression by growth factors and progesterone in human endometrial stromal cells." Mol Hum Reprod 3(9): 781-7.

Schluns, K. S., J. E. Cook, et al. (1997). "TGF-beta differentially modulates epidermal growth factor-mediated increases in leukemia-inhibitory factor, IL-6, IL-1 alpha, and IL-1 beta in human thymic epithelial cells." J Immunol 158(6): 2704-12.

Schneider, D. J. and B. E. Sobel (1991). "Augmentation of synthesis of plasminogen activator inhibitor type 1 by insulin and insulin-like growth factor type I: implications for vascular disease in hyperinsulinemic states." Proc Natl Acad Sci U S A 88(22): 9959-63.

Schulz, A. and G. Bauer (2000). "Synergistic action between tumor necrosis factor-alpha and transforming growth factor type-beta: consequences for natural antitumor mechanisms." Anticancer Res 20(5B): 3443-8. 
Seki, T., H. Imai, et al. (1996). "Production of tissue-type plasminogen activator (t-PA) and type-1 plasminogen activator inhibitor (PAI-1) in mildly cirrhotic rat liver." Thromb Haemost 75(5): 801-7.

Shapiro, D. J., J. E. Blume, et al. (1987). "Regulation of messenger RNA stability in eukaryotic cells." Bioessays 6(5): 221-6.

Shetty, S. and S. Idell (2000). "Posttranscriptional regulation of plasminogen activator inhibitor-1 in human lung carcinoma cells in vitro." Am J Physiol Lung Cell Mol Physiol 278(1): L148-56.

Song, J. W., K. S. Song, et al. (2006). "Plasma level of IL-6 and its relationship to procoagulant and fibrinolytic markers in acute ischemic stroke." Yonsei Med J 47(2): 201-6.

Sprengers, E. D. and C. Kluft (1987). "Plasminogen activator inhibitors." Blood 69(2): 381-7.

Stefansson, S. and D. A. Lawrence (1996). "The serpin PAl-1 inhibits cell migration by blocking integrin alpha $\mathrm{V}$ beta 3 binding to vitronectin." Nature 383(6599): 441-3.

Stoll, S. W. and J. T. Elder (1999). "Differential regulation of EGF-like growth factor genes in human keratinocytes." Biochem Biophys Res Commun 265(1): 214-21.

Stolz, D. B. and G. K. Michalopoulos (1997). "Synergistic enhancement of EGF, but not HGF, stimulated hepatocyte motility by TGF-beta 1 in vitro." J Cell Physiol 170(1): 57-68.

Swiercz, R., R. W. Keck, et al. (2001). "Recombinant PAl-1 inhibits angiogenesis and reduces size of LNCaP prostate cancer xenografts in SCID mice." Oncol Rep 8(3): 463-70.

Thalacker, F. W. and M. Nilsen-Hamilton (1987). "Specific induction of secreted proteins by transforming growth factor- beta and 12-O-tetradecanoylphorbol-13-acetate. Relationship with an inhibitor of plasminogen activator." J Biol Chem 262(5): 2283-90.

Thalacker, F. W. and M. Nilsen-Hamilton (1992). "Opposite and independent actions of cyclic AMP and transforming growth factor beta in the regulation of type 1 plasminogen activator inhibitor expression." Biochem J 287 ( Pt 3): 855-62.

Tu, A. W. and K. Luo (2007). "Acetylation of Smad2 by the co-activator p300 regulates

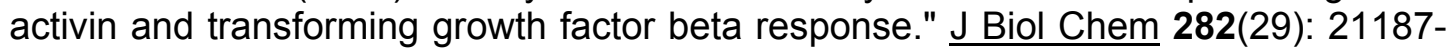
96.

Uttamsingh, S., X. Bao, et al. (2008). "Synergistic effect between EGF and TGF-beta1 in inducing oncogenic properties of intestinal epithelial cells." Oncogene 27(18): 262634. 
van Zonneveld, A. J., S. A. Curriden, et al. (1988). "Type 1 plasminogen activator inhibitor gene: functional analysis and glucocorticoid regulation of its promoter." Proc Natl Acad Sci U S A 85(15): 5525-9.

Verrecchia, F., L. Vindevoghel, et al. (2001). "Smad3/AP-1 interactions control transcriptional responses to TGF-beta in a promoter-specific manner." Oncogene 20(26): 3332-40.

Watanabe, A., M. Kurabayashi, et al. (2001). "Combined effect of retinoic acid and basic FGF on PAl-1 gene expression in vascular smooth muscle cells." Cardiovasc Res 51(1): 151-9.

Wilkins-Port, C. E., C. E. Higgins, et al. (2007). "PAl-1 is a Critical Upstream Regulator of the TGF-beta1/EGF-Induced Invasive Phenotype in Mutant p53 Human Cutaneous Squamous Cell Carcinoma." J Biomed Biotechnol 2007(2): 85208.

Wilkins-Port, C. E., Q. Ye, et al. (2009). "TGF-beta1 + EGF-initiated invasive potential in transformed human keratinocytes is coupled to a plasmin/MMP-10/MMP-1dependent collagen remodeling axis: role for PAI-1." Cancer Res 69(9): 4081-91.

Wrana, J. L., L. Attisano, et al. (1992). "TGF beta signals through a heteromeric protein kinase receptor complex." Cell 71(6): 1003-14.

Zanger, K., S. Radovick, et al. (2001). "CREB binding protein recruitment to the transcription complex requires growth factor-dependent phosphorylation of its GF box." Mol Cell 7(3): 551-8.

Zawel, L., J. L. Dai, et al. (1998). "Human Smad3 and Smad4 are sequence-specific transcription activators." Mol Cell 1(4): 611-7.

Zhang, Y., X. H. Feng, et al. (1998). "Smad3 and Smad4 cooperate with c-Jun/c-Fos to mediate TGF-beta-induced transcription." Nature 394(6696): 909-13.

Zhou, S., L. Zawel, et al. (1998). "Characterization of human FAST-1, a TGF beta and activin signal transducer." Mol Cell 2(1): 121-7.

\section{Footnotes}

We thank Lee Bendickson for contributing towards the data in Figure 1 and Robert Holley and Daniel Rifkin for providing the Mv1Lu cell lines used in these studies. This work was supported in part by NIH grant 1-R01-GM33528.TABLES 


\section{Tables}

Table I. TGF $\beta$ increases the sensitivity of Mv1Lu cells to EGF

\begin{tabular}{|l|l|l|l|}
\hline \multirow{2}{*}{ Growth factor } & \multicolumn{2}{|l|}{$\mathrm{EC}_{50}, \mathbf{n g} / \mathbf{m l}$ (R2 from fit) } & Fold change \\
\cline { 2 - 4 } & $\mathrm{TGF} \beta$ & EGF & \\
\hline $\mathrm{TGF} \beta$ & $1.0(0.73)$ & & \\
\hline $\mathrm{TGF} \beta+\mathrm{EGF}$ & $0.89(0.99)$ & & 1 \\
\hline $\mathrm{EGF}$ & & & \\
\hline $\mathrm{EGF}+\mathrm{TGF} \beta$ & & $2.8(0.79)$ & \\
\hline
\end{tabular}

$\mathrm{EC}_{50}$ of each growth factor was calculated by using the online software BioDatafit 1.02 with four parameter (Hill-slope) model (Chang Bioscience, Inc., Castro Valley, CA; http://www.changbioscience.com/stat/ec50.html) . 
Table II. Synergistic induction of PAI-1 after blocking kinase pathways

\begin{tabular}{|c|c|c|c|c|c|}
\hline Blocking target & Addition & Synergism & Alteration & P-value & $\mathbf{N *}$ \\
\hline \multirow{2}{*}{$\mathrm{MEK} 1 / 2$} & Control (U0124) & $2.5 \pm 0.3$ & \multirow{2}{*}{$-60 \%$} & \multirow{2}{*}{0.09} & \multirow{2}{*}{2} \\
\hline & Inhibitor(U0126) & $1.0 \pm 0.1$ & & & \\
\hline \multirow{2}{*}{ P38 MAPK } & Control SB202474 & $3.0 \pm 0.4$ & \multirow{2}{*}{$-30 \%$} & \multirow{2}{*}{0.08} & \multirow{2}{*}{3} \\
\hline & Inhibitor SB202190 & $2.1 \pm 0.6$ & & & \\
\hline \multirow{4}{*}{$\mathrm{JNK}$} & control & $10.9 \pm 0.9$ & \multirow{2}{*}{$36 \%$} & \multirow{2}{*}{0.27} & \multirow{2}{*}{3} \\
\hline & Inhibitor SP600125 & $14.8 \pm 4.3$ & & & \\
\hline & control & $5.5 \pm 3.0$ & \multirow{2}{*}{$-38 \%$} & \multirow{2}{*}{0.21} & \multirow{2}{*}{3} \\
\hline & Dn-JNK & $3.4 \pm 1.2$ & & & \\
\hline \multirow{2}{*}{ SRC } & Inhibitor PP2 & $2.9 \pm 0.2$ & \multirow{2}{*}{$21 \%$} & \multirow{2}{*}{0.07} & \multirow{2}{*}{3} \\
\hline & Control pp3 & $3.5 \pm 0.3$ & & & \\
\hline \multirow{2}{*}{$\mathrm{PI} 3 \mathrm{~K}$} & Inhibitor LY294002 & $5.2 \pm 1.5$ & \multirow{2}{*}{$23 \%$} & \multirow{2}{*}{0.30} & \multirow{2}{*}{2} \\
\hline & Control LY303511 & $6.4 \pm 0.1$ & & & \\
\hline
\end{tabular}

Synergism is calculated as: Synergism $=T E$ net effect $/(T$ net effect $+E$ net effect $)$. The data is represented as mean \pm sem. $\mathrm{N}$ : the number of experiments. 
Table III. Effect of AP-1 suppression on the synergistic effect of EGF and TGF- $\beta$

\begin{tabular}{|c|c|c|c|c|c|}
\hline $\begin{array}{c}\text { Blocking } \\
\text { target }\end{array}$ & Addition & Synergism & Alteration & P-value & $\mathbf{N *}$ \\
\hline \multirow{2}{*}{$3 \mathrm{TP}$} & Control & $2.5 \pm 0.4$ & \multirow{2}{*}{$-44 \%$} & \multirow{2}{*}{0.02} & \multirow{2}{*}{5} \\
\hline & Inhibitor (Curcumin) & $1.4 \pm 0.3$ & & & \\
\hline \multirow{2}{*}{$3 \mathrm{TP}$} & Control & $2.5 \pm 0.5$ & \multirow{2}{*}{$-36 \%$} & \multirow{2}{*}{0.03} & \multirow{2}{*}{5} \\
\hline & Dn-Fos & $1.6 \pm 0.4$ & & & \\
\hline \multirow{2}{*}{$\begin{array}{l}\text { PAI-1 } \\
\text { mRNA }\end{array}$} & Control & $3.7 \pm 1.0$ & \multirow{2}{*}{$-36 \%$} & \multirow{2}{*}{0.06} & \multirow{2}{*}{3} \\
\hline & Dn-Fos & $2.4 \pm 0.7$ & & & \\
\hline
\end{tabular}

Synergism is calculated as: Synergism $=$ TE net effect $/(T$ net effect + E net effect $)$. The data is represented as mean \pm sem. $\mathrm{N}$ : the number of experiments. 


\section{Supplementary Table}

\begin{tabular}{|c|c|c|c|c|}
\hline Cell line & & gene & Synergism & $\mathrm{N}^{*}$ \\
\hline \multirow{3}{*}{$\begin{array}{l}\text { Mv1Lu } \\
\text { (CCL64) }\end{array}$} & \multirow{3}{*}{ Mink lung epithelial cells } & PAI-1 & $4.5 \pm 0.9$ & 11 \\
\hline & & uPAR & $0.4 \pm 0.8$ & 4 \\
\hline & & $\mathrm{COX} 2$ & $0.3 \pm 0.3$ & 3 \\
\hline MLEC & stably transfected Mv1Lu cells & PAI-1 & $1.7 \pm 0.1$ & 3 \\
\hline \multirow{3}{*}{ HepG2 } & \multirow{3}{*}{ Human heptoblasma } & PAI-1 & $3.4 \pm 0.3$ & 2 \\
\hline & & uPAR & $2.1 \pm 1.9$ & 2 \\
\hline & & uPA & $2.0 \pm 0.1$ & 2 \\
\hline \multirow{3}{*}{ ЕpH4 } & \multirow{3}{*}{$\begin{array}{c}\text { mouse mammary gland } \\
\text { epithelial cells }\end{array}$} & PAI-1 & $1.2 \pm 0.5$ & 4 \\
\hline & & uPAR & $0.9 \pm 0.3$ & 4 \\
\hline & & uPA & $1.4 \pm 0.9$ & 4 \\
\hline HaCaT II-4 ${ }^{\#}$ & $\begin{array}{l}\text { transformed human } \\
\text { keratinocytes }\end{array}$ & PAI-1 & $\sim 4$ & \\
\hline $\mathrm{BSC}-1 * *$ & monkey kidney epithelial cells & PAI-1 & No synergism & \\
\hline AKR-2B & \multirow{2}{*}{ mouse embryo fibroblasts } & \multirow{2}{*}{ PAI-1 } & \multirow{2}{*}{ No synergism } & \\
\hline $84 A^{* *}$ & & & & \\
\hline NRK** & normal rat kidney fibroblasts & PAI-1 & No synergism & \\
\hline
\end{tabular}

\section{Supplementary Table I. Effect of EGF and TGF- $\beta$ on gene induction in various cell}

lines. *N: number of independent experiments. ${ }^{* *}$ Observations regarding synergism were also made in previously published work for Mv1Lu, BSC-1, AKR-2B, and NRK cells (Nilsen-Hamilton and Holley 1983; Thalacker and Nilsen-Hamilton 1992). \# Results reported in (Wilkins-Port, Ye et al. 2009). 


\section{Figures Legends}

Figure 1. Synergistic regulation of PAI-1 protein and mRNA in mink and human cells. A) top panels: Synergistic regulation of PAI-1 protein production. PAI-1 protein production in mink Mv1Lu and human HepG2 cells was established by labeling with a $4 \mathrm{~h}$

pulse of ${ }^{35} \mathrm{~S}$-methionine or ${ }^{35} \mathrm{~S}$-Trans-label after incubating Mv1Lu cells for $2 \mathrm{~h}$ or HepG2 for $8 \mathrm{~h}$ with growth factors. The amount of radiolabeled PAI-1 in the medium (Mv1Lu) or after immunoprecipitation with PAI-1 antiserum. (HepG2) is shown after resolution by SDSPAGE. Bottom panel: The effects of EGF and TGF- $\beta$ on PAI-1 synthesis in Mv1Lu cells were quantified by scanning the identified bands (PAI-1 and 38kDa) in the gel shown in the top left panel $(\mathrm{Mv} 1 \mathrm{Lu})$ and normalizing these values to the total ${ }^{35} \mathrm{~S}-\mathrm{cpm}$ loaded onto the gel for each sample. Duplicate independent samples were tested and the average results with standard errors are shown. B,C) Synergistic regulation of PAI-1 mRNA. Cells were treated for $2 \mathrm{~h}$ with $5 \mathrm{ng} / \mathrm{ml} \mathrm{EGF,} 1 \mathrm{ng} / \mathrm{ml}$ TGF- $\beta$ or the combination of EGF and TGF- $\beta$ at the same concentrations. PAI- 1 , uPAR, COX2 and uPA mRNAs were quantified by RTqPCR for Mv1Lu (upper panels) and HepG2 (lower panels). The inset in the top left panel shows a Northern blot of PAI-1 (open arrow) and 18S RNA (filled arrow) in Mv1Lu cells. Each experiment was performed 11 times for PAI-1, four times for UPAR and three times for COX-2 in Mv1Lu cells and twice for PAI-1, uPAR and uPA in HepG2 cells. The northern blot experiment was performed twice. -, vehicle control; E, EGF; T, TGF- $\beta$; TE, TGF- $\beta$ and EGF. ${ }^{*}: \mathrm{p}<0.05 ; * *: \mathrm{p}<0.01 ; * * *: \mathrm{p}<0.001$.

Figure 2. Synergism is observed at saturating concentrations of both growth factors. A) PAI-1 mRNA induction by EGF ( 0.08 to $100 \mathrm{ng} / \mathrm{ml})$ either alone or in combination with 1 ng/ml TGF- $\beta$ for two hours in Mv1Lu cells. B) PAI-1 mRNA induction by TGF- $\beta$ ( 0.0016 
to $25 \mathrm{ng} / \mathrm{ml}$ ), either alone or in combination with $5 \mathrm{ng} / \mathrm{ml} \mathrm{EGF}$ for $2 \mathrm{~h}$ in Mv1Lu cells. PAI-1 mRNA was quantified by RT-qPCR and normalized to the GAPDH values in the same samples. In both panels the lines show the result of a nonlinear fit of each data set.

Figure 4. MAPK is involved in the synergism. A-E) Effect of blocking specific pathways by kinase inhibitors. Cells were treated for $1 \mathrm{~h}$ with inhibitors (or control analogs) prior to two hours growth factors treatment and PAI-1 mRNA was measured with RT-qPCR. Empty bars: control analogs; filled bars: inhibitor. F) No synergism in phosphorylation of Erk1/2. Cells were treated for $1 \mathrm{~h}$ with $20 \mu \mathrm{M} \mathrm{MEK}$ inhibitor U0126 or its inactive analog U0124 then for10 min with $1 \mathrm{ng} / \mathrm{ml}$ TGF $\beta, 5 \mathrm{ng} / \mathrm{ml}$ EGF or their combination. The phosphorylation of Erk1/2 was determined by western blot. -: vehicle control, T: TGF- $\beta$, TE: EGF and TGF- $\beta . *: p<0.05 ; * *: \mathrm{p}<0.01 ; * * *: \mathrm{p}<0.001$

Figure 5. EGF, but not TGF- $\beta$, increases the half life of PAI-1 mRNA. Mv1Lu cells cultured in DME medium with $0.2 \%$ calf serum were incubated for $2 \mathrm{~h}$ with $1 \mathrm{ng} / \mathrm{ml}$ TGF $\beta$ and $5 \mathrm{ng} / \mathrm{ml}$ EGF or their combination. Coredycepin $(15 \mu \mathrm{g} / \mathrm{ml})$ was then added (set as zero time) to block transcription. Total RNA was isolated at the indicated times and PAI-1 mRNA was quantified by RT-qPCR and normalized to the GAPDH values in the same samples. The results are from at least five independent experiments. The half life of PAI-1 mRNA in TGF- $\beta$-treated cells was calculated to be 36 min (regression coefficient from a least squares analysis $=0.90$ ) and that in EGF-treated cells as $53 \mathrm{~min}$ (regression coefficient $=0.90$ ). The half life of PAI- 1 mRNA in TGF- $\beta$ plus EGF treated cells is 58 min (regression coefficient $=0.80)$. When tested by using analysis of covariance (JMP 7.0) the difference between treatment with TGF- $\beta$ alone and treatment with the combination of EGF and TGF- $\beta$ 
was significant to the level of $p<0.05$. Figure 6. A, C) EGF and TGF- $\beta$ cooperate to increase PAI-1 transcription. Cells were treated for $2 \mathrm{~h}$ with $5 \mathrm{ng} / \mathrm{ml} \mathrm{EGF}, 1 \mathrm{ng} / \mathrm{ml}$ TGF- $\beta$ or their combination. Newly transcribed PAI-1 mRNA (A) and total mRNA (B) were quantified by the nuclear run-on assay. Shown are the average results with the SEM from two independent experiments. C,D) The synergistic mechanism is activated soon after growth factor addition Cells were treated with EGF and TGF- $\beta$ or their combination for various time periods then $4 \mathrm{SU}$ was added for the last 15 min of each incubation. Newly synthesized (C) and total (D) RNAs were isolated and quantified for PAI-1 and GAPDH by RT-qPCR. -, vehicle control; E, EGF; T, TGF- $\beta$; TE, TGF- $\beta$ and EGF. *: $\mathrm{p}<0.05 ;{ }^{*}$ : $\mathrm{p}<0.01$; $\mathrm{p}<0.001$.

Figure 7. The phosphorylation and activities of Smads are not synergistically regulated by EGF and TGF- $\beta$. A No synergism on Smad2/3 phosphorylation. Cells were treated with growth factors for $45 \mathrm{~min}$. Western blots showing the phosphorylation of Smad $2 / 3$ compared with $\beta$-actin in the same samples. B,C): Transcriptional activities mediated by Smad (pSBE4) or Smad plus FAST-1 (p3ARE) in cells stimulated with growth factors. Cells were transiently transfected with luciferase reporters for $17 \mathrm{~h}$ then incubated for $6 \mathrm{~h}$ with growth factors -: vehicle control, E: EGF, T: TGF- $\beta$, TE: EGF and TGFß. ${ }^{*}: \mathrm{p}<0.05 ; * *: \mathrm{p}<0.01 ; * *: \mathrm{p}<0.001$

Figure 8. AP-1 is involved in the synergism between EGF and TGF- $\beta$. A: Transcriptional activities mediated by Smad2/3 and AP-1 respond synergistically to EGF and TGF- $\beta$. Cells were transiently transfected with the 3TP luciferase reporter for $17 \mathrm{~h}$ then for $6 \mathrm{~h}$ with growth factors $\mathbf{B}, \mathrm{C}$ : Synergism is inhibited by curcumin and $\Delta$ FosB. 
Cells were transiently transfected with $3 \mathrm{TP}$ with and without $\Delta \mathrm{FosB}$ for $17 \mathrm{~h}$ then for $6 \mathrm{~h}$ with growth factors with or without $20 \mu \mathrm{M}$ curcumin added $1 \mathrm{~h}$ prior D: Curcumin has no effect on Smad activity. Cells were transfected with pSBE4 and treated with curcumin and growth factors. Promoter activities were measured with luciferase asay. E: No synergism on phosphorylation of Fos and Jun. Cells were treated with growth factors for $40 \mathrm{~min}$. Antibodies against phosphorylated Fos at ser32, ser362 \& Thr232 were used to detect Fos phosphorylation and antibodies against phosphorylated c-Jun at ser 63 and ser73 was used to detect c-Jun phosphorylation. Western blots showing the phosphorylation of Fos and Jun in the same samples. F: Synergistic induction of PAI-1 mRNA is inhibited by $\Delta$ FosB: Cells were transiently transfected with $\Delta$ FosB for $17 \mathrm{~h}$ then for $2 \mathrm{~h}$ with growth factors. -: vehicle control, E: EGF, T: TGF- $\beta$, TE: EGF and TGF $\beta . * *: p<0.05 ; * *: p<0.01 ; * * *: p<0.001$ Empty bars: control; Filled bars: inhibitors.

Figure 9. A,B: Synergism does not require de novo protein synthesis. Cells were first treated with $50 \mu \mathrm{g} / \mathrm{ml}$ cycloheximide for $1 \mathrm{~h}$ and then with $1 \mathrm{ng} / \mathrm{ml} \mathrm{TGF}-\beta, 5 \mathrm{ng} / \mathrm{ml} \mathrm{EGF}$, or their combination for $2 \mathrm{~h}$. PAI-1 mRNA was measured with RT- qPCR. About 3 fold of synergism was observed in both cycloheximide treated (filled bar) and control cells (Empty bar). B-D: Synergism requires a rapidly turning over protein. Cells were treated with $10 \mu \mathrm{g} / \mathrm{ml}$ cycloheximide before, during or after the addition of growth factors as shown in $\mathbf{B}$. PAI-1 mRNA was quantified after $2 \mathrm{~h}$ treatment with $1 \mathrm{ng} / \mathrm{ml}$ TGF- $\beta, 5 \mathrm{ng} / \mathrm{ml}$ EGF, or their combination as shown in $\mathbf{C}$. And the response of PAI-1 mRNA as the fraction of no cycloheximide control for each treatment with growth factors was plotted to determine the decay constants (D) -: vehicle control, E: EGF, T: TGF- $\beta$, TE: EGF and TGF $\beta$. *: p<0.05; **: $\mathrm{p}<0.01 ; * * *: \mathrm{p}<0.001$ 
Figure 10. Proposed model for the regulation of PAI-1 by EGF and TGF- $\beta$. TGF- $\beta$ regulates PAI-1 expression through Smad mediated signaling. EGF synergizes with TGF- $\beta$ in PAI-1 gene expression at the mRNA level. Other stimuli that activate MAPK signaling pathway including FGF-2, IGF-I, TNF $\alpha$ and PMA substitute EGF in synergism with TGF- $\beta$. EGF regulates PAI-1 expression through MAPK signaling pathway. AP-1 and Smad are involved in the synergistically increased transcription. A synergistic recruitment of AP-1 and Smad was proposed. 
Figure 1

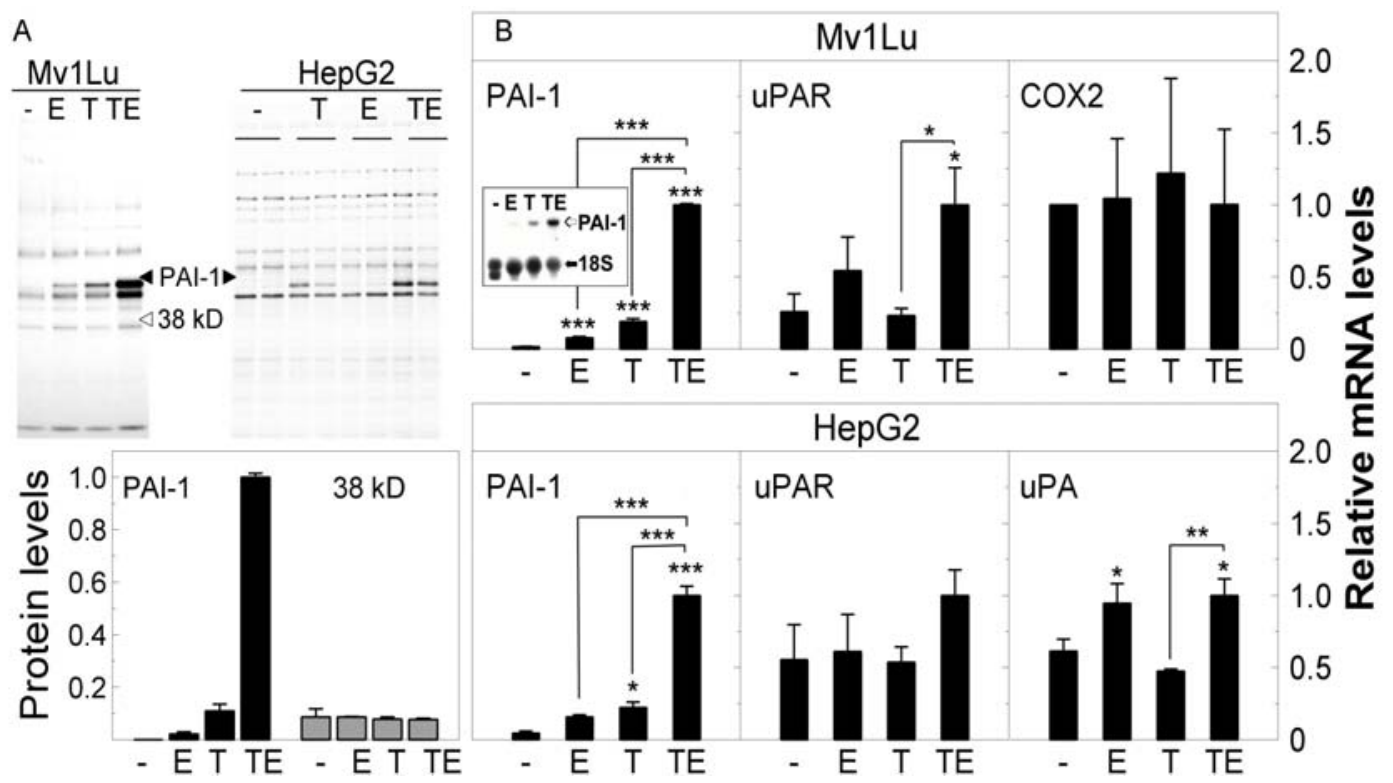


Figure 2
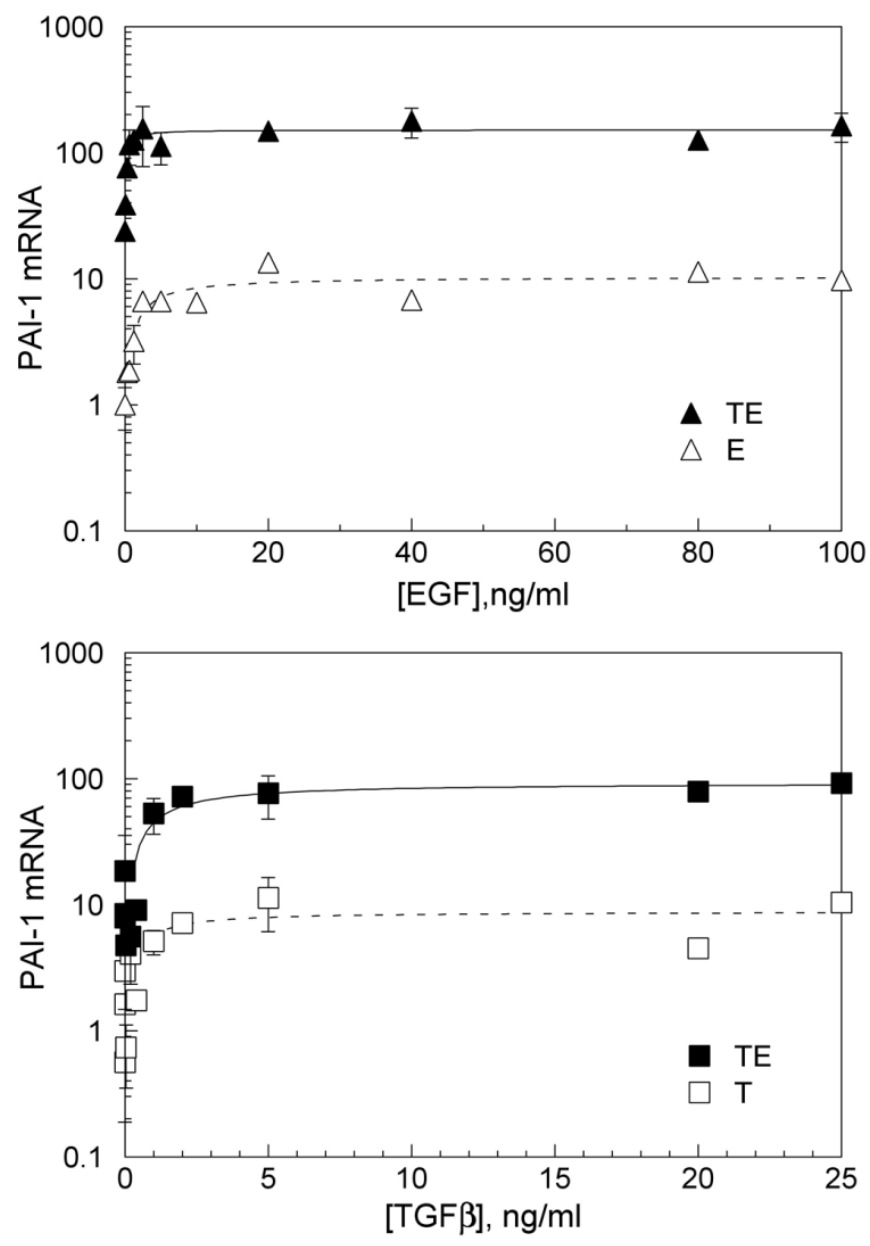
Figure 3
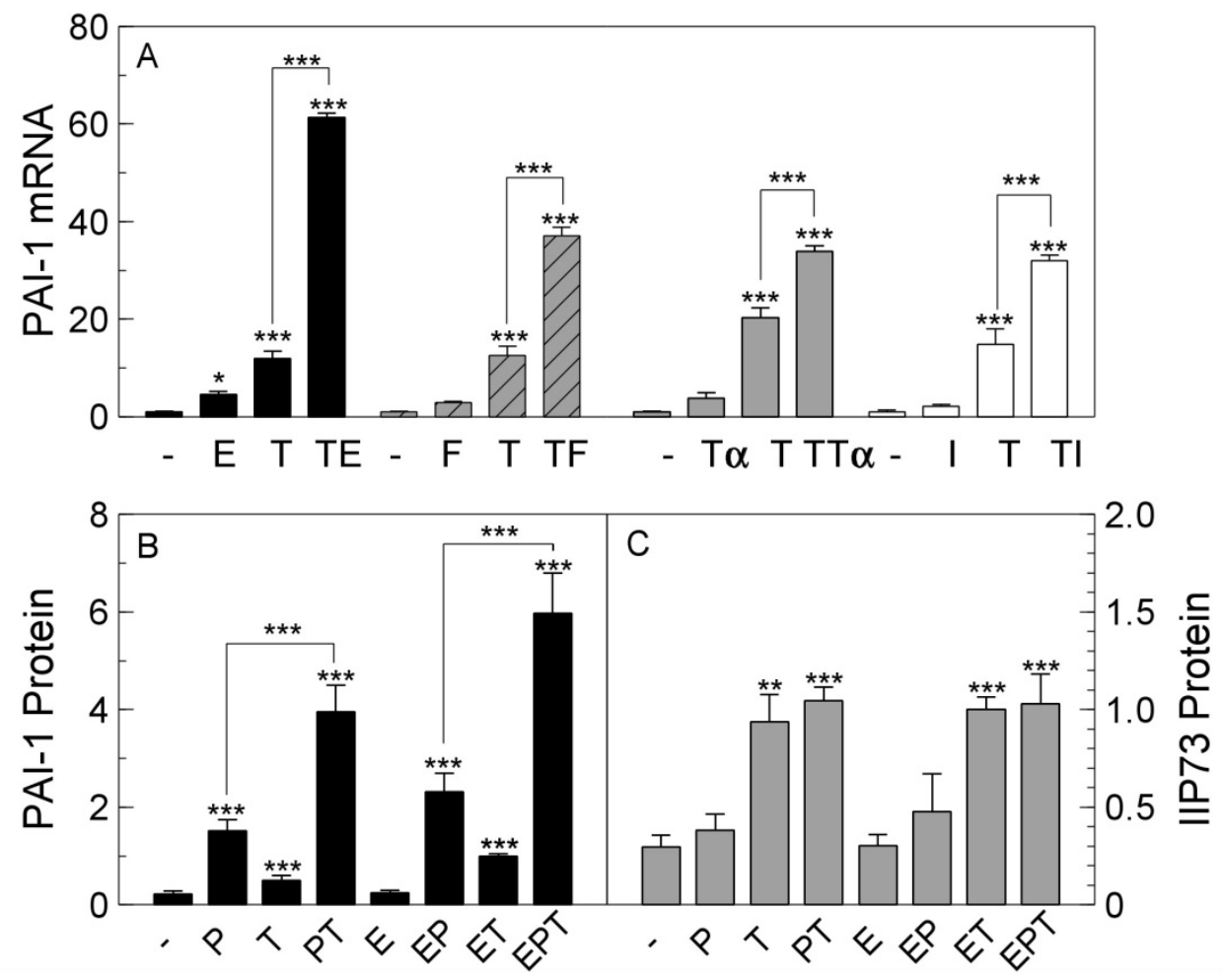
Figure 4
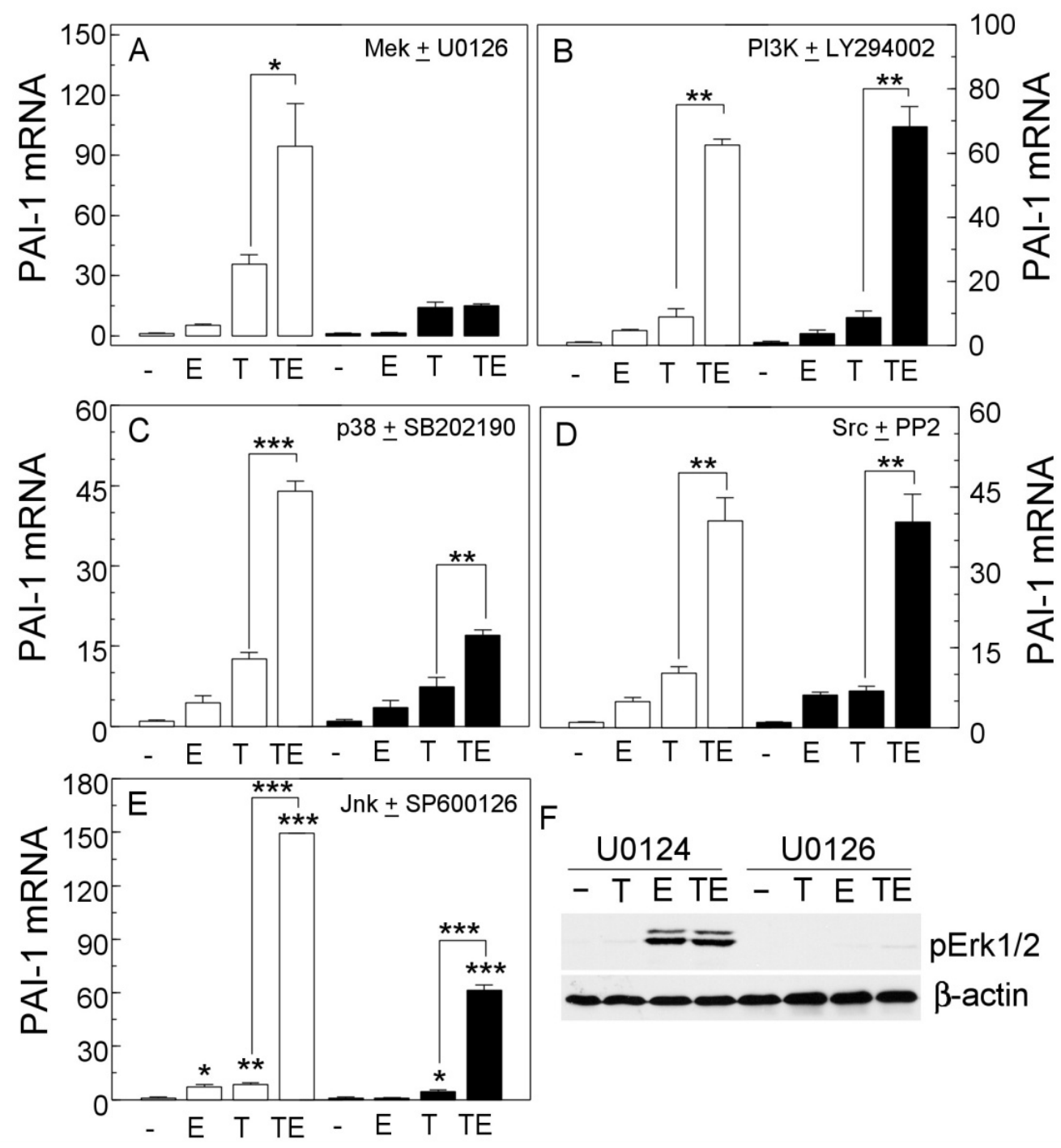
Figure 5

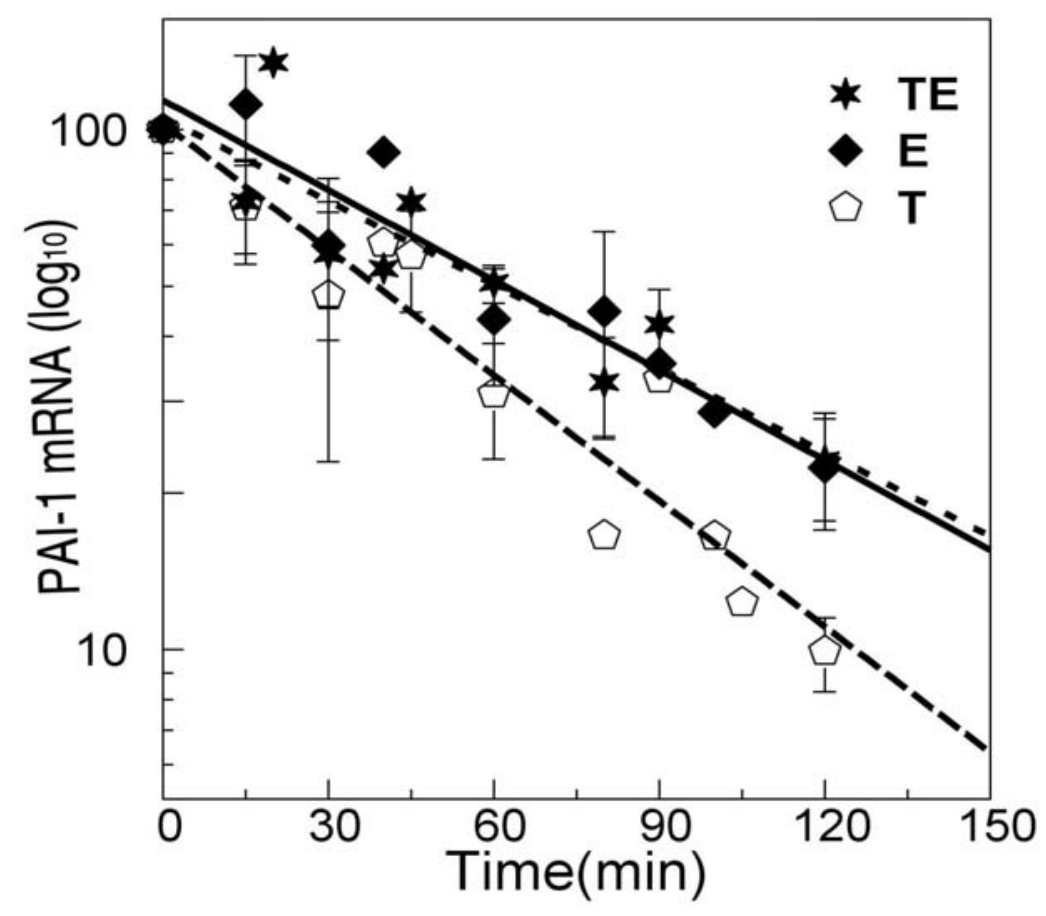


Figure 6
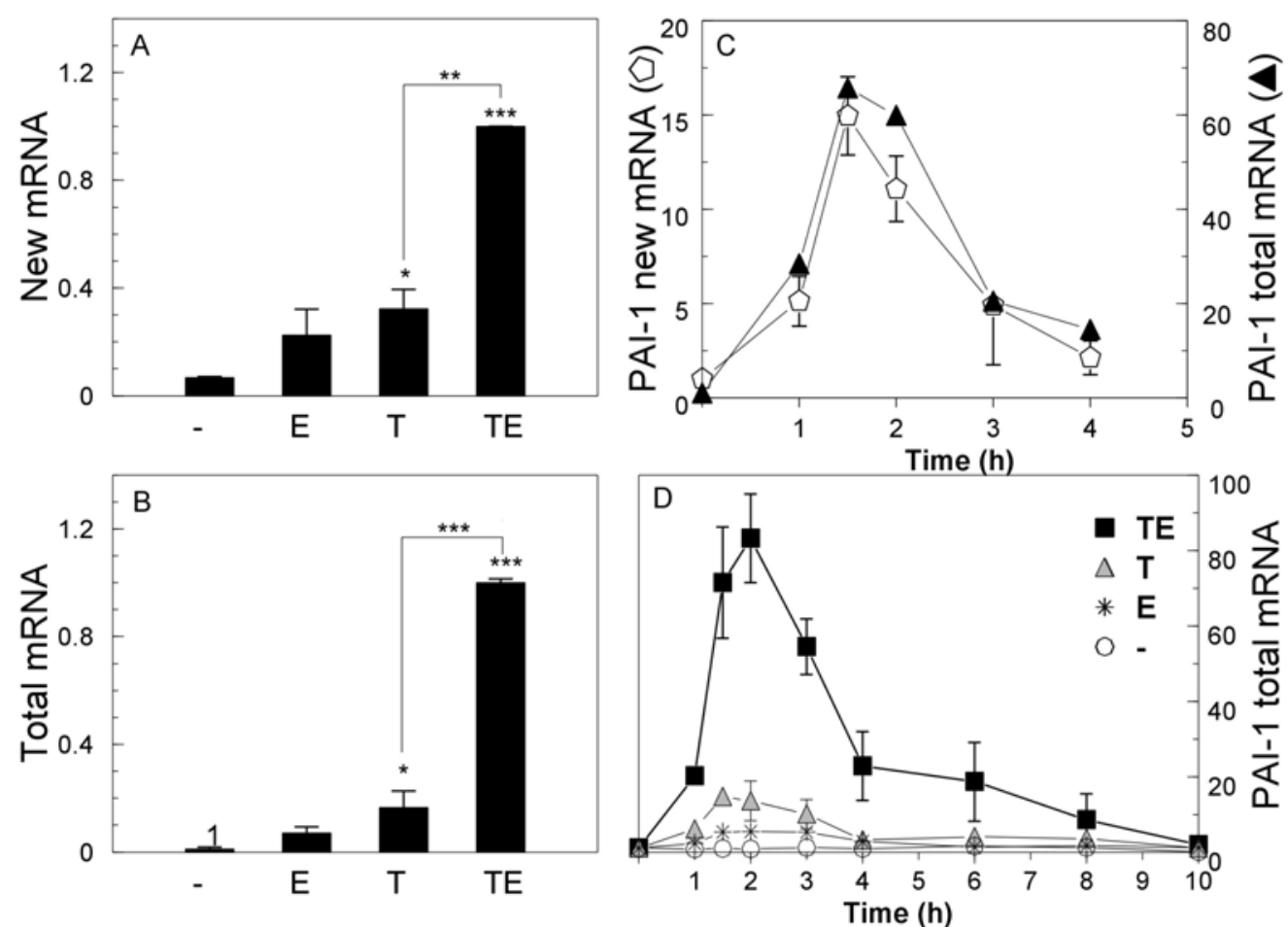
Figure 7

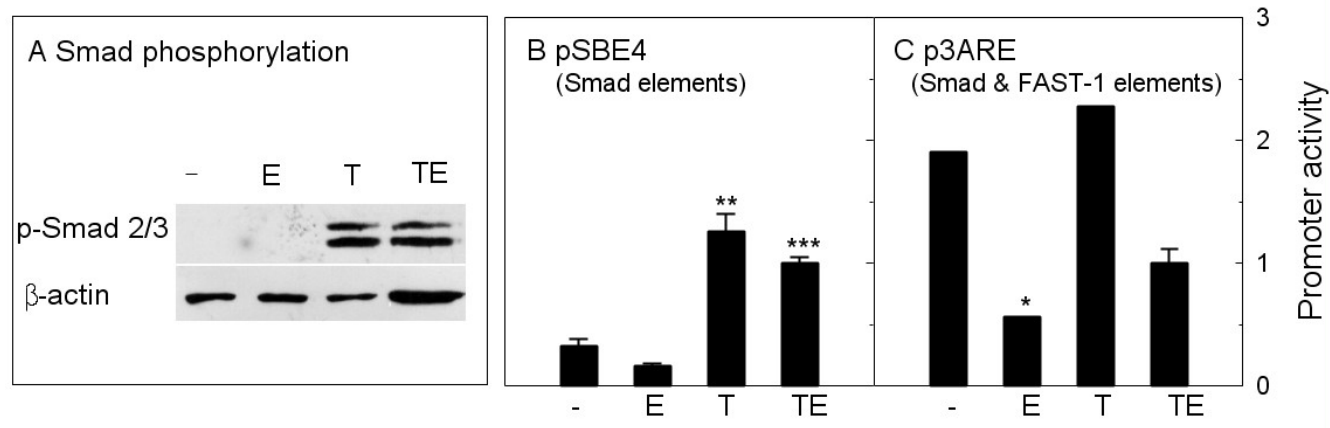


Figure 8

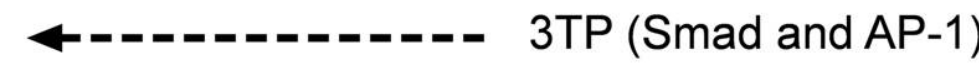
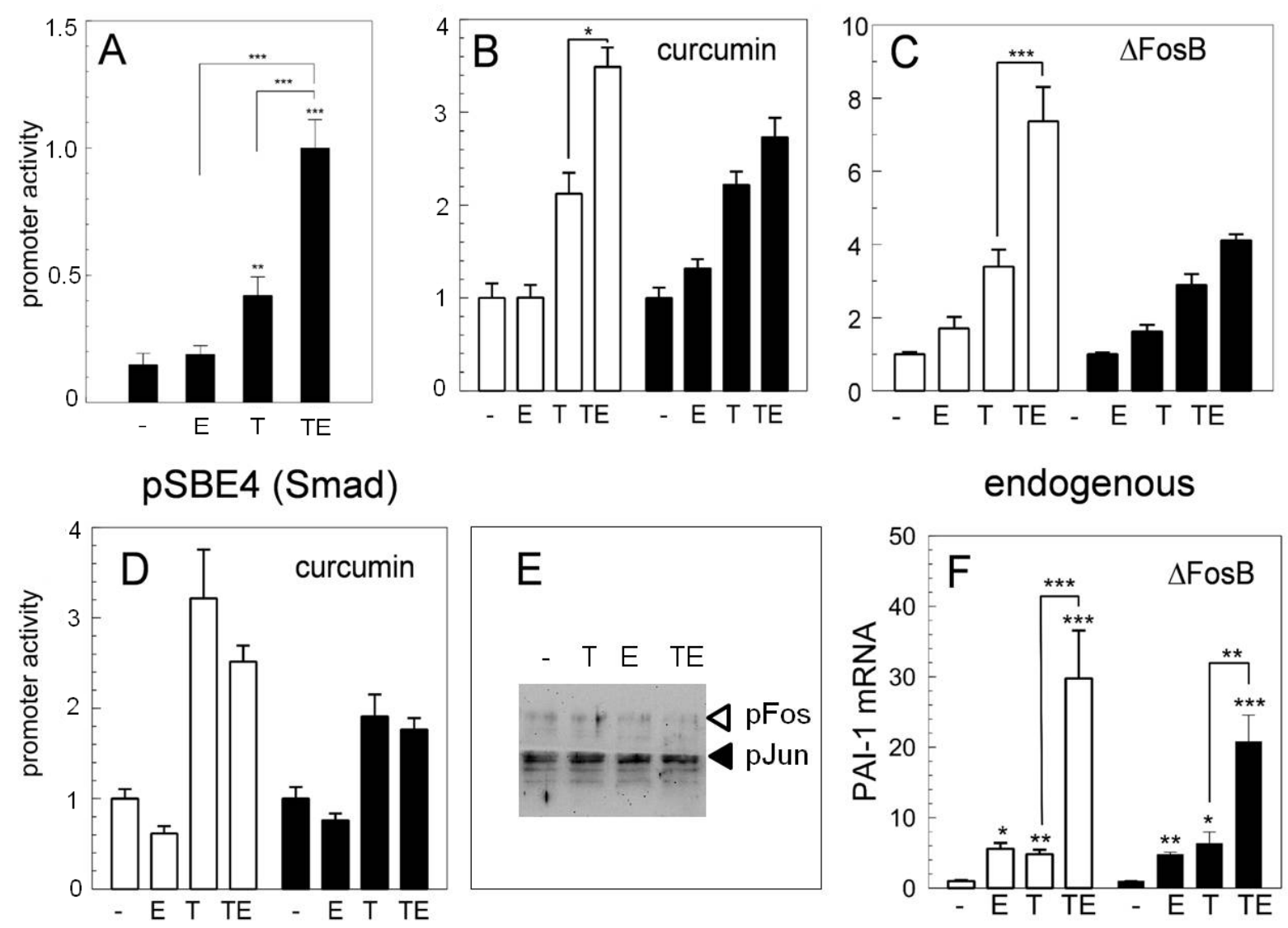
Figure 9

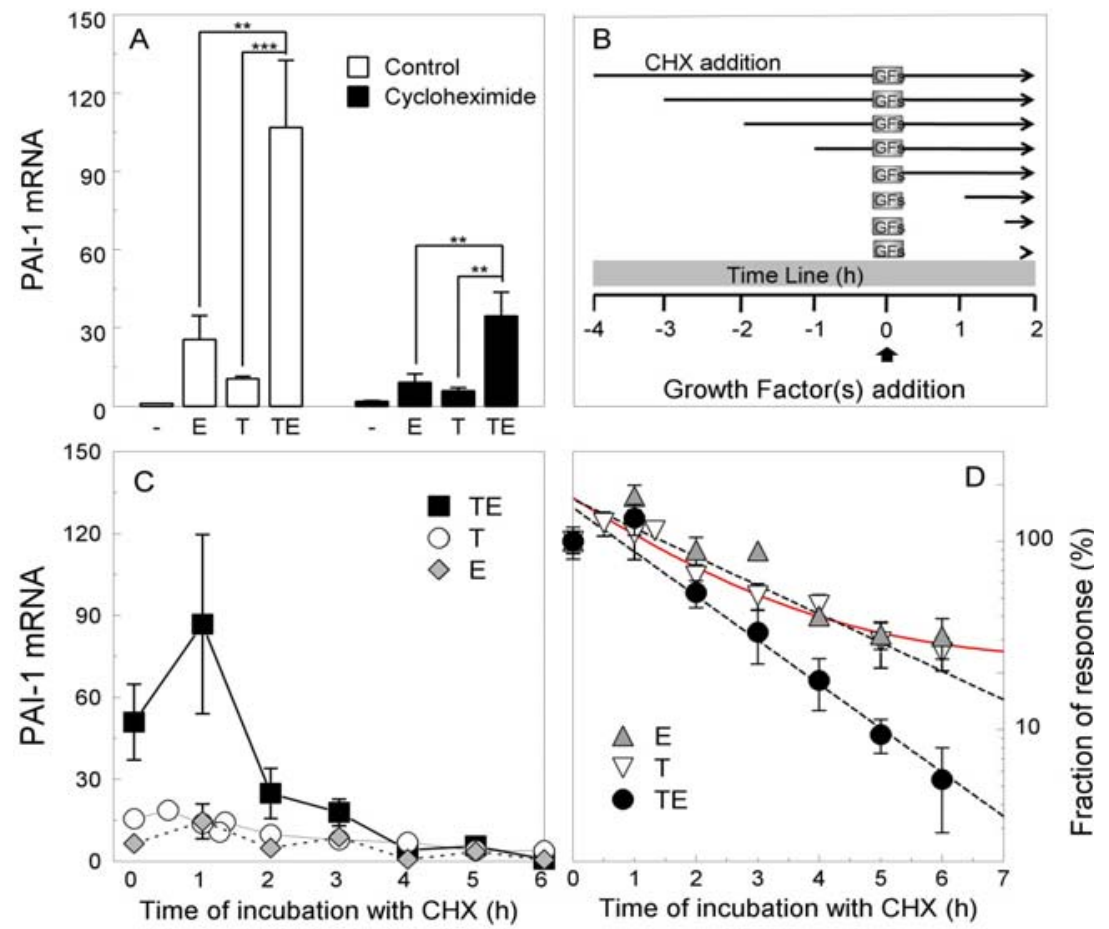


Figure 10

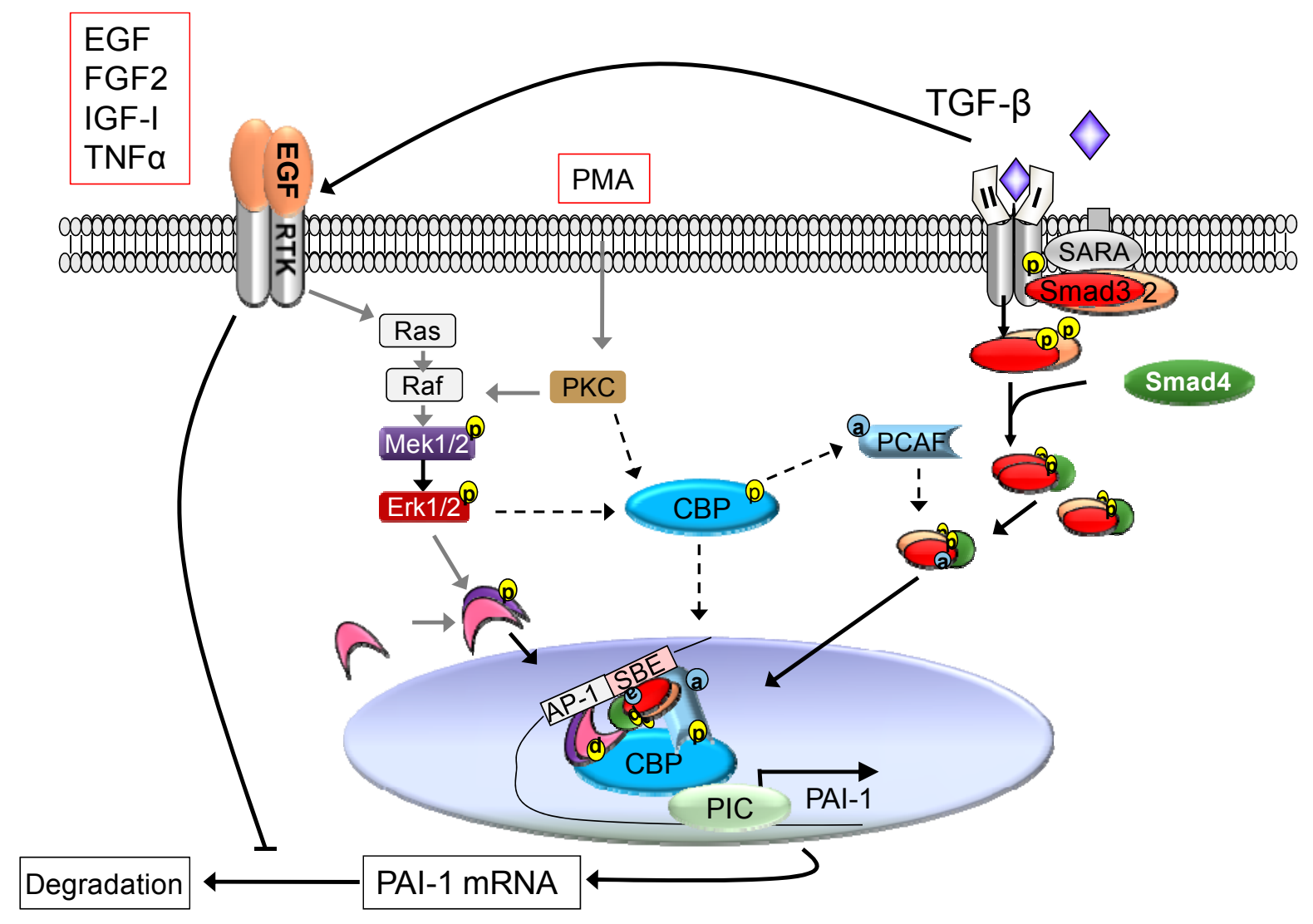




\title{
CHAPTER 4. TILED MICROARRAYS IDENTIFY EFFECTIVE
}

\section{ANTISENSE OLIGODEOXYNUCLEOTIDE AND SIRNA TARGET SEQUENCES}

\author{
A manuscript has been submitted to Biomed central Biotechnology \\ Xiaoling Song ${ }^{1, *}$, Xiangyu Cong ${ }^{1,3, *}$, Ahmed M. Awad ${ }^{1,4, *}$, Long $\mathrm{Qu}^{2}$, Lijie Zhai ${ }^{1}$ and \\ Marit Nilsen-Hamilton ${ }^{1 \S}$ \\ ${ }^{1}$ Department of Biochemistry, Biophysics and Molecular Biology and ${ }^{2}$ Department of \\ Animal Science, Iowa State University, Ames, Iowa 50011, ${ }^{3}$ School of Public Health, Yale \\ University, New Haven, CT 06520, ${ }^{4}$ California State University Channel Islands, Camarillo, \\ CA 93012
}

*These authors contributed equally to this work; §Corresponding author

\section{Abstract}

Identification of regions on mRNAs that are accessible for hybridization in the living cell is required for antisense and RNAi technologies and for accurate prediction of authentic targets of microRNAs. Although the sequence of an mRNA holds some useful information, the secondary and tertiary RNA structure determines access for hybridization. Because in vivo assays are very time consuming and expensive, computational and cell culture analysis have been utilized with varying success for identifying effective oligonucleotide inhibitors. With the advent of microarray spotters and readers as standard equipment in many research 
facilities, this approach to analyze RNA for accessible regions is worthy of investigation for its application to identify antisense and RNAi targets. We have utilized a tiled microarray format to investigate the accessible regions in two mRNAs (Bcl2 and Lcn2) and compared this with cell culture and computational approaches for predicting accessible targets for antisense oligodeoxynucleotides (ODNs) and siRNAs. Our results suggest that a tiled microarray is an effective means of identifying the mRNA regions that are accessible to antisense ODNs and RNAi.

\section{Introduction}

The sequence-specific silencing of gene expression by antisense oligonucleotides (ODNs) and siRNAs has attracted great interest in the development of effective gene therapies for a wide variety of diseases (Opalinska and Gewirtz 2002; Biroccio, Leonetti et al. 2003; Hokaiwado, Takeshita et al. 2008). Requirements for successful ODN- and RNAi-mediated decreases in mRNA levels and inhibition of protein biosynthesis include high affinity and faithful base-pairing specificity of the antisense-mRNA pair, intracellular delivery capability and stability of the antisense ODN or siRNA to nucleases in the biological environment (Fiset and Soussi-Gounni 2001). A fundamental requirement for both technologies is that the target site of the mRNA must be accessible for hybridization with the antisense or siRNA oligonucleotide. Because mRNAs are normally folded in secondary and tertiary structures, only a relatively small portion of the RNA sequence is available for efficient hybridization (Uhlenbeck, Pardi et al. 1997; Rivas and Eddy 1999; Vickers, Wyatt et al. 2000).

Many approaches, experimental and computational, have been developed to identify optimal antisense-accessible sites in mRNAs. In the direct test of in vivo efficacy, ODNs 
complementary to various regions of an mRNA are synthesized individually and their antisense activities are measured using cells in culture (Ziegler, Luedke et al. 1997; Wang, Cheung et al. 2001). However, this approach of empirically testing multiple ODNs in vivo is very expensive and time consuming. The demands of time and expense also limit coverage of the mRNA primary sequence investigated by in vivo analyses and therefore a complete picture of the accessibility of all possible sites on a target mRNA is usually not obtained by these approaches.

Computer algorithms that utilize minimum free energy calculations can predict secondary structures of RNA molecules and have been used to identify target accessibility and as a basis of rational design of antisense and nucleic acid probes (Mathews, Burkard et al. 1999; Ding and Lawrence 2001; Ding, Chan et al. 2004; Ding, Chan et al. 2005). However, these computer programs do not predict tertiary structures that may influence target accessibility. Moreover, RNAs can fold in many different secondary structures with similar free energies that could each further fold into one or more tertiary structures. The uncertainty of the in vivo balance of alternate secondary and tertiary RNA structures makes it very challenging to identify sequences for effective antisense ODNs from the primary structure of the mRNA using computational approaches.

Several in vitro approaches have been developed to identifying optimal target sequences in mRNAs for antisense technology. One approach is to map the antisense-accessible sites on mRNAs by hybridization with random ODN libraries followed by either RNase $\mathrm{H}$ cleavage or extension with reverse transcriptase (Ho, Bao et al. 1998; Allawi, Dong et al. 
2001; Lloyd, Giles et al. 2001). Hybridization of antisense ODNs has also been analyzed by MALDI-TOF to identify the accessible regions on an mRNA (Bleczinski and Richert 1998).

ODN arrays provide a simple tool for quantitative measurement of the binding of a set of complementary ODNs to a target RNA. In this method, an array of ODNs covalently linked to a glass surface is used to measure heteroduplex formation with the corresponding target mRNA, which is radioactively or fluorescently labeled. The results obtained with this approach show a good correlation between binding strengths and antisense activity in vivo (Milner, Mir et al. 1997; Sohail, Hochegger et al. 2001). However, since these cited studies were published, computational methods for folding nucleic acids and identifying hybridization targets have greatly improved.

Here we compared several commonly used computer programs with tiled microarrays carried out under physiological conditions for selecting accessible target sites for effective antisense ODNs in vivo. Two mRNA targets were used; mouse lipocalin 2 (aka SIP24, 24p3, uterocalin, siderocalin, Ryon, Bendickson et al. 2002) and B-cell CLL/lymphoma 2 (Bcl2). The efficacies of ODNs identified by each method were tested as antisense ODNs in vivo for Len2 and compared with literature reports of effective in vivo antisense for both gene products. We found that the experimental microarray analysis shows better specificity by identifying a small number of regions highly accessible for hybridization, compared to computational algorithms. Those regions identified by the tiled microarray were accurate predictions of sites for effective antisense action in vivo. They also predicted an effective siRNA site. Because of their ease of performance and their successful identification of in vivo RNA hybridization targets, we propose that tiled microarrays are an efficient means of 
identifying potential antisense ODNs or siRNAs. Tiled microarrays could also be effectively used as an experimental approach to provide data for validation and improvement of computational approaches for identifying RNA hybridization targets.

\section{Results}

\section{Determination of sites accessible by oligonucleotide arrays}

To identify the regions in the mouse Lcn2 and human $\mathrm{Bcl} 2$ mRNAs that are accessible to antisense hybridization, fluorescently-labeled transcripts corresponding to each mRNA were synthesized and incubated with tiled arrays of complementary ODNs at $37{ }^{\circ} \mathrm{C}$ for $16 \mathrm{~h}$. Hybridization was performed under nondenaturing conditions and at salt concentrations reported for inside the cell. The full-length Lcn2 transcript and a truncated Bcl2 (32-751 nt) transcript were used for hybridization. The tiled arrays consisted of 20 mer complementary ODNs in $10 \mathrm{nt}$ overlapping intervals. The Len2 arrays included overlapping oligonucleotides complementary to the full-length of the Lcn2 mRNA (GenBank: NM_008491, 853 nt). The Bcl2 arrays started at the AUG translation initiation site and included only the coding sequence (GenBank: M14745.1, region 32 to 751, 720 nt).

The quality of the printed arrays were examined using a set of arrays that were not used for hybridization but that were printed at the same time as the arrays used for hybridization. These slides were stained with SYBR green II then scanned using Pro Scan Array HT scanner to detect the nucleic acid. With some exceptions, the intensities of the printed ODNs were similar, which indicated that the printing was consistent from most pins. There were no detectable signals from the three negative controls (no ODN). The intensities from these 
arrays were taken as background and used to normalize the intensities from the hybridized arrays.

Analysis of the data for hybridization of Len2 mRNA with the microarray resulted in the ODNs targeting the mouse Lcn2 mRNA being separated into four clusters through K-means clustering with the highest binding associated with ODN 741-760 in the first cluster (Fig. 1A). The first and second clusters identified three potentially accessible regions of $30 \mathrm{nt}$ or more, which were: 491-530, 561-590 and 741-770. Interestingly, none of these sequences are near the translational start site of the mRNA. The majority of tested antisense ODNs lay in the third and fourth tier clusters in which regions the accessibility of Lcn2 mRNA is indicated to be much lower than for the regions identified in the first and second tier clusters.

We also tested the Bcl 2 coding region using the tiled microarray assay. As well as the tiled 20-mer ODNs covering the coding sequence of Bcl2, two previously identified effective antisense ODNs were included in the microarray. One of these ODNs contained the sequence known as G3139 or Oblimersen that is complementary to the first six codons of the open reading frame of the human Bcl2 mRNA (Tolcher 2005). The second antisense ODN (atg-1 in Fig. 1B) contained a sequence that also targets the translation initiation site but includes an additional six nucleotides (CCTTCC) at the 3'-end (denoted 2292 in reference Ziegler, Luedke et al. 1997). Statistical analysis and K-means clustering of the results from the Bcl2 microarray resolved the previously identified antisense ODNs (Oblimerisen and atg1) in the first tier cluster (red bar in Fig. 1B). The ODNs 1-20 and 8-27 that overlap in sequence with oblimersen and 2292 were found in the second tier cluster (green bars in Fig. 1B). These two ODNs contain the sequences that surround the translational start site and 
have previously been identified as effective antisense sequences (Kitada, Takayama et al. 1994; Gleave, Miayake et al. 1999). Clusters 3-6 included the three ODNs with scrambled sequences. So, it is likely that the first and second tiers contain the only ODNs that specifically hybridize with the Bcl2 coding sequence under native conditions.

\section{Prediction of accessible regions by computational analyses}

Computational analysis was used to predict available sequences for hybridization with the same Lcn2 and Bcl2 RNAs that had been tested against their respective microarrays. We tested three widely used computer programs (Oligowalk, sFold and Block-iT) to predict accessible regions in Lcn2 and Bcl2 RNAs. These programs predicted overlapping but different sets of sequences as optimal for effective antisense as seen in Fig. 2. Although some of the mRNA sequences identified by the microarray were also predicted by computational analysis, many differences are evident between the experimental and computational methods. A comparison of the predictions of the three computational methods also showed considerable disagreement.

\section{Efficiency of selected antisense oligonucleotides on Lcn2 protein levels}

Based on the results from the microarray and the computational analysis, eight ODNs were chosen to test as antisense agents for Len 2 in vivo. Four ODNs were identified from the computational analyses, three from the microarray results and one from a previous literature report that is complementary to a region covering the translational start site (positions 11 through 27). The effects of these ODNs on Lcn2 protein and mRNA levels were tested in mouse $\mathrm{HC} 11$ cells, a mammary cell line that expresses this gene at a high level (Ryon, Bendickson et al. 2002). The Lcn2 protein secreted by these cells was determined by 
western blot analysis and the mRNA by RT-qPCR. All results were normalized to those from cells transfected by an ODN with a scrambled sequence. In some experiments, the transfection efficiency was also determined using a fluorescent AS-ODN. The measured average transfection efficiency was $70 \%$ of the cells transfected.

The amount of the Lcn2 released by the transfected cells (Fig. 3B, upper panel) was normalized to the corresponding amount of total protein captured from the medium as determined from Ponceau S staining of the nitrocellulose membrane (Fig. 3B, lower panel). The amount of the most abundant protein in the medium (albumin) was used as the normalizing factor for loading variation. The results of all experiments were compiled and evaluated for statistical significance of the observed differences (Fig. 4). The average value for the scrambled ODN was $128 \%$ of the control (no ODN) value although this ratio varied between experiments. Statistical analysis identified AS-ODNs $561 \quad(\mathrm{p}<0.0001), 501$ $(\mathrm{p}<0.0001)$ and $741(\mathrm{p}<0.001)$ as causing a highly significant decrease in Lcn2 production. with an average transfection efficiency of $70 \%$, the 50 to $60 \%$ decrease in amount of Lcn2 protein is consistent with the majority of transfected cells realizing a very large decrease in Lcn2 expression. The 741 ODN was chosen based on the agreement between the microarray analysis and all three tested computational programs. The 501 and 561 ODNs were among the first tier cluster in microarray analysis and were also predicted by Oligowalk and BLOCK-iT, but not by sFold. Three other AS-ODNs showed an effect with weaker significance $(\mathrm{p}<0.05$ or $\mathrm{p}<0.01)$ and all other ODNs showed no effect on Lcn2 production (Fig. 4). Thus, the three sequences that most successfully decreased cellular Len2 production were identified by the tiled microarray analysis and by at least two of the three computational analyses. 


\section{Efficiency of selected antisense oligonucleotides and siRNA on Lcn2 mRNA}

We also examined the effects of the antisense ODNs on the Len 2 mRNA and intracellular Lcn2 protein levels of the mouse $\mathrm{HC} 11$ cells. Total RNA and cellular protein were extracted from the cells $48 \mathrm{~h}$ after the second transfection and quantitative measurements of Lcn2 mRNA were performed by RT-qPCR. Compared with the control ODN (scrambled sequence), the 561 and 741 AS-ODNs selectively reduced the Lcn2 mRNA and intracellular Lcn2 protein levels (Fig. 5A).

It has frequently been demonstrated that sequences around the translational start site are good AS-ODN targets (Gleave, Miayake et al. 1999; Marcucci, Byrd et al. 2003; Tolcher 2005). Moreover, an effective AS-ODN for Lcn2 has been reported that is complementary to the region 11-27 of the mRNA that covers the translational start site (Devireddy, Teodoro et al. 2001). None of the methods employed to identify optimal AS-ODNs predicted that an ODN with a sequence complementary to a region near the translational start site of Lcn2 would be an effective AS-ODN. Therefore we tested an AS-ODN complementary to position 11-27 (AS-ODN11) to determine if it effectively inhibits Len2 production by HC11 cells. Although the AS-ODN had little effect on protein or RNA levels when used at $0.2 \mu \mathrm{M}$, it was very effective in inhibiting protein production when used at a 10-times higher concentration as was used in the previous study ( $2 \mu \mathrm{M}$, Fig. 5B). However, by contrast to the effects of AS-ODNs 561 and 741, AS-ODN11 did not decrease the Lcn2 mRNA level even at the concentration of $2 \mu \mathrm{M}$.

We also tested the effectiveness of siRNAs targeted to the same regions in the Lcn2 mRNA in two different cell lines (Fig. 5C,D) In both instances a similar profile of decrease 
in Lcn2 mRNA was observed as for the AS-ODN series (Fig. 5A).

\section{Discussion}

Experimental approaches for identifying regions in the RNA susceptible to antisense suppression involve testing a series of potential AS-ODNs for their abilities to specifically inhibit translation of the target mRNAs. Many AS-ODNs have been directed against regions of the mRNA near the translational start site with the objective of interfering with translational initiation. Thus, RNA walking between the cap site and the translational start is one approach to identifying effective AS-ODNs (Bacon and Wickstrom 1991). However, it is now recognized that other mechanisms of effective antisense prevail, such as the mechanism that involves RNAse H-dependent RNA degradation. RNA structure is also recognized as an important consideration for identifying sequences that can be used to design effective AS-ODNs. Thus, computational approaches have been developed to evaluate RNA structure for the purpose of rational design of effective AS-ODNs. Four factors have been proposed as the basis for rationally designing AS-ODNs using computational approaches (Chan, Lim et al. 2006). These are 1) predicting RNA secondary structure, 2) identifying the appropriate local RNA secondary structures, 3) calculating GC content and motif search, and 4) predicting the binding energy $\left(\Delta \mathrm{G}\right.$ at $\left.37^{\circ} \mathrm{C}\right)$. However, there is good evidence that the $\mathrm{GC}$ content and binding energies of short segments of the RNA are subservient to the secondary and tertiary structure of the mRNA.

In vitro experimental approaches have also been developed for identifying accessible sequences in mRNA molecules. In the MAST approach a combinatorial ODN library is hybridized with the full-length RNA under nondenaturing conditions. The RNA and 
hybridized ODNs are captured and the ODNs cloned and sequenced. This procedure was successful in identifying accessible regions on the mRNAs encoding $\beta$-globin, RhoA and luciferase (Zhang, Mao et al. 2003). Microarrays were developed to examine the structure of an mRNA over a range of about 100 nt (Milner, Mir et al. 1997; Sohail, Akhtar et al. 1999; Sohail and Southern 2000). These arrays are produced using an innovative approach to synthesizing an array of ODNs of varying lengths that are complementary to regions in the target mRNA. Studies using scanning microarrays provided evidence that microarrays can be a powerful tool for identifying accessible regions on an mRNA measured under physiological conditions. By contrast, we have used a tiled microarray of equal length ODNs to analyze the structures of about $800 \mathrm{nt}$ segments of the Lcn2 and Bcl2 mRNAs. The microarrays comprised ODNs with overlapping sequences that covered the entire Lcn2 mRNA sequence and the entire Bcl2 coding region. Although previously not readily available, microarray spotting and reading equipment is becoming increasingly common place. A tiled microarray such as used in this work could be used to analyze the accessible sites on any mRNA that can be synthesized in vitro.

We analyzed the accessible sequences on Len 2 mRNA by both tiled microarray and computational methods to identify optimal AS-ODNs. Notably, the tiled microarray method identified a much smaller cohort of potential antisense sequences than any of the computational methods, indicating improved specificity. ODNs predicted as optimal for antisense by experimental and computational procedures were then tested with $\mathrm{HC} 11$ cells that synthesize large amounts of Lcn2. The results from the western blot analysis and the RT-qPCR studies are in agreement and suggest that the tiled microarray method can be used to accurately identify antisense sequences for effective AS-ODNs. The results of the tiled 
microarray also successfully predicted siRNA targets in this example. However, effective siRNA sequences must also have characteristics compatible with binding Argonaute such that the appropriate strand is chosen as the guide strand for mRNA cleavage (Parker, Roe et al. 2006). Therefore, although the tiled microarray will identify potential siRNA sequences, other considerations need to be applied to identify those that are biologically effective.

Neither microarray nor computational algorithms predicted any sequences around the translational start site as potential effective targets for AS-ODNs for Lcn2. However, a 17mer ODN (AS-ODN11) has previously been reported to decrease Lcn2 expression (Devireddy, Teodoro et al. 2001). We tested this AS-ODN at $200 \mathrm{nM}$ and $2 \mu \mathrm{M}$ and found that it suppressed Lcn2 protein production only at the higher concentration but did not decrease the level of Lcn2 mRNA. These results support observations made by others that AS-ODNs targeted to the region of the translational start site are likely to be effective in suppressing translational initiation (Higgins, Perez et al. 1993; Reed 1997; Dias and Stein 2002). However, a BLAST search of the AS-ODN11 sequence revealed that, as well as being complementary to position $11-27$ of $\mathrm{Lcn} 2$, it is also complementary to position 702-719 of the mRNA that encodes Nradd (Neurotrophin receptor associated death domain, GeneID: \#67169, NM_026012), a death domain protein (Wang, Shao et al. 2003; Gowrishankar, Zeidler et al. 2004). Thus, the effect of AS-ODN11 on Lcn2 expression could be an indirect consequence of the inhibition of Nradd production due to a primary antisense effect on the level of Nradd mRNA.

In a retrospective analysis, we also evaluated the Bcl2 mRNA, for which effective antisense ODNs have been previously identified, to determine if the tiled microarray would 
again accurately predict the most effective AS-ODNs. Because the Bcl2 mRNA is extremely large $(6,030 \mathrm{nt})$, we selected the coding region (720 nt) for analysis in this study. Using Mfold, this region was predicted to fold into the same basic structure independently or in the context of the full-length mRNA. Studies of RNA structure have revealed very few long-distance base-pair interactions beyond $800 \mathrm{nt}$. For example, in the $16 \mathrm{~S}$ and $23 \mathrm{~S}$ rRNA structures solved by X-ray crystallography, $99.9 \%$ of the pairings are of bases within $600 \mathrm{nt}$ of each other in the primary sequence (Harms, Schluenzen et al. 2001; Schuwirth, Borovinskaya et al. 2005). Thus, the results from analysis of the accessibility of the Bcl2 coding region should reflect its accessibility in the full length Bcl2 mRNA given that the same structure is predicted of the coding region whether alone or in context of the $5^{\prime}$ and $3^{\prime}$ UTRs. Another consideration for selecting the coding region instead of full length is that the accuracy of computational prediction decreases with increasing length of the analyzed sequence because the complexity of analysis increases dramatically with the length of analyzed sequence.

When the Bcl2 coding region was analyzed by tiled microarray, three ODNs were identified as the most available for hybridization. All three ODN complementary sequences clustered around the translational start site. This is precisely the region of the Bcl2 mRNA that has previously been identified as a prime target for AS-ODNs for reducing Bcl2 expression (Kitada, Takayama et al. 1994; Gleave, Miayake et al. 1999; Tolcher 2005). However, these sequences were not predicted as effective AS-ODNs by computational analysis either of the full-length mRNA or the truncated RNA containing only the coding region, although a region very close to the start site was predicted by BLOCK-IT (Figure 2). 
Our results suggest that a tiled microarray analysis of an mRNA is an efficient means of identifying effective AS-ODNs and potential siRNAs. The two mRNAs analyzed by this means were found to have a small number of highly accessible regions. The accessible regions identified by tiled microarray were confirmed by cell studies, in this study (Lcn2) and in others $(\mathrm{Bcl} 2)$, to be effective regions for AS-ODN targeting. It is of interest to note that the optimal AS-ODN targets were found to be at opposite ends of the mRNAs for Lcn2 and $\mathrm{Bcl} 2$. While the most effective AS-ODN for Bcl2 is near the translational start site, which is the most frequently targeted region for AS-ODN design, the most effective targets for Lcn2 were found near the $3^{\prime}$ end of the mRNA. It would be time consuming and expensive to find these latter target sequences by RNA walking and screening AS-ODNs with cultured cells.

\section{Conclusions}

In this study effective AS-ODN sequences for both $\mathrm{Lcn} 2$ and $\mathrm{Bcl} 2$ were identified by in vitro tiled microarray studies. Our results suggest that hybridization of ODN arrays to a target mRNA under physiological conditions might be used as a rapid and reliable in vitro method to accurately identify targets on mRNA molecules for effective antisense and potential siRNA activity in vivo. 


\section{Methods}

\section{Oligonucleotides}

All ODNs used in this study were purchased from Integrated DNA Technologies (Coralville, IA). The ODNs used for the tiled microarrays were $20 \mathrm{mer}$ deoxyribophosphodiesters and were obtained in a 96-well plate format at a total amount of 15 nmoles each. DEPC-water was added to each well for a final ODN concentration of $100 \mu \mathrm{M}$. The plate was stored at $-20^{\circ} \mathrm{C}$ until used. The antisense ODNs (AS-ODNs) used in cell culture studies were phosphorothioate oligodeoxynucleotides. One AS-ODN (AS-735) was fluorescein-labeled, with 6-FAM, at its 5'-end to visualize cellular uptake.

\section{Preparation of fluorescently labeled transcripts}

Fluorescently labeled RNA transcripts for hybridization to the ODN arrays were synthesized by in vitro transcription. The Bcl 2 encoding DNA was amplified from a template plasmid using PCR $\left(94^{\circ} \mathrm{C}, 30 \mathrm{sec} ; 55^{\circ} \mathrm{C}, 30 \mathrm{sec} ; 72^{\circ} \mathrm{C}, 1 \mathrm{~min} ; 25\right.$ cycles $)$. A T7 promoter sequence was included in the $5^{\prime}$ primer to produce a template for transcription of the sense-strand of the amplified region. The sequences of the 5'- and 3'-end primers were TAATACGACTCACTATAGGATGGCGCACGCTGG and TCACTTGTGGCCCAGATAGGCACCCAG, respectively. The PCR-amplified product was used as a template for in vitro transcription. The Lcn 2 mRNA was prepared from the template plasmid that contained a T7 promoter sequence. The plasmid was linearized with EcoRI. Transcription reactions to produce the Bcl2 and Lcn2 RNAs were carried out in $20 \mu \mathrm{L}$ volumes at $37^{\circ} \mathrm{C}$ for $1 \mathrm{~h}$ in the presence of $2.5 \mathrm{mM}$ each ATP, CTP, and GTP, $2.1 \mathrm{mM}$ UTP and $0.4 \mathrm{mM}$ ChromaTide Alexa 
Fluor 546-14-UTP (Molecular Probes, Carlsbad, CA) using an AmpliScribe T7-Flash Transcription Kit (Epicentre, Madison, WI). After DNase I treatment, the RNA products were purified by ammonium acetate precipitation as described in the transcription kit protocol. The absorbances of RNA $\left(\mathrm{A}_{260}\right)$ and Alexa Fluor $\left(\mathrm{A}_{555}\right)$ were measured and the base-to-dye ratio for the fluorophore-labeled RNA was determined.

\section{Preparation of the tiled oligonucleotide arrays}

Antisense ODNs were designed as 20mers that are complementary to the mRNA target from 5' to $3^{\prime}$ in $10 \mathrm{nt}$ overlapping intervals. The ODN solutions were transferred to a Corning 96-well microplate, dried by vacuum centrifugation and redissolved to a concentration of 150 $\mu \mathrm{M}$ in epoxide spotting solution (Corning Life Sciences, Acton, MA). ODNs were then printed onto Corning Epoxide Coated Slides according to the manufacturer's protocol (55\% relative humidity during printing, followed by incubation at $70 \%$ relative humidity for $12-17$ h). Some spots on the slides were printed with spotting solutions containing either ODNs with scrambled sequences or with no ODNs as a negative controls. After printing, a prehybridization step was performed to block the unused surfaces on the slides. The ODN printing quality was examined by staining one or two slides with Sybr green II that were scanned using a Pro Scan Array HT scanner.

\section{Hybridization of $m R N A s$ with arrays and image analysis}

Arrays were hybridized under physiological conditions using the hybridization buffer (13.5 mM NaCl, $150 \mathrm{mM} \mathrm{KCl,} 0.22 \mathrm{mM} \mathrm{Na}_{2} \mathrm{HPO}_{4}, 0.44 \mathrm{mM} \mathrm{KH}_{2} \mathrm{PO}_{4}, 100 \mu \mathrm{M} \mathrm{MgSO}, 120$ $\mathrm{nM} \mathrm{CaCl} 2,120 \mu \mathrm{M} \mathrm{MgCl} 2,1 \mathrm{U} / \mathrm{mL}$ ribonuclease inhibitor, $6 \mathrm{mM}$ glutathione, $20 \mathrm{mM}$ 
HEPES, $\mathrm{pH}$ 7.25). The array was covered with a cover glass and a solution of $25 \mathrm{nM}$ fluorescently labeled RNA in $100 \mu \mathrm{L}$ physiological buffer was pipetted onto the arrayed surface. The slide was transferred to a hybridization chamber and left for hybridization at $37^{\circ} \mathrm{C}$ for $16 \mathrm{~h}$. After washing in $150 \mathrm{mM} \mathrm{NaCl}, 15 \mathrm{mM} \mathrm{NaCitrate,} 0.01 \% \mathrm{SDS}$, the slide was dried by centrifugation at 1,600xg for 2 min and scanned using Pro Scan Array HT scanner.

\section{RNA folding predictions}

The minimum free energy secondary structures of Bcl2 and Lcn2 RNAs were estimated using the MFold and SFold web servers for nucleic acid folding and hybridization prediction (Zuker 2003; Ding, Chan et al. 2004). These algorithms were also used to predict the antisense sequences and their binding affinity to the RNA target. The data were analyzed by the Soligo program in the sFOLD package (Ding, Chan et al. 2004), OligoWalk (Mathews, Burkard et al. 1999), and Block-iT programs.

\section{Cell culture and transfection}

HC11 epithelial cells were cultured in medium consisting of RPMI 1640 medium supplemented with L-glutamine (Gibco BRL), 10\% fetal calf serum (FCS) and $10 \mathrm{U} / \mathrm{mL}$ penicillin/streptomycin in a humidified atmosphere with $10 \% \mathrm{CO}_{2}$ at $37^{\circ} \mathrm{C}$. Cells were maintained in the exponential phase of growth by subculturing every 3 days.

Transfection of the HC11 cells with AS-ODNs was performed in 6-well plates. Cells were seeded at a concentration of $2 \times 10^{5}$ cells/well in $2 \mathrm{~mL}$ culture medium (containing $10 \%$ FCS). After 18-20 h the cells were washed with $1 \mathrm{~mL}$ PBS (137 mM NaCl, $2.7 \mathrm{mM} \mathrm{KCl}, 10$ $\mathrm{mM} \mathrm{Na} 2 \mathrm{PO} 4,2 \mathrm{mM} \mathrm{K} 2 \mathrm{PO} 4, \mathrm{pH}$ 7.4) followed by $1 \mathrm{~mL}$ culture medium, then $800 \mu \mathrm{L}$ fresh 
RPMI was added to each well. A transfection mixture containing either AS-ODN or no oligo control (final concentration of $0.2 \mu \mathrm{M}$ unless otherwise stated) and $3 \mu \mathrm{L}$ Oligofectamine reagent (Invitrogen Inc., Carlsbad, CA) in $200 \mu \mathrm{L}$ RPMI medium was added to each well to a final volume of $1 \mathrm{~mL}$. After $4 \mathrm{~h}$ incubation at $37^{\circ} \mathrm{C}, 500 \mu \mathrm{L}$ fresh RPMI medium containing $30 \% \mathrm{FCS}$ was added and the cells were incubated at $37^{\circ} \mathrm{C}, 10 \% \mathrm{CO}_{2}$ for a further $20 \mathrm{~h}$. At this time, the media were removed from the wells, the cells were washed with PBS and a second transfection was performed using the same protocol. Four hours after transfection, cells were incubated in RPMI with $0.3 \%$ fetal bovine serum for another $44 \mathrm{~h}$ prior termination. The transfection efficiency was determined by using fluorophore-labeled AS-735 as a representative AS-ODN. The medium was collected from each well of cells treated with AS-ODNs, spun at $10,000 \mathrm{xg}$ for $10 \mathrm{~min}$ and the supernatants were stored at $-20^{\circ} \mathrm{C}$ for determination of secreted Lcn2 protein level. Cells were scraped into TRIZOL reagent (Invitrogen Inc., CA) to isolate total RNA and cellular protein according to the manufacturer's instructions. The control condition for all experiments was transfection with an ODN containing a scrambled sequence of AS-591 (Sc; TGTGTGCGTGGGAGCAAGAG). This sequence was blasted against the mouse genome and transcriptome. From this analysis no sequence in the mouse genome was found to be $100 \%$ complementary to Sc. The best matches were in the UTRs of three RNAs for which, in each case, $80 \%$ of the bases were perfect matches. Transfection with siRNA was done as for AS-ODNs except the second transfection was omitted. The control siRNA was non-targeting scrambled siRNA (Ambion, cat\#4611G). 


\section{Western blotting}

Protein was concentrated from the conditioned media by precipitation in $10 \%$ trichloroacetic acid (TCA), incubated for $1-2 \mathrm{~h}$ at $4^{\circ} \mathrm{C}$ to allow total protein precipitation and then spun at 3,000xg for $15 \mathrm{~min}$. The protein pellets were washed once with 10\% TCA and twice with cold acetone $\left(-20^{\circ} \mathrm{C}\right.$ acetone) and left for air drying at $4^{\circ} \mathrm{C}$. To determine the Lcn2 protein expression level, total protein was resuspended in $30 \mu \mathrm{L}$ loading buffer and resolved by $12 \%$ SDS-PAGE. Proteins were transferred to a nitrocellulose membrane (Amersham Biosciences, Piscataway, NJ) by electroblotting at $400 \mathrm{~mA}$ for $1 \mathrm{~h}$, followed by Ponceau S staining of the membrane for quantitative determination of the transferred protein. The non-specific binding sites of the membrane were blocked with $5 \%$ non-fat dried milk in Tween 20 wash buffer (TWB). The membrane was then incubated with rabbit anti-SIP24/Len2 primary antibody (1:500 dilution, Davis, Tabatabai et al. 1991) followed by peroxide-labeled anti-mouse secondary antibody (1:25,000 dilution). The blot was washed with TWB and the immunoreaction was detected using enhanced chemiluminescence ECL reagents (Amersham Biosciences) followed by exposure to x-ray film (Kodak, Rochester, NY). The film was analyzed by densitometric scanning of the Len2 bands and the intensity of each band was normalized to the corresponding total protein band from the Ponceau S staining. The relative protein levels of the treatment groups were calculated with respect to the control values in the absence of ODN. All experiments were performed at least seven times. 


\section{RNA isolation, reverse transcription and quantitative PCR}

Total RNA was isolated from the transfected cells using Trizol reagent (Gibco BRL) according to the manufacturer's instructions. At the final step, RNA pellets were dissolved in $20 \mu \mathrm{L}$ DEPC-water and stored at $-80^{\circ} \mathrm{C}$. Reverse transcription was performed using SuperScript II RT (Invitrogen Inc., CA) and the resulting cDNA was used as a template for Lcn2 mRNA reverse transcription and amplification by quantitative PCR (RT-qPCR). The qPCR reaction was conducted using Taq DNA polymerase (Promega, Madison, WI), and SYBR green I. A plasmid containing the Lcn2 coding sequence was used as template to establish the standard curve. The forward and reverse primers for Lcn2 were CAGGCCCAGGACTCAACTCAGAA and TCTGGACCGCATTGCCTGC respectively. The amount of Lcn2 mRNA was determined and normalized to the amount of GAPDH (mouse Glyceraldehyde-3-phosphate dehydrogenase, GenBank: M32599) or cyclophilin (mouse CypA, GenBank: NM_008907) mRNAs (as internal controls) that were measured in the same samples. The forward and reverse primers for GAPDH were TGACATCAAGAAGGTGGTGAAGCA and GGTCCACCACCCTGTTGCTGT respectively. The forward and reverse primers for cyclophilin were CTTTTCGCCGCTTGCTGCA and ACCACCCTGGCACATGAATCCT respectively. Standard curves for GAPDH and cyclophilin were based on templates created by PCR amplifying cDNAs containing these sequences with the primers previously identified.

\section{Statistical analysis}

To obtain the microarray data, the scanned digital images of both hybridized microarrays and the SYBR green II stained microarrays without hybridization were analyzed using 
GridGrinder (Corning, Inc.). For each spot on each array, the median pixel intensity was multiplied by the number of pixels in the spot area to provide the total spot intensity. Each of the total spot intensities on the hybridization array was then divided by its corresponding total spot intensity on the staining array to normalize the potential spot-to-spot variations brought about by variations such as printing pin efficiencies. The normalized intensities corresponding to the same oligonucleotide were then averaged as the final signal for the oligonucleotide. K-means clustering (MacQueen 1967; Everitt, Landau et al. 2001; Tibshirani, Walther et al. 2001) was applied to the final signals from all oligonucleotides to identify intrinsic groups of oligonucleotides with $\mathrm{K}$ chosen under the assistance of the gap statistic (Tibshirani, Walther et al. 2001).

For the Western blot and RT-qPCR data in figures 4 and 5(A,B), mixed linear models were used for analysis on the natural logarithms of fractions of controls. Fixed factors included the oligonucleotide, target molecule (extracellular protein, intracellular protein and mRNA) and their interaction. Random factors included independent experiments to account for block effects, gels and qPCR reactions within experiments to account for shared measurement errors and oligonucleotide within experiments to account for cell culture effects. Variance parameters were estimated using the residual maximum likelihood method and fixed effect parameters were estimated by generalized least squares. Heterogeneity of error variances were observed and accounted for by using sandwich-type empirical standard errors for fixed effect parameters and their contrasts. The analysis was performed in the Mixed Procedure of SAS (9.2.3) and code is available upon request. Labels for the level of significance relative to "none" (to which no ODN was added) are: *** for $\mathrm{p}<0.001, * *$ for $\mathrm{p}<0.01$, and * for $\mathrm{p}<0.05$. 


\section{Authors' contributions}

XS carried out the majority of the cell biology studies with antisense and part of the statistical analysis. XC conceived of the idea to use tiled microarrays, carried out most of the microarray studies on Lcn2 and contributed to the computer analysis. AA initiated the cell biology studies and performed the Bcl2 microarray analysis. LQ performed the cluster analyses and the majority of statistics analysis of the experimental results. LZ performed the siRNA cell studies. MNH initiated the study, oversaw the work and participated in analysis of the data. AA wrote the first draft of the original manuscript, which was significantly revised in content and form by MNH with the participation of all coauthors. All authors read and approved the final manuscript.

\section{Acknowledgements}

This work was supported by the Biological Systems Science Division, Office of Energy

Science Research, of the U. S. Department of Energy (Contract W-7405-Eng-82 with the Ames National Laboratories). 


\section{References}

."Block-IT." from https://rnaidesigner.invitrogen.com/sirna/setOption.do?designOption= sirna\& pid=900824367321685845.

Allawi, H. T., F. Dong, et al. (2001). "Mapping of RNA accessible sites by extension of random oligonucleotide libraries with reverse transcriptase." RNA 7(2): 314-27.

Bacon, T. A. and E. Wickstrom (1991). "Walking along human c-myc mRNA with antisense oligodeoxynucleotides: maximum efficacy at the 5' cap region." Oncogene Res 6(1): 13-9.

Biroccio, A., C. Leonetti, et al. (2003). "The future of antisense therapy: combination with anticancer treatments." Oncogene 22(42): 6579-88.

Bleczinski, C. F. and C. Richert (1998). "Monitoring the hybridization of the components of oligonucleotide mixtures to immobilized DNA via matrix-assisted laser desorption/ionization time-of-flight mass spectrometry." Rapid Commun Mass Spectrom 12(22): 1737-43.

Chan, J. H., S. Lim, et al. (2006). "Antisense oligonucleotides: from design to therapeutic application." Clin Exp Pharmacol Physiol 33(5-6): 533-40.

Davis, T. R., L. Tabatabai, et al. (1991). "Basic fibroblast growth factor induces 3T3 fibroblasts to synthesize and secrete a cyclophilin-like protein and beta 2-microglobulin." Biochim. Biophys. Acta 1095(2): 145-152.

Devireddy, L. R., J. G. Teodoro, et al. (2001). "Induction of apoptosis by a secreted lipocalin that is transcriptionally regulated by Il-3 deprivation." Science 293(5531): 829-834.

Dias, N. and C. A. Stein (2002). "Antisense oligonucleotides: basic concepts and mechanisms." Mol Cancer Ther 1(5): 347-55.

Ding, Y., C. Y. Chan, et al. (2004). "Sfold web server for statistical folding and rational design of nucleic acids." Nucleic Acids Res 32(Web Server issue): W135-41.

Ding, Y., C. Y. Chan, et al. (2005). "RNA secondary structure prediction by centroids in a Boltzmann weighted ensemble." RNA 11(8): 1157-66.

Ding, Y. and C. E. Lawrence (2001). "Statistical prediction of single-stranded regions in RNA secondary structure and application to predicting effective antisense target sites and beyond." Nucleic Acids Res 29(5): 1034-46. 
Everitt, B. S., S. Landau, et al. (2001). Cluster Analysis. New York, Oxford University Press Inc.

Fiset, P. O. and A. Soussi-Gounni (2001). "Antisense oligonucleotides: problems with use and solutions." Rev. Biol. Biotech. 1: 27-33.

Gleave, M. E., H. Miayake, et al. (1999). "Targeting bcl-2 gene to delay androgenindependent progression and enhance chemosensitivity in prostate cancer using antisense bcl-2 oligodeoxynucleotides." Urology 54(6A Suppl): 36-46.

Gowrishankar, K., M. G. Zeidler, et al. (2004). "Release of a membrane-bound death domain by gamma-secretase processing of the p75NTR homolog NRADD." J Cell Sci 117(Pt 18): 4099-111.

Harms, J., F. Schluenzen, et al. (2001). "High resolution structure of the large ribosomal subunit from a mesophilic eubacterium." Cell 107(5): 679-88.

Higgins, K. A., J. R. Perez, et al. (1993). "Antisense inhibition of the p65 subunit of NFkappa B blocks tumorigenicity and causes tumor regression." Proc Natl Acad Sci U S A 90(21): 9901-5.

Ho, S. P., Y. Bao, et al. (1998). "Mapping of RNA accessible sites for antisense experiments with oligonucleotide libraries." Nat Biotechnol 16(1): 59-63.

Hokaiwado, N., F. Takeshita, et al. (2008). "RNAi-based drug discovery and its application to therapeutics." IDrugs 11(4): 274-8.

Kitada, S., S. Takayama, et al. (1994). "Reversal of chemoresistance of lymphoma cells by antisense-mediated reduction of bcl-2 gene expression." Antisense Res Dev 4(2): 71-9.

Lloyd, B. H., R. V. Giles, et al. (2001). "Determination of optimal sites of antisense oligonucleotide cleavage within TNFalpha mRNA." Nucleic Acids Res 29(17): 3664-73.

MacQueen, J. B. (1967). Some Methods for classification and Analysis of Multivariate Observations, Proceedings of 5-th Berkeley Symposium on Mathematical Statistics and Probability, Berkeley, University of California Press. 1: 281-297.

Marcucci, G., J. C. Byrd, et al. (2003). "Phase 1 and pharmacodynamic studies of G3139, a Bcl-2 antisense oligonucleotide, in combination with chemotherapy in refractory or relapsed acute leukemia." Blood 101(2): 425-32.

Mathews, D. H., M. E. Burkard, et al. (1999). "Predicting oligonucleotide affinity to nucleic acid targets." RNA 5(11): 1458-69. 
Milner, N., K. U. Mir, et al. (1997). "Selecting effective antisense reagents on combinatorial oligonucleotide arrays." Nat Biotechnol 15(6): 537-41.

Opalinska, J. B. and A. M. Gewirtz (2002). "Nucleic-acid therapeutics: basic principles and recent applications." Nat Rev Drug Discov 1(7): 503-14.

Reed, J. C. (1997). "Promise and problems of Bcl-2 antisense therapy." J Natl Cancer Inst 89(14): 988-90.

Rivas, E. and S. R. Eddy (1999). "A dynamic programming algorithm for RNA structure prediction including pseudoknots." J Mol Biol 285(5): 2053-68.

Ryon, J., L. Bendickson, et al. (2002). "High expression in involuting reproductive tissues of uterocalin/24p3, a lipocalin and acute phase protein." Biochemical J I367: 271-277.

Schuwirth, B. S., M. A. Borovinskaya, et al. (2005). "Structures of the bacterial ribosome at 3.5 A resolution." Science 310(5749): 827-34.

Sohail, M., S. Akhtar, et al. (1999). "The folding of large RNAs studied by hybridization to arrays of complementary oligonucleotides." RNA 5(5): 646-55.

Sohail, M., H. Hochegger, et al. (2001). "Antisense oligonucleotides selected by hybridisation to scanning arrays are effective reagents in vivo." Nucleic Acids Res 29(10): 2041-51.

Sohail, M. and E. M. Southern (2000). "Selecting optimal antisense reagents." Adv Drug Deliv Rev 44(1): 23-34.

Tibshirani, R., G. Walther, et al. (2001). Estimating the number of clusters in a data set via the gap statistic. Journal of the Royal Statistical Society Series B-Statistical Methodology. 63: 411-423.

Tolcher, A. W. (2005). "Targeting Bcl-2 protein expression in solid tumors and hematologic malignancies with antisense oligonucleotides." Clin Adv Hematol Oncol 3(8): 635-42, 662.

Uhlenbeck, O. C., A. Pardi, et al. (1997). "RNA structure comes of age." Cell 90(5): 833-40.

Vickers, T. A., J. R. Wyatt, et al. (2000). "Effects of RNA secondary structure on cellular antisense activity." Nucleic Acids Res 28(6): 1340-7.

Wang, A., P. K. Cheung, et al. (2001). "Specific inhibition of coxsackievirus B3 translation and replication by phosphorothioate antisense oligodeoxynucleotides." Antimicrob Agents Chemother 45(4): 1043-52. 
Wang, X., Z. Shao, et al. (2003). "NRADD, a novel membrane protein with a death domain involved in mediating apoptosis in response to ER stress." Cell Death Differ 10(5): 58091.

Zhang, H. Y., J. Mao, et al. (2003). "mRNA accessible site tagging (MAST): a novel high throughput method for selecting effective antisense oligonucleotides." Nucleic Acids Res 31(14): e72.

Ziegler, A., G. H. Luedke, et al. (1997). "Induction of apoptosis in small-cell lung cancer cells by an antisense oligodeoxynucleotide targeting the Bcl-2 coding sequence." $\underline{\mathrm{J} \text { Natl }}$ Cancer Inst 89(14): 1027-36.

Zuker, M. (2003). "Mfold web server for nucleic acid folding and hybridization prediction." Nucleic Acids Res 31(13): 3406-15. 


\section{Figure Legends}

Figure 1. Selecting effective antisense nucleic acids targeting Lcn 2 mRNA by microarray.

Tiled microarrays were performed and analyzed as described in Materials and Methods. The average normalized intensities determined for each oligonucleotide from scanning 9 slide printings were analyzed by $\mathrm{K}$-means clustering with $\mathrm{K}=4$ for $\mathrm{Lcn} 2$ and 6 for Bcl2. A) For Lcn2, the horizontal lines separate the 4 clusters defined for Lcn2, which are differentiated by the colors of the respective bars [1 (red), 2 (green), 3 (yellow) and 4 (brown)]. The control sequences (black) were, in order of presentation: buffer, and 9 different random sequences B) For Bcl2, the horizontal lines separate the first two clusters and the last 4 clusters are below the $2^{\text {nd }}$ line. Clusters are differentiated by the colors of the respective bars [1 (red), 2 (green), 3 (yellow) and 4-6 (shades of brown of increasing intensity)]. The controls were three separate wells containing a scrambled version of AS-ODN 422.

\section{Figure 2. Computational predictions.}

The predictions of Oligowalk (blue), S-fold (hatched area) and Block-IT (red lines) are compared with the results from the experimental microarray (green lines) for Lcn2 (A) and Bcl2 (B). For Oligowalk and S-fold the lowest $\Delta \mathrm{G}(\mathrm{kcal} / \mathrm{moL})$ indicate the sites predicted to be the most effective antisense targets. For Block-IT, the length of the red line is the given rank based on the probability of successful knock down. The arrowheads identify the oligonucleotides tested for their antisense activity in cultured cells. The white arrowheads show oligonucleotides that had no significant effect on Lcn2 production (this study) or on Bcl2 (op.cit.) and the filled arrow heads show the sequences that were successful in cells as antisense ODNs. 
Figure 3. Transfection efficiency and Western blot analysis to quantify secreted Lcn2 protein levels.

HC11 cells were transfected with $200 \mathrm{nM}$ AS-ODNs and then the medium was collected and evaluated by Western blot as described in Materials and Methods. A) Images of cells transfected with FAM-labeled AS-ODN. Left panel, fluorescent image and right panel, phase contrast image of the same field. B) Western blot results showing the Western blot image and the Ponceau S stained membrane from the same gel. The numbers below each stained protein band in the Western blot image is the intensity of that band normalized to the Ponceau S stained band of the same sample, which is directly below the number.

Figure 4. Antisense oligonucleotides identified by the microarray decrease secreted Lcn2 expression.

Phosphorothioate AS-ODNs $(200 \mathrm{nM})$ were tested for their ability to inhibit Lcn2 production by $\mathrm{HC} 11$ cells as measured by western blot. Shown are the results from 12 independent experiments. The yellow dots show the raw data points. In each experiment all values were normalized to the average value for the Lcn2 production by cells transfected with an ODN consisting of a scrambled sequence of AS-591 (Sc; TGTGTGCGTGGGAGCAAGAG). A statistical model was developed, the results of which are shown as brown bars behind each data set. 
Figure 5. Intracellular and secreted Lcn2 protein and $m R N A$ levels are decreased by microarray-identified antisense ODNs and siRNA.

A. Antisense ODNs: HC11 cells were transfected with $200 \mathrm{nM}$ AS-ODNs with a scrambled ODN (Sc) as control. Forty eight hours after the start of the second transfection, the culture medium was collected and the cells fractionated to obtain cellular protein and RNA. The samples of cells and culture medium were analyzed by Western blot to quantify Lcn2. Lcn2 mRNA was quantified by RT-qPCR. C. siRNA: Cells were transfected with siRNA 561 and the cells collected $24 \mathrm{~h}$ later for analysis of Len 2 mRNA by RT-qPCR.

\section{B. Targeting the translational start site decreases Len2 protein production but not the} mRNA level. HC11 cells were transfected with AS-ODNs and the amount of Lcn2 in the medium, collected $48 \mathrm{~h}$ after the beginning of the second transfection, was determined by Western blot. The level of Lcn2 mRNA was determined by real time RT-qPCR.

For panels A and B The data are expressed as fractions of the values obtained in the same experiment when the cells were treated with a scrambled ODN. The same statistical model was used as for figure 4, the results of which are shown as red and brown bars behind each data set. Original data points are shown as markers: brown triangles, mRNA; yellow circles, extracellular Lcn2; inverted green triangles, intracellular Lcn2.

C,D. The microarray also identified effective siRNAs: Cells were transfected with siRNA 561 and the cells collected $24 \mathrm{~h}$ later for analysis of Len 2 mRNA by RT-qPCR. Examples of two experiments are shown, one with HC11 cells and the other with Mv1Lu cells. Mv1Lu cells were cotransfected with a plasmid expression vector for Lcn2, which was transcribed 
from a $\beta$-actin promoter with a CMV enhancer. siRNA targets were within Lcn2 (numbered as for AS-ODNs) or a scrambled sequence (Scr). Shown are individual values (triangles) and the simple means (green bars).

For all panels: The data are expressed as fractions of the values obtained in the same experiment when the cells were treated with a scrambled ODN (Sc). All AS-ODN concentrations were $0.2 \mu \mathrm{M}$ except for ODN11, which was tested at 0.2 and $2 \mu \mathrm{M}$. 


\section{Figures}

Figure 1. Selecting effective antisense nucleic acids targeting Lcn2 mRNA by microarray.

A

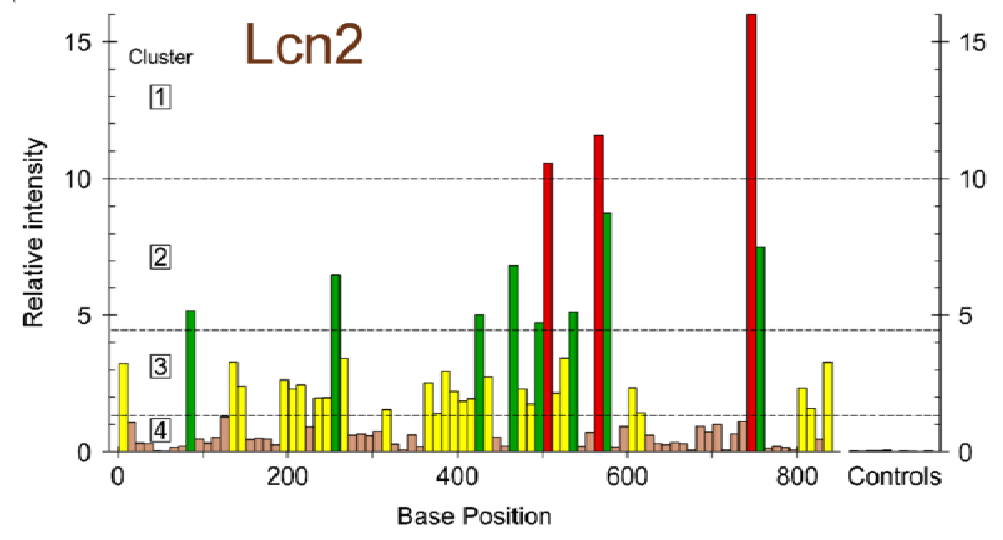

B

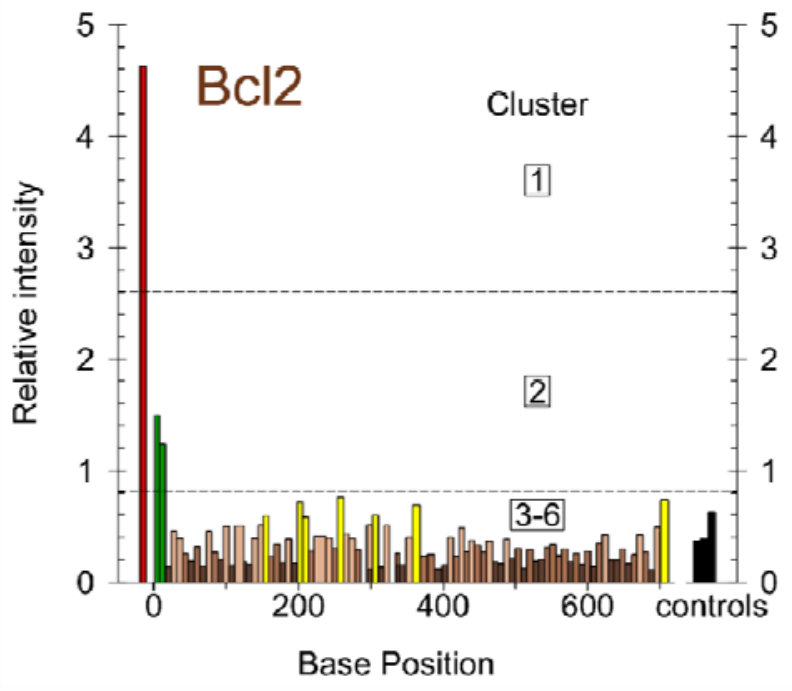


Figure 2. Computational predictions.
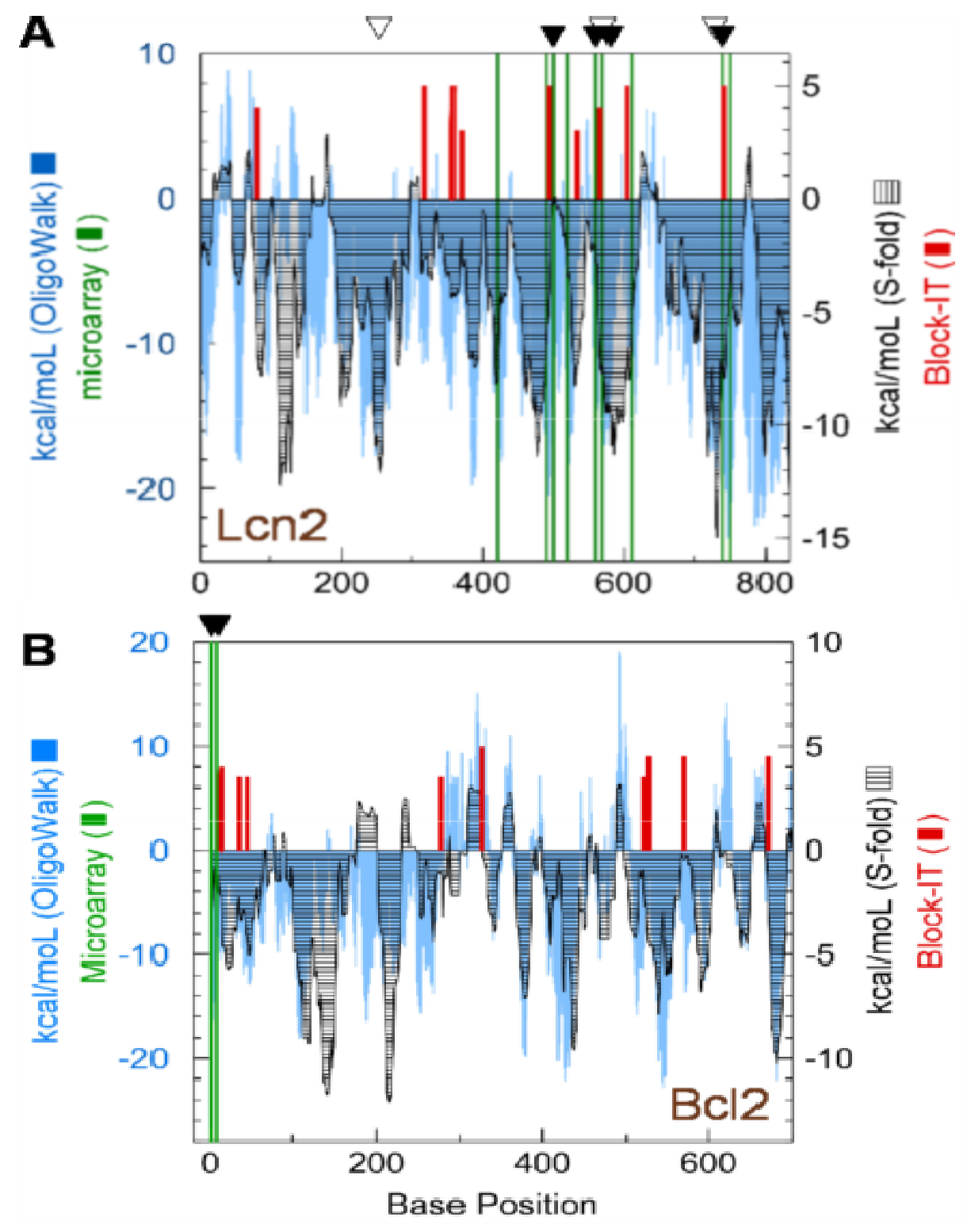
Figure 3. Transfection efficiency and Western blot analysis to quantify secreted Len2 protein levels.
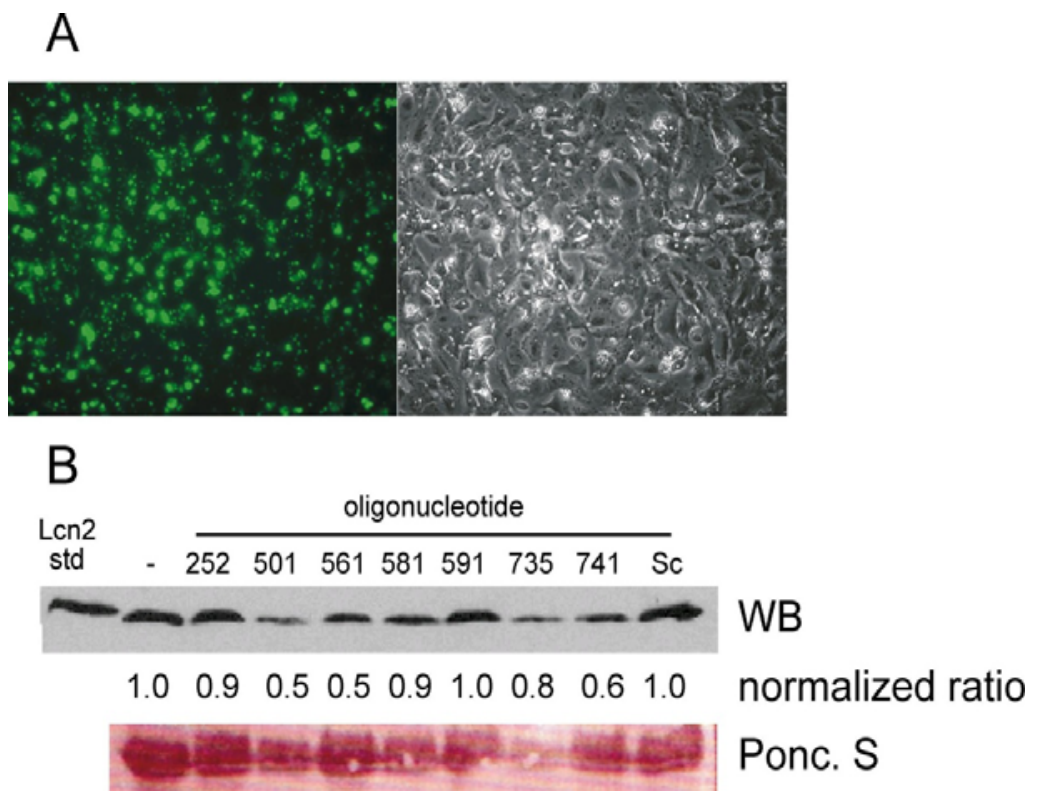
Figure 4. Antisense oligonucleotides identified by the microarray decrease secreted

\section{Lch2 expression.}

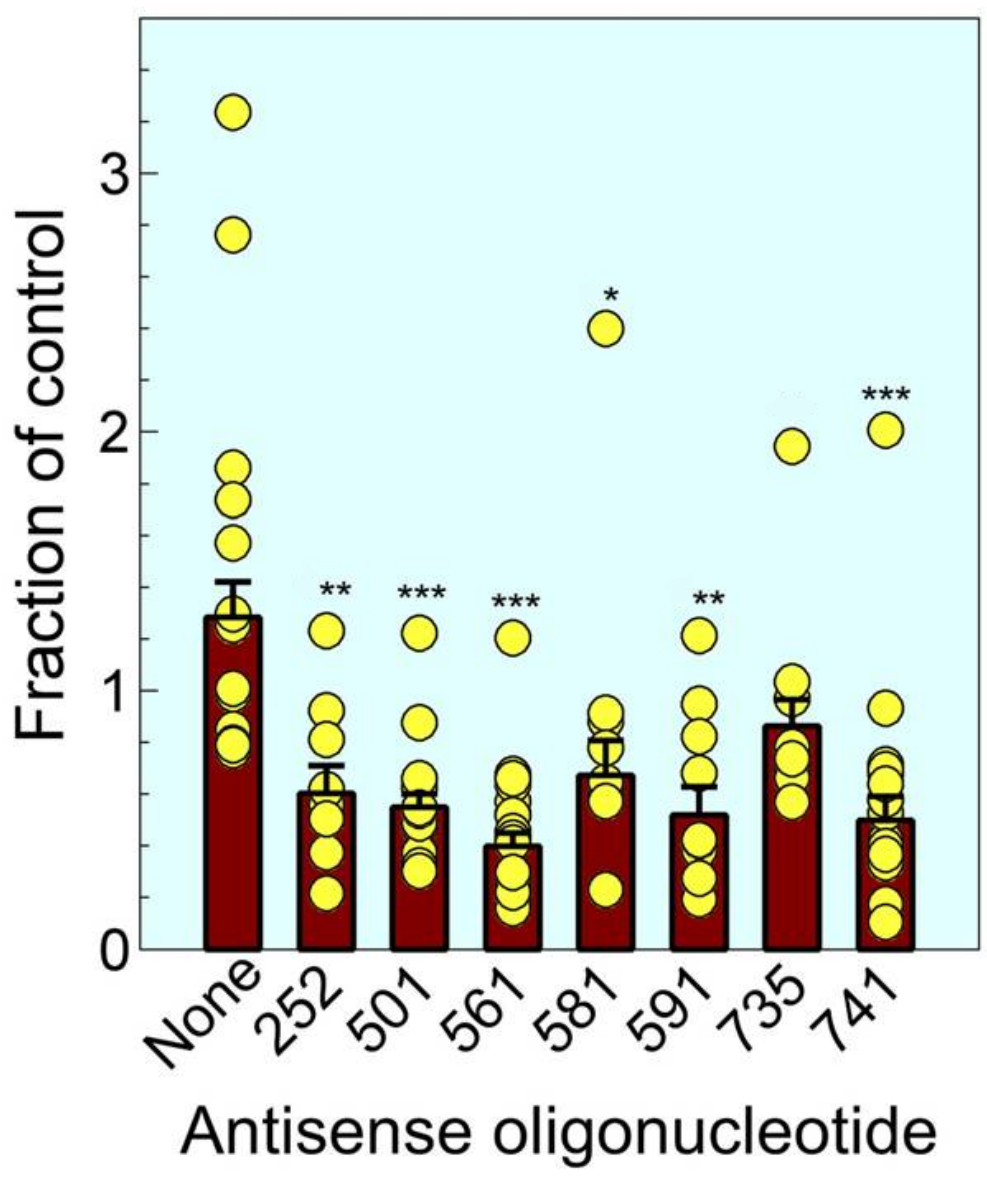


Figure 5. Intracellular and secreted Lcn2 protein and $m R N A$ levels are decreased by microarray-identified antisense ODNs and siRNA.

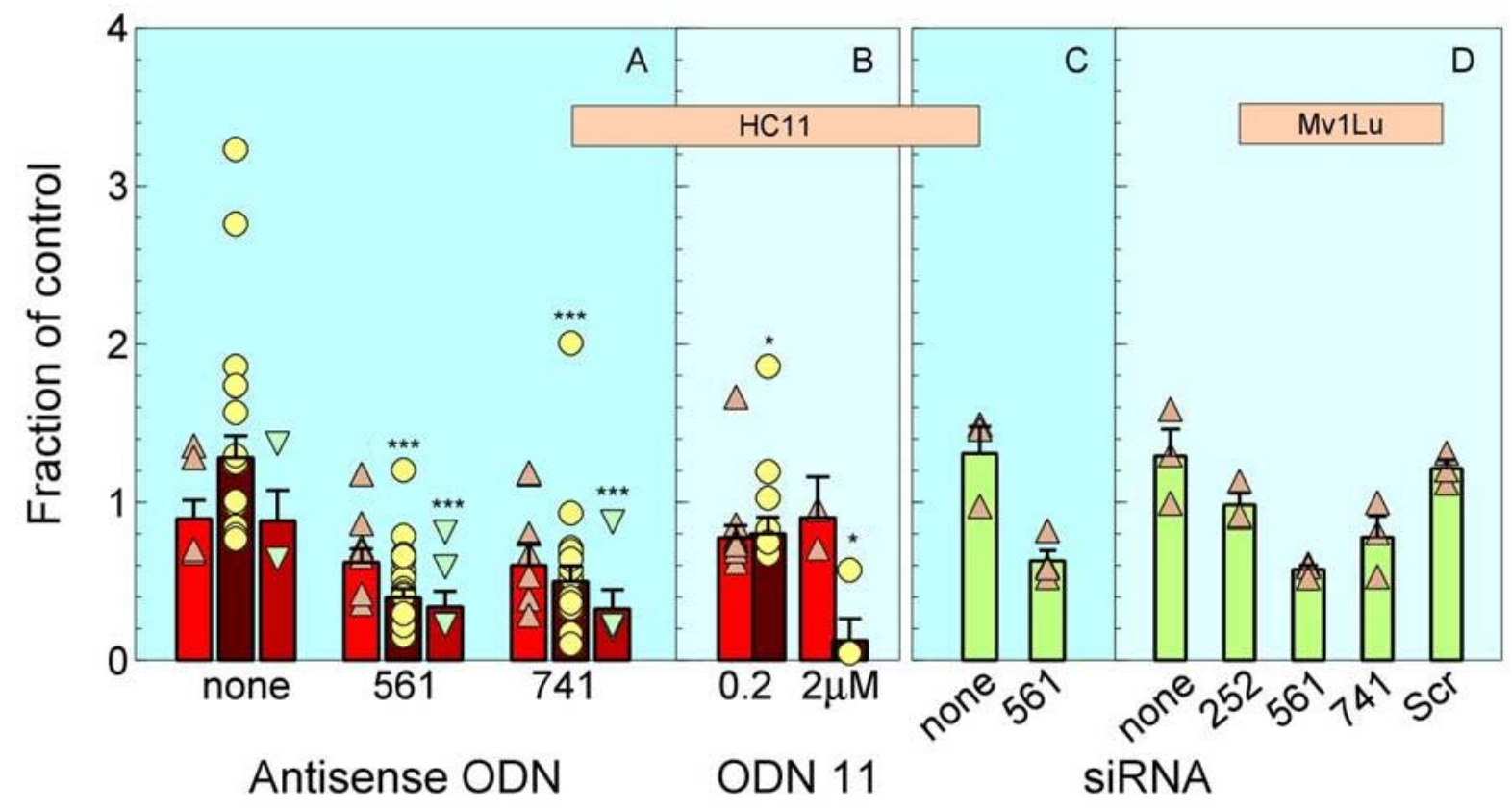




\section{CHAPTER 5. GENERAL CONCLUSION AND DISCUSSION}

\section{Goal of this study}

As the major physiological inhibitor of plasminogen activator (PA), the type I plasminogen activator inhibitor (PAI-1) is important for controlling blood clotting and tissue remodeling events such as those involving cell migration. The changing needs for protease activities under various physiological conditions necessitates a tight cellular control of gene expression to enable rapid changes in the levels of PAI-1 and PA activity. Previous studies have shown that transforming growth factor- $\beta$ (TGF- $\beta$ ) and epidermal growth factor (EGF) interact synergistically to increase the PAI-1 protein level (Nilsen-Hamilton and Holley 1983; Thalacker and Nilsen-Hamilton 1992). The goal of this study is to understand the mechanism of this synergistic regulation of PAI-1 by EGF and TGF- $\beta$.

\section{Significance of this study}

Plasminogen activator inhibitor 1 (PAI-1) has important roles in regulating fibrinolysis (Kawasaki, Dewerchin et al. 2000; Gils and Declerck 2004), maintaining the integrity of the extracellular matrix (Degryse, Sier et al. 2001) and modulating the motility of cells (Deng, Curriden et al. 1996; Providence, Higgins et al. 2008). PAI-1 levels are elevated in a variety of diseases including cardiovascular diseases (Scarabin, Aillaud et al. 1998), fibrosis (Yang, Hsieh et al. 2003; Liu 2008), some malignant tumors (Kruithof, Gudinchet et al. 1988; Urano, Wu et al. 1996). EGF and TGF- $\beta$ dramatically elevates PAI-1 levels in several epithelial cell lines including cancer cells (Thalacker and Nilsen-Hamilton 1987; Thalacker and Nilsen-Hamilton 1992; Wilkins-Port, Ye et al. 2009). Cooperation between 
EGF and TGF- $\beta$ has been shown to affect many cell activities including cell transformation (Roberts, Frolik et al. 1983), the epithelial-mesenchymal transition (Uttamsingh, Bao et al. 2008; Hardy, Booth et al.; Taylor, Parvani et al.), migration (Stolz and Michalopoulos 1997), proliferation (Saltis, Agrotis et al. 1992) and survival (Saha, Datta et al. 1999). EGF and TGF- $\beta$ - mediated signaling is frequently found over-activated in advanced stages of tumors. PAI-1 over-expression has been shown as an early event during the epithelial mesenchymal transition (EMT) (Wilkins-Port, Ye et al. 2009). Understanding the synergistic regulation mechanism of PAI-1 will help us understand the fundamental mechanism behind this regulation and the function of PAI-1 in a broad range of processes. Furthermore, strategies of blocking PAI-1 level have been shown to reduce thrombosis (Elokdah, Abou-Gharbia et al. 2004; Smith, Dixon et al. 2006; Hennan, Morgan et al. 2008) and angiogenesis (Leik, Su et al. 2006). Understanding the mechanism underlying the synergistic regulation of PAI-1 expression by EGF and TGF- $\beta$ will help to identify potential targets that can be used to modulate PAI-1 levels in cardiovascular diseases and cancers.

\section{Major findings and conclusion}

Synergistic regulation of PAI-1 by EGF and TGF- $\beta$ was observed at both the protein and mRNA levels (Figure 1, Chapter 3). TGF- $\beta$ and EGF interact synergistically to increase the PAI-1 mRNA level about two orders of magnitude over the basal level in human HepG2 and mink Mv1Lu cells. PAI-1 protein levels are also dramatically induced by the combination of these two growth factors. Synergism in PAI-1 expression was observed in both human and mink cell lines, demonstrating that this phenomenon is not confined to a particular species.

A previous study showed that the synergistic regulation of PAI-1 protein by EGF and 
TGF- $\beta$ was observed in the mink lung epithelial cells but not in fibroblasts (Thalacker and Nilsen-Hamilton 1992). In this study the synergism on PAI-1 mRNA was tested in several epithelial cells including Mv1Lu mink lung epithelial cell, human hepatoblasma cell HepG2, and mouse mammary gland epithelial EpH4 cells (Supplementary Table I, Chapter 3). Although the range of cells tested was not sufficiently broad to identify cell specificity, the data suggests that the synergism between EGF and TGF $\beta$ in regulating PAI-1 is not observed in all cells, is only observed in epithelial cell types and is a characteristic that can be lost (compare MLEC and Mv1Lu cells). Consistent with the correlation between epithelial characteristic loss and synergism between EGF and TGF $\beta$, we observed that the MLEC cells display a fibroblast-morphology rather than the epithelial morphology of the parent Mv1Lu cell line.

Synergism occurs even when both growth factors are present at saturating concentrations (Fig 2, Chapter 3). The results clearly showed that neither growth factor can substitute for the other in raising the level of PAI-1 mRNA to the that observed with both together, which is about an order of magnitude above that achieved with either growth factor alone. Thus, the mechanism by which PAI-1 gene expression is regulated by a combination of EGF and TGF $\beta$ is different from those initiated by either growth factor alone.

TGF- $\beta$ also increases the sensitivity of cells to EGF, enabling synergism at suboptimal EGF concentrations. TGF- $\beta$ increases the sensitivity of cells to EGF but not vice versa. Analysis of the $\mathrm{EC}_{50} \mathrm{~s}$ of the concentration dependencies of the responses of PAI-1 mRNA levels to EGF and TGF- $\beta$ revealed that TGF- $\beta$ increases the sensitivity of the cells to EGF by an order of magnitude, but the presence of $\mathrm{EGF}$ did not change the $\mathrm{EC}_{50}$ for TGF- $\beta$ 
responsiveness (Table I, Chapter 3). This feature of the effect of TGF- $\beta$ again suggests a difference in the mechanism by which EGF regulates PAI-1 expression in the presence or absence of TGF- $\beta$. These results also suggest that TGF- $\beta$ can cooperate with low concentrations of EGF to increase PAI-1 expression that would not alone be high enough to have an effect.

The synergism with TGF- $\beta$ is downstream from tyrosine kinases and PKC. TGF- $\beta$ acts synergistically with tyrosine kinase activators to induce PAI-1 mRNA even though the extent of synergism varied with the growth factor or cytokine (Fig. 3A, Chapter 3). The fact that TGF- $\beta$ synergizes with PMA, a PKC agonist, in PAI-1 mRNA expression indicated the synergism is not a unique event downstream of tyrosine kinases (Fig. 3B,C, Chapter 3).

Synergism between EGF and TGF- $\beta$ occurs downstream of Mek. Experiments using specific chemical inhibitors of protein kinases including Mek1/2, p38 MAPK, PI3K, Src and Jnk showed that, although the synergism between EGF and TGF- $\beta$ was decreased when both p38 MAPK and Mek activity were blocked, it was only completely lost when Mek was blocked (Fig. 4A,C, Chapter 3). There was no synergism on the phosphorylation of Erk1/2 or Smad2/3 (Fig. 4F, Capter 3), which indicates that synergism occurs further downstream of Erk1/2 in the Mek signaling pathway.

The mechanism(s) of the cooperative action of EGF and TGF- $\beta$ involve synergistic transcriptional activation (Fig. 6, Chapter 3) and an increase in mRNA stability, which is regulated only by EGF (Fig. 5, Chapter 3). The combined effect of transcription and mRNA stabilization results in a rapid two-order of magnitude increase of PAI-1 within two hours of growth factor addition and a rapid decline after transcription peaks. 
The phosphorylation and activities of Smads are not synergistically regulated by EGF and TGF- $\beta$ (Fig. 7, Chapter 3). EGF decreased TGF- $\beta$-induced Smad 3-mediated promoter activity if only the Smad binding element (SBE) was present (pSBE4, Fig. 7B, Chapter 3).

Transcription factors Smads and AP-1 regulated by EGF and TGF- $\beta$ are required for the synergistic effect on PAI-1 induction. This was demonstrated because the synergism occurs only when both the Smad binding element and the AP-1 recognition site are present in the promoter region (p3TP, Fig. 8A, Chapter 3). There was about 3-fold synergism of EGF and TGF $\beta$ on $\mathrm{p} 3 \mathrm{TP}-\mathrm{luciferase}$ reporter activity, which was about the same increase as for PAI-1 transcription induced by EGF and TGF- $\beta$. Consistently, we found the AP-1 transcriptional factor is required for the synergistic effect on p3TP reporter (Fig. 8B, C, Chapter 3). Suppression of AP-1 activity by a dominant negative regulator $\Delta \mathrm{Fos} B$ blocked $40 \%$ of the synergism of both luciferase activities in the $\mathrm{p} 3 \mathrm{TP}$ reporter system and the endogenous mRNA levels of PAI-1. Similar results were found when AP-1 activity was blocked by the chemical inhibitor curcumin. AP-1 transcriptional factor is also required for the synergistic effect on PAI-1 mRNA (Fig. 8F, Chapter 3).

We found de novo protein synthesis is not necessary for the synergism and a rapidly turning-over protein is required for the synergism of EGF and TGF- $\beta$. This conclusion is supported by the following data: pretreating cells with protein synthesis inhibitor cycloheximide decreased the level of PAI-1 induced by growth factor treatments but did not alter the synergistic effect of EGF and TGF $\beta$ (Fig. 9A, B, chapter 3). We also found that the PAI-1 mRNA level was negatively correlated with the incubation time with cycloheximide and PAI-1 mRNA level decreased at a constant rate, which suggests a rapidly turning-over 
protein is involved in the synergistic regulation of PAI-1 mRNA by EGF and TGF- $\beta$ (Fig. 9D, Chapter 3). However, the decay curves in cells treated only with EGF or TGF- $\beta$ were not well fit to a single exponential decay (Fig. 9D). The biphasic decay curves reflect the presence of a small amount of the protein responsible for synergism that is augmented by the combination of EGF and TGF- $\beta$.

In summary, the synergism with TGF- $\beta$ is downstream from tyrosine kinases and PKC. The MAPK pathway is required for the synergism. The interaction between Smad and AP-1 is hypothesized to play an essential role in the synergistic regulation.

\section{Impacts of this study}

This work demonstrates the existence of a multidimensional cellular mechanism by which EGF and TGF- $\beta$ promote dramatic and rapid changes in PAI-1 expression that may contribute to some important physiological and pathological events.

In this study, we found that TGF- $\beta$ increases the sensitivity of the PAI- 1 response to EGF but not vice versa. This effect, not previously reported, allows a 10-fold lower EGF concentration to produce half maximal PAI- 1 induction in the presence of TGF- $\beta$ compared with in the absence. The increase in sensitivity to EGF would allow cells to utilize the synergistic mechanism when a low concentration of EGF is in the environment. This is a very effective way for a single growth factor to achieve a large change in gene expression by picking up a new signal from a growth factor that is already present and providing a synergistic boost to the newly arrived growth factor. 
We found that the synergistic effect of EGF and TGF- $\beta$ on transcription requires both transcription factor AP-1 and Smad. It is reported that in heptocytes EGF increases Smadmediated transcriptional activation, and synergizes with TGF- $\beta$ in the transcriptional activation of the SBE promoter, which can be blocked by dominant negative AP-1 (Peron, Rahmani et al. 2001). However, our study showed that signaling by Smad alone is not sufficient to produce the synergism of EGF and TGF- $\beta$. We also found no synergism in phosphorylation of Smad. Instead, EGF reduced the basal and TGF- $\beta$-induced Smad3/4 mediated-transcriptional activation in the SBE4 promoter. Similar results were observed for Smad2/4 mediated transcriptional activity from the $3 \mathrm{ARE}$ promoter. Our results are consistent with a previous study, which showed that EGF treatment results in rapid phosphorylation of the linker region but not the c-terminal domain of Smad 2/3 in MV1Lu cells. Phosphorylation of the linker region blocks Smad nuclear translocation and Smadmediated transcriptional activity (Kretzschmar, Doody et al. 1999). EGF also inhibits TGF- $\beta$-induced nuclear accumulation of activated Smad in Mv1Lu cells in a concentration dependent manner (Kretzschmar, Doody et al. 1999). So it is unlikely that the synergism occurs through Smad-mediated signaling. However with the presence of adjacent AP-1, Smad mediated transcription was greatly potentiated. The synergism occurs only when both AP-1 and Smad binding site are present. Our results are consistent with the notion that the synergistic regulation of gene expression by EGF and TGF- $\beta$ requires adjacent Smad and AP1 binding sites on the promoter and therefore is not observed in all genes.

\section{Limitations of this study}

A limitation of this study is that most of the studies were performed in mink lung epithelia cells (Mv1Lu). There is limited information on the mink genome and transcriptome 
data and this meant that only two other genes, uPAR and COX2, could be tested for the synergistic regulation by the EGF and TGF- $\beta$ in Mv1Lu cells. Because the antibodies resources against mink proteins are also relatively limited, we were able to successfully detect the phosphorylation of some proteins but not all.

A second limitation is that these results were observed from studies of in vitro cell cultures. The question of synergism has not been addressed in animal systems or tested in vivo. During the establishment of cell lines, some of the original gene expression profiles may be changed. For example, cultured cells usually are grown in normal air condition with about $20 \%$ of oxygen, while in vivo most of cells lives in lower $(<5 \%)$ oxygen concentrations. Some genes may behave differently with the change of oxygen concentration. Although elevated levels of EGF, TGF- $\beta$ as well as PAI-1 have been found in many diseases state in vivo, it is difficult to determine if the elevated PAI-1 results from the synergistic interaction between these two growth factors due to the presence of too many variables and difficulty of the experimental systems.

The third limitation is that only two types of cells, epithelial and fibroblast, were tested for the synergistic regulation of PAI-1 by EGF and TGF- $\beta$. The number of cells tested in this study is also limited. To make a general conclusion that the synergism is epithelial cell specific, it is necessary to test in more cell types to see whether the synergistic effect is present in other cell types, such as endothelial cells or smooth muscle cells.

\section{Questions remain to be answered}

1. Whether the synergistic induction of PAI-1 is related to the epithelial mesenchymal transition (EMT). The synergistic induction of PAI-1 by EGF and TGF- $\beta$ has been tested in 
several epithelial origin and fibroblast cells in this study and by others (Nilsen-Hamilton and Holley 1983; Thalacker and Nilsen-Hamilton 1992; Wilkins-Port, Ye et al. 2009). Although the range of cells tested is not sufficiently broad to identify a cell specificity, the data is consistent with the notion that synergism between EGF and TGF $\beta$ in regulating PAI-1 is cell type specific. For example this synergistic effect was not observed in five other cell lines including monkey kidney epithelial BSC-1 cells, mouse embryo fibroblast (AKR-2B 84A) cells, normal rat kidney fibroblasts (NRK) (Thalacker and Nilsen-Hamilton 1992) and mouse mammary gland epithelial EpH4 cells. Synergism is observed in cells of epithelial origin, such as mink lung epithelial Mv1Lu cells (Nilsen-Hamilton and Holley 1983; Thalacker and Nilsen-Hamilton 1992), human keratinocytes HaCaT II-4 cells (Wilkins-Port, Ye et al. 2009) and human liver hepatoma HepG2 cells (this study). The fact that synergistic induction of PAI-1 is only observed in cells of epithelial origin indicates the synergistic increase of PAI-1 might be one of the early events during the process of EMT induced by EGF and TGF- $\beta$. Although the synergistic regulation of PAI-1 in HaCaT II4 cells was reported to be related to EGF and TGF- $\beta$-induced EMT, there is no study on other cell lines. Our data showed that the synergism is lost when the epithelial characteristics are lost (compare MLEC and Mv1Lu cells), which is one of the milestone of EMT. Consistent with the correlation between epithelial characteristics and synergism of EGF and TGF- $\beta$, we observed that the MLEC cells displayed fibroblast morphology. It will be of interest to test the hypothesis that the synergistic induction by EGF and TGF- $\beta$ relates PAI-1 regulation to regulation of the EMT. We can test this by using broad range of cells and by examining the necessity of PAI-1 in EGF and TGF- $\beta$ induced EMT. 
2. How the MAPK pathways contributed to the synergistic regulation? Our data suggested the synergism is downstream of MAPK, however the mechanism of how these MAPKs contribute to the synergism is not clear. Our results showed that AP-1, one MAPK downstream target, is specifically required in PAI-1 synergistic regulation by EGF and TGF- $\beta$. Ablation of AP-1 activity reduced the reporter activity of 3TP and PAI-1 mRNA level stimulated by the combination of growth factors. Activation of AP-1 is the result of interaction of phosphorylated Fos and Jun family proteins. It is speculated that AP-1 is specifically activated in the dual growth factor treatment. However, our preliminary results from western blot by using antibodies against phosphorylated Fos or Jun family protein showed neither Jun nor Fos is synergistically activated. Further studies are needed to address this question, including test the involvement of more targets downstream of MAPK signaling. For example, one MAPK target p300 interacts with both Smad and AP-1 to enhance the Smad-mediated transcriptional activity (Verrecchia, Pessah et al. 2000). CREB binding protein (CBP) and p300 (also known as E1A binding protein) are co-activators of Smad2 and Smad3. They recruit the Smad nuclear complexes to the basal transcription machinery via direct interaction (Derynck, Zhang et al. 1998; Feng, Zhang et al. 1998). TGF- $\beta$-induced Smad-mediated PAI-1 expression is enhanced by promoting CBP-mediated Smad3 acetylation (Das, Ghosh-Choudhury et al. 2008). It will be interest to test whether CBP/P300 has a role in this synergistic regulation. One way of doing this is to check the acetalyation of Smad by western blot.

3. What is the rapidly turning-over protein in the synergism? Our data suggested a rapidly turning-over is involved in the synergism of EGF and TGF- $\beta$. Transcription factor AP-1 proteins are very unstable and bind of c-Jun accelerates the degradation of c-Fos (Tsurumi, Ishida et al. 1995). However there is no proof that AP-1 is the rapidly turning- 
over protein. For example, P300/CBP-associated factor (PCAF) has a half-life of $2 \mathrm{~h}$ (Jin, Zeng et al. 2004). The question can be addressed by the following experiments to determine: 1) is the rapidly turning-over protein regulated by MEK? Suppression of MEK eliminated the synergism; 2) whether AP-1 or CBP are the rapidly turning over proteins. This can be determined by examining protein turning-over rates after knocking down the expression of Fos or Jun family proteins; 3) studies using chromatin immuno-precipitation (Chip) and proteomics techniques may be useful to identify the unique proteins that occupy the promoter in cells activated by the combination of EGF and TGF- $\beta$.

4. What is the mechanism of PAI-1 transcriptional regulation by EGF. Our study showed PAI-1 stimulation by EGF requires the MAPK pathway and the maximal induction of PAI-1 also requires the activity of Jnk, PI3K, p38 MAPK and AP-1. However, PAI-1 regulation by EGF does not act through Smad-mediated signaling, because EGF does not activate Smad. Others have shown that EGF inhibits Smad's nuclear accumulation. AP-1 is not sufficient for the regulation by EGF because although there was 2-fold increase in the transcriptional activation of PAI-1 mRNA, EGF barely activated the 3TP. Suppression of AP-1 activity also did not significantly reduce the effect of EGF on the 3TP promoter activity. There was only slight decrease (14\%) in the level of PAI-1 induced by EGF after AP-1 activity was blocked. A previous study in human glioma cells showed that the orderly activation of EGFR, Src, PKC $\delta$, SPHK1 and S1P signaling is required for EGF activation of PAI-1 transcription in a c-Jun dependent manner (Paugh, Paugh et al. 2008). Although EGF activates Erk1/2, Jnk phosphorylation and DNA binding activity of AP-1, none of them were involved in PAI-1 stimulation in these cells (Paugh, Paugh et al. 2008). In our study, we found that Src activity is not required for regulation by EGF because inhibition of Src activity didn't significantly block PAI-1 induction by EGF in Mv1Lu cells. Thus the 
requirement of Src in the regulation of PAI-1 by EGF may be cell type dependent. To address this question, other transcription factors that are activated by MAPK should be investigated for their involvement in PAI-1 regulation by EGF because blockade of MEK activity removed most of the PAI-1 induction. Analysis of the cis-elements in PAI-1 promoter region will help to screen for potential transcription factors. Previous studies on genes that are regulated by EGF will facilitate progress as well.

5. What is the mechanism of stabilization of PAI-1 mRNA by EGF. We have shown that PAI-1 mRNA has a very short half-life. The stability of PAI-1 mRNA can be changed in response to different stimuli (Fattal, Schneider et al. 1992; Sandberg, Eriksson et al. 1997; Norata, Banfi et al. 2004). EGF also regulates PAI-1 through stabilizing the mRNA. However, the mechanism by which EGF regulates PAI-1 mRNA stability remains unknown. A similar effect of EGF has also been found on mRNA of other genes, including Cox2 (Slice, Hodikian et al. 2003), TßRII (Song, Krebs et al. 2006), EGFR (Jinno, Merlino et al. 1988), IL-1alpha, IL-1beta and IL-6 (Le, Lazorick et al. 1991), p21/CIP1 (Johannessen, Knardal et al. 1999). TGFa, which also binds to EGFR, substitute for EGF in mRNA stabilization (Le, Lazorick et al. 1991; McCulloch, Walker et al. 1998). Our results showed that blocking the activation of Erk1/2 did not alter the half-life of PAI-1 mRNA in TGF- $\beta$ treatment, either alone or in combination with EGF. Thus, it is unlikely that the stabilization of PAI-1 mRNA is regulated by the Erk MAPK pathway.

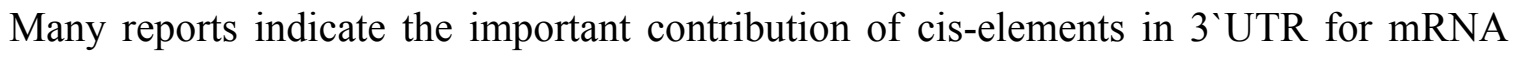
stabilization of mRNA in response to EGF (Kesavan, Das et al. 1990; Balmer, Beveridge et al. 2001). The 3 'UTR of PAI-1 is also an important region for the regulation of PAI-1 mRNA stability. There are many C-rich regions that can be recognized by poly $(\mathrm{C})$ binding 
protein 1 (PCBP1). An AGCCCU motif that mediated stabilization of Gastrin mRNA by EGF (Lee, Liao et al. 2007) also exists in the 3'UTR of PAI-1 mRNA. It will be of interest to determine how PAI-1 mRNA stability is achieved through these elements. One way we can test this is by mutating these regions or elements.

\section{Conclusions of using tiled microarray to identify $R N A$ accessible region}

The efficiency of silencing gene expression by antisense oligonucleotide and RNAi technology has great potential to be used in gene therapy for variety of diseases, where successful know down of genes relies on information of optimal RNA accessible region. Different technologies have been developed to provide information for optimal RNA accessible sites, including software prediction by using computer algorithm and experimental screening. However these computer programs do not predict RNA tertiary structures that may affect RNA accessible sites. Experimentally screening every possible RNA site is expensive and time consuming.

In this study we showed that tiled microarray is an effective way to identify accessible regions in mRNAs with high accuracy. Here We investigated the accessible regions of two mRNAs (B-cell CLL/lymphoma 2 [Bcl2] and mouse lipocalin 2 [Lcn2]) by tiled microarray and computational algorithms. The efficacy of microarray and computational algorithm predictions for Lcn2 were tested in cell culture by using antisense oligodeoxynucleotides (ODNs) and siRNA. For Bcl2, the microarray results were compared to the data in literature where antisense oligodeooxynucleotides were reported effective in vivo. Effective AS-ODN sequences for both Lcn2 and Bcl2 were identified by in vitro tiled microarray studies. . 
Firstly, we found that the tiled microarray analysis provides more selective identification of available sites on the mRNA than do computational algorithms. Using the tiled microarray assay identified a small number of optimal accessible regions for both Lcn2 mRNA and Bcl2 coding region (Fig. 1, Chapter 4). In contrast, computer programs (Oligowalk, sFold and Block-iT) predicted overlapping but different sets of sequences as optimal for effective antisense as seen in (Fig. 2, Chapter 4). Although some of the mRNA sequences identified by the microarray were also predicted by computational analysis, many differences are evident between the experimental and computational methods.

Three ODNs were identified by tiled microarray as the most available for hybridization in Bcl2 coding region, which all clustered around the translational start site (Fig.1, Chapter 4). This is precisely the region of the Bcl 2 mRNA that has previously been identified as a prime target for AS-ODNs for reducing Bcl2 expression (Kitada, Takayama et al. 1994; Gleave, Miayake et al. 1999; Tolcher 2005).

Secondarily, the regions identified by titled microarray accurately predicted the most accessible area in RNA as tested by antisense ODNs and siRNA in vivo. Based on the results from the microarray and the computational analysis, eight ODNs were chosen to test as antisense agents for Lcn2 in vivo. Four ODNs were identified from the computational analyses, three from the microarray results $(501,561$ and 741 AS-ODN). The three sequences that most successfully decreased secreted Lcn 2 production were identified by the tiled microarray analysis and by at least two of the three computational analyses (Fig.4, Chapter 4). 
The effects of the antisense ODNs on the Lcn2 mRNA and intracellular Lcn2 protein levels of the mouse HC11 cells were also examined. The 561 and 741 AS-ODNs selectively reduced the Lcn2 mRNA and intracellular Lcn2 protein levels (Fig. 5A, Chapter 4). One AS-ODN complementary to a region covering the translational start site (positions 11 through 27) from a previous literature report was also tested in our study. By contrast to the effects of AS-ODNs 561 and 741, AS-ODN11 did not decrease the Len2 mRNA level (Fig. 5B, Chapter 4). Although the AS-ODN was very effective in inhibiting protein production when used at a 10-times higher concentration as was used in the previous study, it had little effect on protein or RNA levels when used at $0.2 \mu \mathrm{M}$.

We also tested the effectiveness of siRNAs targeted to the same regions in the Lcn2 mRNA in two different cell lines (Fig. 5C,D, Chapter 4) In both instances a similar profile of decrease in Lcn2 mRNA was observed as for the AS-ODN series (Fig. 5A, Chapter 4).

With the advantage of high throughput and high accuracy information provided for RNA accessible regions, we proposed tiled microarray is an efficient way of identifying effective antisense ODNs or siRNAs. Tiled microarrays also provide a high throughput approach for validating and improving the results from computational programs. Our results suggest that hybridization of ODN arrays to a target mRNA under physiological conditions might be used as a rapid and reliable in vitro method to accurately identify targets on mRNA molecules for effective antisense and potential siRNA activity in vivo. 


\section{References}

Balmer, L. A., D. J. Beveridge, et al. (2001). "Identification of a novel AU-Rich element in the $3^{\prime}$ untranslated region of epidermal growth factor receptor mRNA that is the target for regulated RNA-binding proteins." Mol Cell Biol 21(6): 2070-84.

Das, F., N. Ghosh-Choudhury, et al. (2008). "Akt kinase targets association of CBP with SMAD 3 to regulate TGFbeta-induced expression of plasminogen activator inhibitor-1." $\underline{\mathrm{J}}$ Cell Physiol 214(2): 513-27.

Degryse, B., C. F. Sier, et al. (2001). "PAI-1 inhibits urokinase-induced chemotaxis by internalizing the urokinase receptor." FEBS Lett 505(2): 249-54.

Deng, G., S. A. Curriden, et al. (1996). "Is plasminogen activator inhibitor-1 the molecular switch that governs urokinase receptor-mediated cell adhesion and release?" J Cell Biol 134(6): 1563-71.

Derynck, R., Y. Zhang, et al. (1998). "Smads: transcriptional activators of TGF-beta responses." Cell 95(6): 737-40.

Elokdah, H., M. Abou-Gharbia, et al. (2004). "Tiplaxtinin, a novel, orally efficacious inhibitor of plasminogen activator inhibitor-1: design, synthesis, and preclinical characterization." J Med Chem 47(14): 3491-4.

Fattal, P. G., D. J. Schneider, et al. (1992). "Post-transcriptional regulation of expression of plasminogen activator inhibitor type $1 \mathrm{mRNA}$ by insulin and insulin-like growth factor 1." J Biol Chem 267(18): 12412-5.

Feng, X. H., Y. Zhang, et al. (1998). "The tumor suppressor Smad4/DPC4 and transcriptional adaptor $\mathrm{CBP} / \mathrm{p} 300$ are coactivators for smad3 in TGF-beta-induced transcriptional activation." Genes Dev 12(14): 2153-63.

Gils, A. and P. J. Declerck (2004). "Plasminogen activator inhibitor-1." Curr Med Chem 11(17): 2323-34.

Gleave, M. E., H. Miayake, et al. (1999). "Targeting bcl-2 gene to delay androgenindependent progression and enhance chemosensitivity in prostate cancer using antisense bcl-2 oligodeoxynucleotides." Urology 54(6A Suppl): 36-46.

Hardy, K. M., B. W. Booth, et al. (2010). "ErbB/EGF Signaling and EMT in Mammary Development and Breast Cancer." J Mammary Gland Biol Neoplasia.

Hennan, J. K., G. A. Morgan, et al. (2008). "Effect of tiplaxtinin (PAI-039), an orally bioavailable PAI-1 antagonist, in a rat model of thrombosis." J Thromb Haemost 6(9): $1558-64$.

Jin, Y., S. X. Zeng, et al. (2004). "MDM2 mediates p300/CREB-binding protein-associated factor ubiquitination and degradation." J Biol Chem 279(19): 20035-43.

Jinno, Y., G. T. Merlino, et al. (1988). "A novel effect of EGF on mRNA stability." Nucleic Acids Res 16(11): 4957-66. 
Johannessen, L. E., S. L. Knardal, et al. (1999). "Epidermal growth factor increases the level of the cyclin-dependent kinase (CDK) inhibitor p21/CIP1 (CDK-interacting protein 1) in A431 cells by increasing the half-lives of the p21/CIP1 transcript and the p21/CIP1 protein." Biochem J 337 ( Pt 3): 599-606.

Kawasaki, T., M. Dewerchin, et al. (2000). "Vascular release of plasminogen activator inhibitor-1 impairs fibrinolysis during acute arterial thrombosis in mice." Blood 96(1): 153-60.

Kesavan, P., P. Das, et al. (1990). "Regulation of stability and synthesis of EGF-receptor mRNAs encoding for intact and truncated receptor forms." Oncogene 5(4): 483-8.

Kitada, S., S. Takayama, et al. (1994). "Reversal of chemoresistance of lymphoma cells by antisense-mediated reduction of bcl-2 gene expression." Antisense Res Dev 4(2): 71-9.

Kretzschmar, M., J. Doody, et al. (1999). "A mechanism of repression of TGFbeta/ Smad signaling by oncogenic Ras." Genes Dev 13(7): 804-16.

Kruithof, E. K., A. Gudinchet, et al. (1988). "Plasminogen activator inhibitor 1 and plasminogen activator inhibitor 2 in various disease states." Thromb Haemost 59(1): 7-12.

Le, P. T., S. Lazorick, et al. (1991). "Regulation of cytokine production in the human thymus: epidermal growth factor and transforming growth factor alpha regulate mRNA levels of interleukin 1 alpha (IL-1 alpha), IL-1 beta, and IL-6 in human thymic epithelial cells at a post-transcriptional level." J Exp Med 174(5): 1147-57.

Lee, P. T., P. C. Liao, et al. (2007). "Epidermal growth factor increases the interaction between nucleolin and heterogeneous nuclear ribonucleoprotein $\mathrm{K} /$ poly $(\mathrm{C})$ binding protein 1 complex to regulate the gastrin mRNA turnover." Mol Biol Cell 18(12): 500413.

Leik, C. E., E. J. Su, et al. (2006). "Effect of pharmacologic plasminogen activator inhibitor1 inhibition on cell motility and tumor angiogenesis." J Thromb Haemost 4(12): 2710-5.

Liu, R. M. (2008). "Oxidative stress, plasminogen activator inhibitor 1, and lung fibrosis." Antioxid Redox Signal 10(2): 303-19.

McCulloch, R. K., C. E. Walker, et al. (1998). "Regulation of EGF-receptor expression by EGF and TGF alpha in epidermoid cancer cells is cell type-specific." Int J Biochem Cell Biol 30(11): 1265-78.

Nilsen-Hamilton, M. and R. W. Holley (1983). "Rapid selective effects by a growth inhibitor and epidermal growth factor on the incorporation of [35S]methionine into proteins secreted by African green monkey (BSC-1) cells." Proc Natl Acad Sci U S A 80(18): $5636-40$.

Norata, G. D., C. Banfi, et al. (2004). "Oxidised-HDL3 induces the expression of PAI-1 in human endothelial cells. Role of p38MAPK activation and mRNA stabilization." $\mathrm{Br} \mathrm{J}$ Haematol 127(1): 97-104.

Paugh, B. S., S. W. Paugh, et al. (2008). "EGF regulates plasminogen activator inhibitor-1 (PAI-1) by a pathway involving c-Src, PKCdelta, and sphingosine kinase 1 in glioblastoma cells." FASEB J 22(2): 455-65. 
Peron, P., M. Rahmani, et al. (2001). "Potentiation of Smad transactivation by Jun proteins during a combined treatment with epidermal growth factor and transforming growth factor-beta in rat hepatocytes. role of phosphatidylinositol 3-kinase-induced AP-1 activation." J Biol Chem 276(13): 10524-31.

Providence, K. M., S. P. Higgins, et al. (2008). "SERPINE1 (PAI-1) is deposited into keratinocyte migration "trails" and required for optimal monolayer wound repair." Arch Dermatol Res 300(6): 303-10.

Roberts, A. B., C. A. Frolik, et al. (1983). "Transforming growth factors from neoplastic and nonneoplastic tissues." Fed Proc 42(9): 2621-6.

Saha, D., P. K. Datta, et al. (1999). "Synergistic induction of cyclooxygenase-2 by transforming growth factor-betal and epidermal growth factor inhibits apoptosis in epithelial cells." Neoplasia 1(6): 508-17.

Saltis, J., A. Agrotis, et al. (1992). "TGF-beta 1 potentiates growth factor-stimulated proliferation of vascular smooth muscle cells in genetic hypertension." Am J Physiol 263(2 Pt 1): C420-8.

Sandberg, T., P. Eriksson, et al. (1997). "Differential regulation of the plasminogen activator inhibitor-1 (PAI-1) gene expression by growth factors and progesterone in human endometrial stromal cells." Mol Hum Reprod 3(9): 781-7.

Scarabin, P. Y., M. F. Aillaud, et al. (1998). "Associations of fibrinogen, factor VII and PAI1 with baseline findings among 10,500 male participants in a prospective study of myocardial infarction--the PRIME Study. Prospective Epidemiological Study of Myocardial Infarction." Thromb Haemost 80(5): 749-56.

Slice, L. W., R. Hodikian, et al. (2003). "Gastrin and EGF synergistically induce cyclooxygenase-2 expression in Swiss 3 T3 fibroblasts that express the CCK2 receptor." J Cell Physiol 196(3): 454-63.

Smith, L. H., J. D. Dixon, et al. (2006). "Pivotal role of PAI-1 in a murine model of hepatic vein thrombosis." Blood 107(1): 132-4.

Song, K., T. L. Krebs, et al. (2006). "Novel permissive role of epidermal growth factor in transforming growth factor beta (TGF-beta) signaling and growth suppression. Mediation by stabilization of TGF-beta receptor type II." J Biol Chem 281(12): 7765-74.

Stolz, D. B. and G. K. Michalopoulos (1997). "Synergistic enhancement of EGF, but not HGF, stimulated hepatocyte motility by TGF-beta 1 in vitro." J Cell Physiol 170(1): 5768.

Taylor, M. A., J. G. Parvani, et al. (2010). "The Pathophysiology of Epithelial-Mesenchymal Transition Induced by Transforming Growth Factor-beta in Normal and Malignant Mammary Epithelial Cells." J Mammary Gland Biol Neoplasia.

Thalacker, F. W. and M. Nilsen-Hamilton (1987). "Specific induction of secreted proteins by transforming growth factor-beta and 12-O-tetradecanoylphorbol-13-acetate. Relationship with an inhibitor of plasminogen activator." J Biol Chem 262(5): 2283-90. 
Thalacker, F. W. and M. Nilsen-Hamilton (1992). "Opposite and independent actions of cyclic AMP and transforming growth factor beta in the regulation of type 1 plasminogen activator inhibitor expression." Biochem J 287 ( Pt 3): 855-62.

Tolcher, A. W. (2005). "Targeting Bcl-2 protein expression in solid tumors and hematologic malignancies with antisense oligonucleotides." Clin Adv Hematol Oncol 3(8): 635-42, 662.

Tsurumi, C., N. Ishida, et al. (1995). "Degradation of c-Fos by the 26S proteasome is accelerated by c-Jun and multiple protein kinases." Mol Cell Biol 15(10): 5682-7.

Urano, T., K. Wu, et al. (1996). "Novel mechanism to enhance tPA-induced fibrinolysis: effect of limited proteolysis of PAI-1 by neutrophil elastase." Pol J Pharmacol 48(2): 209-13.

Uttamsingh, S., X. Bao, et al. (2008). "Synergistic effect between EGF and TGF-betal in inducing oncogenic properties of intestinal epithelial cells." Oncogene 27(18): 2626-34.

Verrecchia, F., M. Pessah, et al. (2000). "Tumor necrosis factor-alpha inhibits transforming growth factor-beta /Smad signaling in human dermal fibroblasts via AP-1 activation." J Biol Chem 275(39): 30226-31.

Wilkins-Port, C. E., Q. Ye, et al. (2009). "TGF-beta1 + EGF-initiated invasive potential in transformed human keratinocytes is coupled to a plasmin/MMP-10/MMP-1-dependent collagen remodeling axis: role for PAI-1." Cancer Res 69(9): 4081-91.

Yang, S. F., Y. S. Hsieh, et al. (2003). "The upregulation of type I plasminogen activator inhibitor in oral submucous fibrosis." Oral Oncol 39(4): 367-72. 


\section{APPENDIX I. ABBREVIATIONS}

(According to alphabetic order)

\begin{tabular}{|c|c|}
\hline 3UTR & 3`Untranslated region \\
\hline ANOCVA & Analysis of covariance \\
\hline AIG & Anchorage-independent growth \\
\hline AKT2 & v-akt murine thymoma viral oncogene homolog 2 \\
\hline ANOVA & Analysis of variance \\
\hline AP-1 & Activator protein 1 \\
\hline AP-2 & Activator protein 2 \\
\hline ARE & AU-rich element \\
\hline $\mathrm{BCS}$ & Budd-Chiari syndrome \\
\hline AS-ODN & Antisense oligodeoxynucleotides \\
\hline CBP & CREB binding protein \\
\hline $\mathrm{CD}$ & Cytochalasin D \\
\hline $\mathrm{CHX}$ & Cycloheximide \\
\hline $\mathrm{CHX}$ & Cycloheiximide \\
\hline
\end{tabular}

Co-Smad Common partner Smad

Cox $2 \quad$ Cyclooxygenase 2

CPPD Calcium pyrophosphate dehydrate

E1A The protein product from the early 1A region of adenoviruses

ECM Extracellular matrix

EGF Epidermal growth factor 
EGFR Epidermal growth factor receptor

EIP-1 $\quad$ EGF/TGF $\alpha$-inducible protein, ailas of PAI-1

EMT Epithelial-to-mesenchymal transition

ERK Extracellular signal-regulated kinase

FAST Forkhead activin signal transducers

FGF-2 Fibroblast growth factor 2

GnRH Gonadotropin-releasing hormone

GPI Glycosyl phosphatidyl inositol

GRE Glucocorticoid regulatory element

HDAC Histone deacetylase

HGF Heptocyte growth factor

HIF-1 Hypoxia-inducible factor 1

HLTF Helicase-like transcription factor

HNF-4 Hepatocyte nuclear factor 4

HRE Hhypoxia-response element

IGF-1 Insulin-like growth factor 1

IL-1 Interleukin-1

IL-6 Interleukin-6

I-Smad Inhibitory Smad

JAK Janus kinase 2

JNK c-Jun NH2-terminal protein kinase

LIF Leukemia-inhibitory factor

LPS Lipopolysaccharide

LRP low-density lipoprotein receptor-related protein 


\begin{tabular}{|c|c|}
\hline MAP & Mitogen-activated protein \\
\hline MAPK & Mitogen-activated protein kinase \\
\hline MAX & MYC associated factor $\mathrm{X}$ \\
\hline MEK & Mitogen-activated protein kinase/ERK kinase \\
\hline MEK1/2 & Mitogen-activated protein kinase kinase \\
\hline MH1 & MAD homolog 1 \\
\hline MH2 & MAD homolog 2 \\
\hline MMP & Metalloproteinase \\
\hline MMP & Matrix metalloproteinase \\
\hline $\mathrm{NF} \kappa \mathrm{B}$ & Nuclear Factor-KappaB \\
\hline ODN & Oligodeoxynucleotides \\
\hline Ox-HDL & Oxidized high-density lipoprotein \\
\hline p300 & E1A binding protein \\
\hline PAI-039 & Tiplaxtinin \\
\hline PAI-1 & Plasminogen activator inhibitor type-1 (also called SERPINE1) \\
\hline PAI-CRS & PAI-1 cAMP responsive sequence \\
\hline PCAF & P300/CBP-associated factor \\
\hline PDGF & Platelet-derived growth factor \\
\hline PGE2 & Prostaglandin E2 \\
\hline PI3K & Phosphatidylinositol 3'-kinase \\
\hline $\mathrm{PKC}$ & Protein kinase $\mathrm{C}$ \\
\hline $\mathrm{PKC} \delta$ & Protein kinase $\mathrm{C}$ \\
\hline PLB & Passive lysis buffer \\
\hline $\operatorname{PLC} \gamma$ & phospholipase $\mathrm{C} \gamma$ \\
\hline
\end{tabular}




\begin{tabular}{ll} 
PMA & Phorbol 12-Myristate-13-Acetate \\
Src & v-src sarcoma (Schmidt-Ruppin A-2) viral oncogene homolog (avian) \\
PPi & Inorganic pyrophosphate \\
pSmadC & Phosphorylation of Smad at the carboxyl terminus \\
pSmadL & Phosphorylation of Smad at the linker region \\
R-Smad & Receptor-regulated Smad \\
RTK & Tyrosine kinase receptors \\
S1P & Sphingosine 1-phosphate \\
SARA & Smad Anchor for Receptor Activation \\
SBE & Smad-binding element \\
SCC & Squamous cell carcinoma \\
SERBP1 & PAI-1 mRNA binding protein 1 \\
SERPINE1 & Serine protease inhibitor, clade E, member 1 \\
siRNA & Small interference RNA \\
SMAD & Sma/Mad homologues \\
Smad2 & Smad family protein member 2 \\
Sp-1 & Specificity protein 1 \\
SphK1 & Sphingosine kinase 1 \\
STAT & Signal transducer and activator of transcription \\
TAD & Transactivation domain \\
TFE3 & Transcription factor microE3 \\
TGF $\alpha$ & Transforming growth factor alpha \\
TGF- $\beta 1 ~$ & Transforming growth factor- $\beta$ 1 \\
TGF- $\beta$ R & TGF- $\beta$ receptor \\
\hline
\end{tabular}




$\begin{array}{ll}\text { TGIF } & \text { TG-interacting factor } \\ \text { TNF } \alpha & \text { Tumor necrosis factor-alpha (TNF-alpha) } \\ \text { t-PA } & \text { Tissue-type plasminogen activator } \\ \text { TRE } & \text { PMA-responsive element } \\ \text { TSA } & \text { Trichostatin A } \\ \text { T } \beta 4 & \text { Thymosin beta } 4 \\ \text { uPA } & \text { Urokinase-type plasminogen activator } \\ \text { uPAR } & \text { Urokinase-type plasminogen activator receptor } \\ \text { USF } & \text { Upstream transcription factor } \\ \text { USF1 } & \text { Upstream transcription factor 1 } \\ \text { USF2 } & \text { Upstream transcription factor 2, c-fos interacting }\end{array}$




\section{ACKNOWLEDGEMENTS}

I would like to take this chance to acknowledge those who have helped me during the process of conducting my researches and writing of this thesis: Firstly, I would like to thank my major adviser Dr. Marit Nilsen-Hamilton, whose encouragement, guidance and support from the initial to the final enabled me to go though many troubles in both researches and personal life. I could never make it without her dedicated support. I would like to thank my POS Committee member Dr. W. Allen Miller, Dr. Christopher K. Tuggle, Dr. Gustavo MacIntosh and Dr. Linda Ambrosio for their kindly help and constructive suggestions for my research projects. I want to acknowledge all my labmates for their friendships and helps. Special thanks are given to our lab manager Lee Bendickson who has provided lots of technical supports and helped me with my frontsheets /labnotes. I want to thank coauthors of my manuscripts Dr. Frederic W. Thalacker, Dr. Tsung-Hsien Chuang, Dr. Ahmed M. Awad, Dr. Xiangyu Cong, Dr. Long Qu and Lijie Zhai for their kindly help. I want to thank Genetics program coordinator Linda Wild for her help from joining in the program to finishing my $\mathrm{PhD}$ study.

Finally, I would also like to thank my parents, my sister and brother for their consistent care to support me all the way along. Special thanks go to my dear husband Zhiyong, and my dear son Kevin for their love and support from various aspects during this process. 